\begin{abstract}
UNIVERSIDADE DE SÃO PAULO
INSTITUTO DE RELAÇÕES INTERNACIONAIS

PROGRAMA DE PÓS-GRADUAÇÃO EM RELAÇÕES

INTERNACIONAIS
\end{abstract}

ANDREAS F. WERNER

FRESHWATER ON THE INTERNATIONAL AGENDA EMERGENCE OF A REGIME COMPLEX 


\author{
UNIVERSIDADE DE SÃO PAULO \\ INSTITUTO DE RELAÇÕES INTERNACIONAIS \\ PROGRAMA DE PÓS-GRADUAÇÃO EM RELAÇÕES
}

INTERNACIONAIS

\title{
FRESHWATER ON THE INTERNATIONAL AGENDA - EMERGENCE OF A REGIME COMPLEX
}

\begin{abstract}
ANDREAS F. WERNER
Tese apresentada ao Programa de PósGraduação em Relações Internacionais do Instituto de Relações Internacionais da Universidade de São Paulo, para a obtenção do título de Doutor em Ciências - Programa de Pós-Graduação em Relações Internacionais

Orientadora: Profa. Dra. Maria Hermínia Tavares de Almeida
\end{abstract}

São Paulo

2015 
To my supportive parents, Monika and Frank

To my loving wife, Megha 


\section{ACKNOWLEDGEMENTS}

Throughout this long and challenging journey towards the completion of this thesis and my doctorate at the Institute of International Relations (IRI), University of São Paulo (USP), I have received a great deal of support by many a kind, for which it is now time to express my gratitude.

First and foremost, I would like to sincerely thank my supervisor, Maria Hermínia Tavares de Almeida, for allowing me to let my research interests drive this thesis and for enabling me to find my own path into the academic world. Despite the back and forths during the course of producing this work, she always firmly believed in me, my ideas and my work, and guided me towards doctorhood.

I wish to my express my gratitude to the members of the final thesis defense committee for their thorough examination of my thesis and valuable comments on my research and its implications, which will prove invaluable for my future.

Special thanks are also due to all members of Polmet, who have constructively critiqued earlier chapters and drafts and thus helped me advance my research, in particular Suhayla Khalil, Ivan Fernandes, Bruno De Marco Lopes and Nadim Gannoum.

Many other members of IRI have contributed to my postgraduate development in various forms over time. I am especially indebted to Janina Onuki, who proved extremely approachable and kind to provide input before, during and after the submission of the thesis in the form of discussions, courses and participation in the qualification committee; Kai Enno Lehmann, for his mentoring and support while co-teaching the undergraduate course on regimes as part of PAE; as well as Amâncio de Oliveira, Adriana Schor, Maria Antonieta Del Tedesco Lins, Pedro Dallari and Deisy Ventura for interesting courses and discussions. From the administrative team of the institute, Giselle de Castro deserves special mention for her constant availability and tireless efforts. 
In terms of refining my research project, the interaction with visiting researchers, experts and leading scholars of related fields proved vital. The personal discussions with David Victor, Michael Zürn, Jeroen Warner, Benjamin Kiersch and Wagner Costa Ribeiro have heightened my awareness of current debates in the field and have certainly enriched my academic development.

More broadly, IRI became a home for me and provided favorable conditions for research and personal growth. Having received an institutional CAPES (Coordenação de Aperfeiçoamento de Pessoal de Nível Superior) scholarship, financial concerns were eased very early on, which I appreciated a lot. Furthermore, the interactions with senior members and staff of the institute as elected postgraduate student representative at the congregation for two years, gave me a great chance to view institutional processes behind the scenes, both being excellent opportunities for which I am very grateful.

Last, but of course not least, I would like to thank my family and friends as never-ending sources of support, faith and encouragement. Special thanks to my parents, Monika and Frank Werner, for their unconditional love and for always being there for me; and to my wife, Megha Amrith, for standing by me over the years, her continual encouragement and dedicated proofreading. It was a particular pleasure to share this academic voyage at IRI with my dearest friends Suhayla, André S. and André M., Cássia and Marcelo. 


\begin{abstract}
In the $21^{\text {st }}$ century, water scarcity due to pollution, increasing demand and mismanagement has become a global phenomenon of growing concern. Often depicted in media reports, endorsed by global summits - such as the recent "Rio+20" Conference in 2012 in Brazil and campaigned for by NGOs all over the world, freshwater issues play an important role within bigger debates on global environmental issues. Despite a clear increase in the intensity and scope of these issues over the last decades, they are not novel as such and have a history. This Ph.D. thesis analyzes the emergence and evolution of the freshwater topic on the international agenda since the early 1970s, when the first international freshwater-related conferences and conventions took place. In order to explain this genesis and evolution, the freshwater topic is situated within the broader international environmental agenda and is connected with International Relations scholarship on agenda-setting as well as international regimes. Subsequently, the empirical freshwater conventions and conference data is analyzed through these theoretical lenses, showing that the freshwater issue is in fact an umbrella topic which can be further subdivided into smaller water-related topics. The treatment of these sub-topics has led to conventions in two cases (wetlands and international watercourses) which are taken to be regimes in their own right, whereas others have so far remained limited to international conferences and events (sanitation, access to potable water etc.). Rather than seeing these as unconnected, individual regimes and conferences as has been done within contemporary scholarship, it will be argued that these in fact represent sub-regimes and parts of a bigger freshwater regime complex. Moreover, it will be argued that the origins of this regime complex are not due to specific countries' deliberate aims of constructing international institutional overlap to subsequently explore forum-shopping opportunities to their advantage but, rather, that developments in this issue-area unintentionally resulted in this overlap for functional reasons.
\end{abstract}

Keywords: Freshwater - International Agenda - Agenda Setting - Issue Emergence Regime Complex 


\section{RESUMO}

No século 21, a escassez hídrica devido a causas como poluição, crescente demanda e má administração tem se tornado um fenômeno cada vez mais preocupante. Os recursos de água doce possuem um papel importante nos debates mais amplos sobre o meio ambiente, figuram frequentemente nas reportagens da mídia, são endossados nas cúpulas globais tais como a recente "Rio+20" em 2012 no Brasil - e são o foco de campanhas de ONGs no mundo inteiro. Apesar de um crescimento evidente na intensidade e no escopo dessas questões nas últimas décadas, elas não são novas, mas sim integram um processo histórico. Esta tese de doutorado analisa a emergência e evolução do tema da água doce na agenda internacional a partir do início dos anos 1970, quando tiveram lugar as primeiras conferências e convenções relacionadas com essa questão. Com o intuito de explicar esta gênese e evolução, o tema da água doce está situado dentro da agenda ambiental mais ampla e se conecta com a literatura de relações internacionais sobre agenda-setting e regimes internacionais. Subsequentemente, os dados empíricos das convenções e conferências de água são analisados por meio dessas lentes teóricas, o que mostra que a temática hídrica é de fato um tópico guarda-chuva, que pode ser subdivido ainda em temas menores com relação à água. O tratamento desses subtemas tem levado a convenções em dois casos (zonas úmidas e cursos d'água internacionais), que são percebidos como regimes próprios, quando outros têm ficado limitados até agora a conferências internacionais e meros eventos (saneamento, acesso à água potável etc.). Em vez de ver estes como regimes e conferências individuais e isolados, como tem sido feito na literatura contemporânea, argumentar-se-á que eles de fato representam subregimes e partes de um complexo de regime de água doce mais amplo. Além disso, argumentar-se-á que as origens desse complexo de regime não se devem a objetivos conscientes de certos países com o fim de construir uma sobreposição institucional para subsequentemente explorar oportunidades de fórum-shopping; mas bem os desdobramentos nessa área resultaram nessa sobreposição por razões funcionais, de forma não intencional.

Palavras-chave: Água doce - Agenda Internacional - Agenda Setting -Emergência de Tema - Complexo de Regime 


\section{ABBREVIATIONS}

CBD

CLRTAP

CNR

$\mathrm{CoP}(\mathrm{s})$

GWP

Habitat

ICBP

ICJ

ICWE

IDWSSD

IEP

IGO

ILA

ILC

IR

IUCN

IWC

IWLP

IWRB

MDG(s)

MDPAP

NGO

SADC

SDG(s)

UN
Convention on Biological Diversity

Convention of Long-Range Transboundary Air Pollution

Committee on Natural Resources

Conference of the Parties

Global Water Partnership

UN Conference on Human Settlements

International Council for Bird Protection

International Court of Justice

International Conference on Water and the Environment

International Drinking Water Supply and Sanitation Decade

International Environmental Politics

Intergovernmental organization

International Law Association

International Law Commission

International Relations

International Union for Conservation of Nature

International Watercourses Convention

International Water Law Project

International Waterfowl and Wetlands Bureau

Millennium Development Goal(s)

Mar del Plata Action Plan

Non-governmental organization

Southern African Development Community

Sustainable Development Goal(s)

United Nations 
UNCED

UNCHE

UNCLOS

UND

UNDP

UNEP

UNESCO

UNGA

WCD

WWC

$\mathrm{WWF}(\mathrm{s})$
United Nations Conference on Environment and Development

United Nations Conference on the Human Environment

United Nations Convention on the Law of the Sea

United Nations Documents

United Nations Development Programme

United Nations Environment Programme

United Nations Educational, Scientific and Cultural Organization

United Nations General Assembly

World Commission on Dams

World Water Council

World Water Forum(s) 


\section{FIGURES AND TABLES}

Figure 1: Issue treatment in the problem-structural approach p.39

Figure 2: Expectations of issue treatment in the problem-structural approach p.47

Figure 3: Evolution of the geographical scope of the Ramsar Convention p.96

$\begin{array}{ll}\text { Figure 4: Regime pyramid } & \text { p.124 }\end{array}$

Figure 5: Regime complex spectrum and typology p.125

$\begin{array}{ll}\text { Figure 6: } & \text { Regime complex emergence } \\ & \text { p.127 }\end{array}$

Table 1: Chronology of important freshwater events on the international p.17 agenda since the 1970 s

Table 2: Scholarly consensus (or lack thereof) about important freshwater $\quad$ p.27 events on the international agenda

Table 3: International agenda-setting process through agenda access points p.35

Table 4: Development of membership to the Ramsar Convention p.95

Table 5: Worldwide shared river and groundwater basins by continent p.100

Table 6: Voting patterns of the most important countries participating in GA p.105 and GA $6^{\text {th }}$ Committee

Table 7: Summary of the Ramsar and IWC processes/(sub-)regimes p.118

Table 8: Analysis of the freshwater regime complex dimensions p.136 


\section{TABLE OF CONTENTS}

ABSTRACT 11

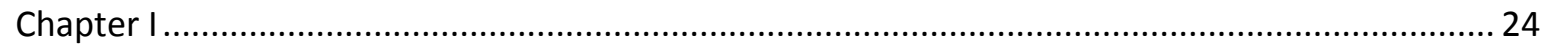

SCHOLARSHIP ON FRESHWATER, THEORETICAL FRAMEWORK AND METHODOLOGY.................... 24

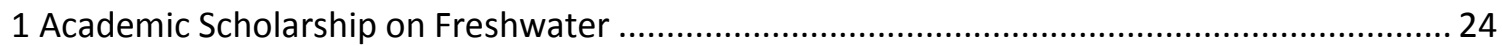

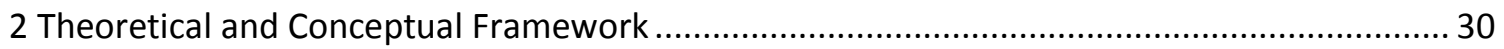

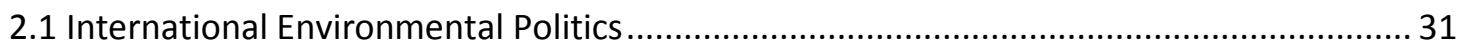

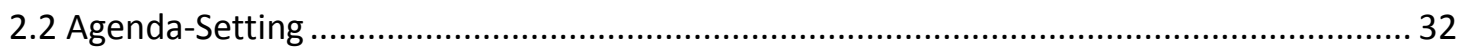

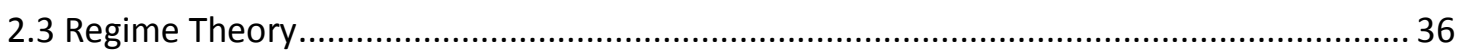

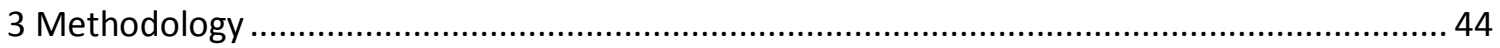

3.1 Research Questions and -Objectives ............................................................................. 44

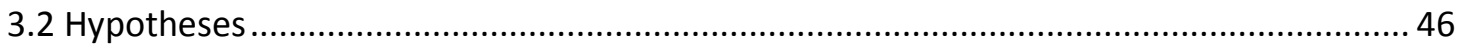

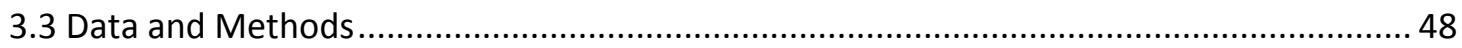

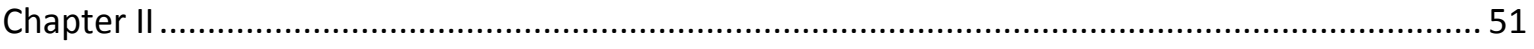

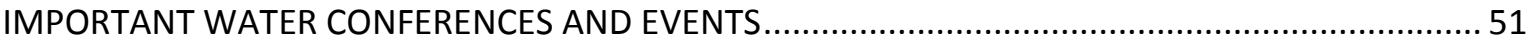

11977 UN Conference on Water and First International Water Decade .................................... 52

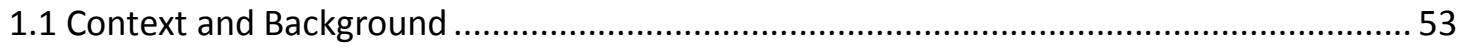

1.2. Origins, Process, Important Countries and Players ......................................................... 54

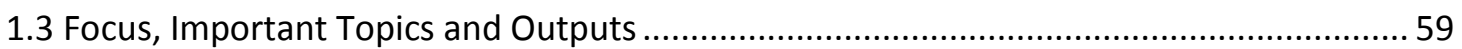

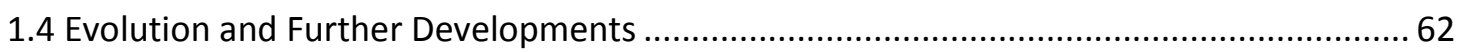

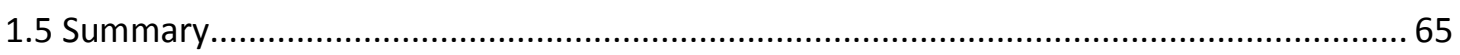


21992 International Conference on Water and the Environment (ICWE) and UN Conference on

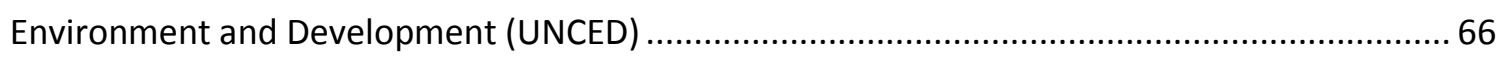

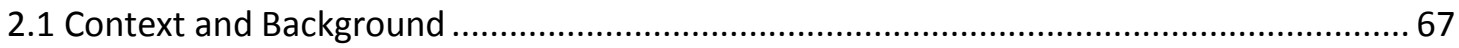

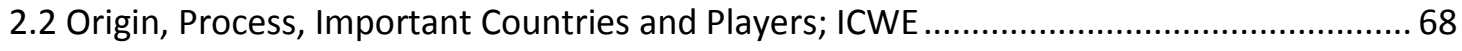

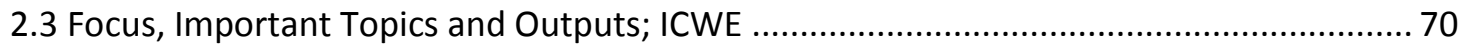

2.4 Origin, Process, Important Countries and Players; UNCED ................................................ 74

2.5 Focus, Important Topics and Outputs; UNCED ................................................................ 77

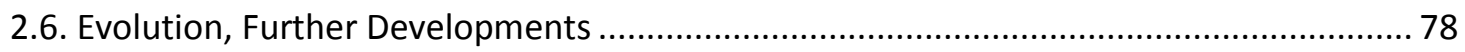

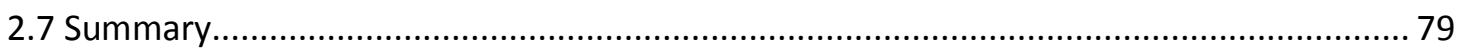

3 Key Freshwater Conferences during the Emergence Period.................................................. 79

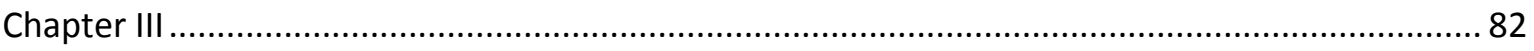

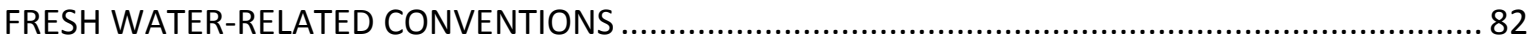

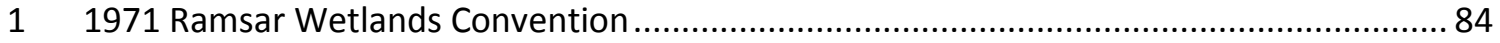

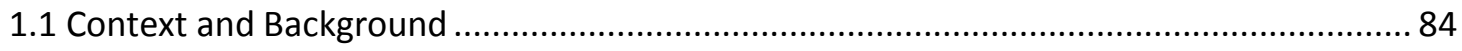

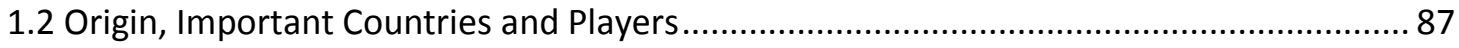

1.3 The Ramsar Regime: Rules, Norms and Wetlands Governance...................................... 91

1.4 Evolution, Further Developments and Current State....................................................... 95

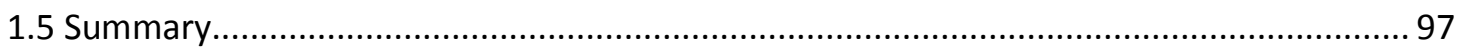

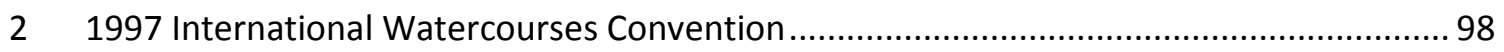

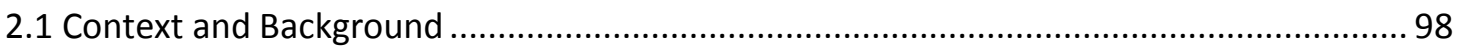

2.2 Origins, Important Countries and Players ………............................................................ 102

2.3 The IWC Regime: Rules, Norms and Transboundary Water Governance ......................... 106

2.4 Evolution, Further Developments and Current State.................................................... 112

2.5 Summary

3 The Freshwater Regime Complex and Implications ........................................................ 117

3.1 Freshwater Related (Sub-)Regimes on the International Agenda................................. 117

3.2 Emergence of a Freshwater Regime Complex.......................................................... 121

3.3 Origins of the Freshwater Regime Complex............................................................ 125 
CONCLUSION

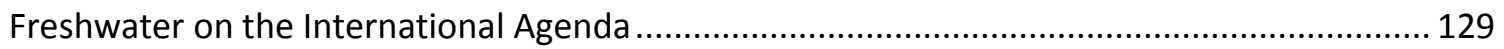

Global Freshwater Governance and Regime Theory .............................................................. 132

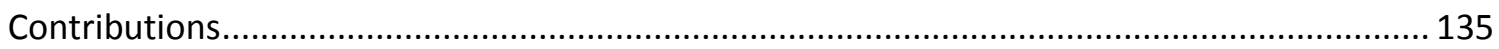

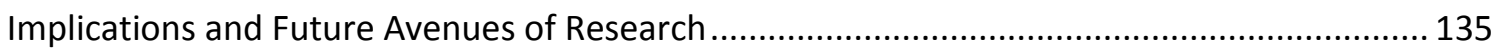

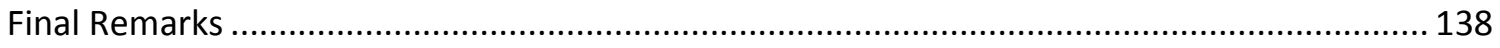

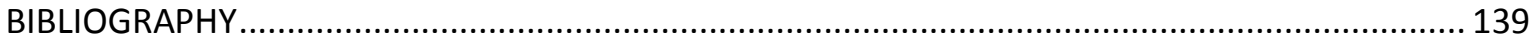

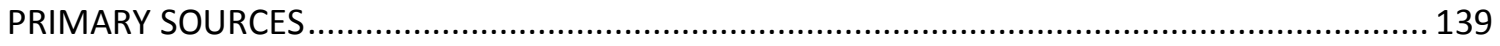

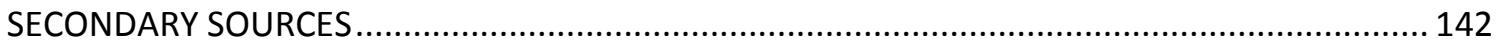




\section{INTRODUCTION}

\section{Overview}

This thesis analyzes the emergence of the freshwater topic as an environmental issue on the international agenda, aiming to contribute to the literature on global environmental politics, international agenda setting and regime theory. In particular, this study focuses on the conditions and actor constellations under which freshwater became a topic of international concern and how these individual steps and building blocks led to the global governance structures that (partially) regulate this issue area to date.

It is shown that the freshwater topic is in fact an umbrella issue, which can and has been broken down further into sub-topics, such as shared international watercourses and their use by the respective countries, wetland management, sanitation and safe water access, water pollution and freshwater management, amongst others. Since the 1970s these subtopics have been the substance of international conferences and events, several of which have led to international conventions (on wetlands and shared water courses) that are currently viewed as individual regimes.

However, going beyond this perception, it is argued that this fragmented treatment of the freshwater umbrella topic on the international agenda has not only led to separated regimes which exist in their own right but rather that these two regimes are actually sub-regimes and form the basis of a more comprehensive regime complex that regulates specific aspects of the overarching freshwater issue. Moreover, it is argued that the origins of this regime complex are not due to specific countries' deliberate aims of constructing international institutional overlap to subsequently explore forum-shopping opportunities to their advantage but, rather, that developments in this issue-area resulted unintentionally in this overlap for functional reasons. 


\section{Freshwater as an International Concern}

In the $21^{\text {st }}$ century water scarcity is a global phenomenon of growing concern. This is due to not only to unfavorable natural conditions, but often caused by pollution, increasing demand for water resources and mismanagement. Often depicted in media reports, endorsed by global summits such as the recent "Rio+20" Conference in July 2012 in Brazil and campaigned for by NGOs all over the world, freshwater issues play an important role within bigger debates on environmental topics. Despite a clear increase in the intensity and scope of these issues over the last decades they are not novel as such and international cooperation and negotiations with regard to freshwater resources have a history. While local, national, bilateral and also regional concerns over these resources certainly go back all the way to the beginnings of civilization, the foundations of current global governance structures in this issue area were created in the emergence period of the topic on the international agenda between the early 1970s and the late 1990s.

Before delving into the conference-data and related analysis of this period (c.f. chapters II and III), it is important to point out that water as such has been on the international agenda in many different forms and frames and has led to several conflicts, resolutions and regulations over the course of time (e.g. as a natural border between countries, as a medium used for navigation, issues related to sharing bodies of water such as lakes, rivers and aquifers between countries etc.). For this reason, international water law, which derives from international agreements and legal cases, encompasses a greater universe of cases than is used in this thesis and goes far beyond the more restricted level of environmental freshwater debates and regulation attempts. While bilateral and smaller, regional-scale conflicts over water and other natural resources for agricultural food production, as well as over natural borders, certainly go back millennia, environmental cooperation on an international level in a wider sense appears sporadically only after the $17^{\text {th }}$ century. As Bernauer (1997) shows, as far back as 1616 one can find an agreement between Austria and Turkey on the navigational rights on the Danube River. Another, oftcited example comes from 1815, the year in which the Congress of Vienna introduced the right of free navigation on international rivers. However, these first attempts at freshwater regulation consider the actual environment only secondarily, since navigation is clearly the priority goal of these agreements and thus it is highly questionable if these should be considered the origins of environmental cooperation in this issues area or rather mere 
forerunners that lay the foundations upon which subsequent environmental concerns could be added.

The freshwater issue came to be understood more broadly as an environmental topic with clear social implications and centers around the sub-issues of pollution (i.e. the quality of water but also the quantity if the polluted water is not usable at all anymore); the general (mis-)use of natural resources, sustainability and their functions within the biosphere and, particularly for the case of the water, the hydrosphere; and the availability, access and usage right of potable water as well as related social issues such as sanitation and poverty eradication. At the heart of the issue thus lies the (threat of) scarcity due to lack of sufficient quantity and/or quality of fresh and its consequences, which then trickles down into many other related sub-issues.

The first global events and the treatment of environmental issues with a focus on the conservation of nature relevant to the freshwater topic can be traced back to the 1970s, originating with the 1971 Ramsar Conference on Wetlands and the 1977 UN $^{1}$ Conference on Water in Mar del Plata. Subsequent events, conferences and conventions frequently cite these as their predecessors and foundation upon which they construct further agreements and norms. The following table serves as a first overview of freshwater conferences, conventions and other related events on the international agenda since the 1970s.

\footnotetext{
${ }^{1}$ The 1972 UN Conference on Human Environment (UNCHE) elevated environmental concerns on the whole and paved the way for subsequent, more narrowly focused events, but it did not deal with water issues directly.
} 
Table 1

Chronology of important freshwater events on the international agenda since the 1970s

Sources $^{2}$

Elaborated by the author on the basis of reviewed literature as well as relevant UN and NGO's websites (THOMAS; HOWLETT, 1993; SALMAN, 2003; BISWAS, 2004; SOUZA, 2005; GLEICK; LANE, 2005; TOPALOGLU, 2008; RIBEIRO, 2008; GUPTA et al, 2013; WWC, 2014; UNESCO WWAP, 2015; UND, 2015)

\begin{tabular}{|c|c|c|}
\hline Year & Event & Location \\
\hline 1971 & Ramsar Convention on Wetlands & Ramsar, Iran \\
\hline 1972 & UN Conference on the Human Environment & Stockholm, Sweden \\
\hline 1973 & Third UN Conference on the Law on the Sea & New York, USA \\
\hline 1976 & Habitat Conference & Vancouver, Canada \\
\hline 1977 & UN Conference on Water & Mar del Plata, Argentina \\
\hline $1981-1990$ & UN International Drinking Water Supply and Sanitation Decade & Global \\
\hline \multirow{2}{*}{1990} & UNDP Global consultation on Safe Water and Sanitation , 1990's & New Delhi, India \\
\hline & World Summit for Children; Health, food supply & New York, USA \\
\hline $1990-2000$ & International Decade for Natural Disaster Reduction & Global \\
\hline \multirow{2}{*}{1992} & International Conference on Water and the Environment & Dublin, Ireland \\
\hline & UN Conference on Environment and Development (UNCED) & Rio de Janeiro, Brazil \\
\hline \multirow[t]{2}{*}{1994} & $\begin{array}{l}\text { Ministerial Conference on Drinking Water Supply and } \\
\text { Environmental Sanitation }\end{array}$ & Noordwijk, Netherlands \\
\hline & Intl. Conference on Population and Development & Cairo, Egypt \\
\hline \multirow{2}{*}{1995} & $\begin{array}{l}\text { World Summit for Social Development; Poverty, water supply and } \\
\text { sanitation }\end{array}$ & Copenhagen, Denmark \\
\hline & $\begin{array}{l}\text { Fourth UN World Conference on Women; Gender Issues, water } \\
\text { supply and sanitation }\end{array}$ & Beijing, China \\
\hline \multirow{3}{*}{1996} & UN Conference on Human Settlements (Habitat II) & Istanbul, Turkey \\
\hline & World Food Summit; Food, Health, Water and Sanitation & Rome, Italy \\
\hline & Second Summit of the Americas, Sustainable Development & Santa Cruz, Bolivia \\
\hline \multirow{3}{*}{1997} & Cape Town Declaration & Cape Town, S. Africa \\
\hline & International Watercourses Convention (IWC) & New York, USA \\
\hline & First World Water Forum & Marrakech, Morocco \\
\hline \multirow[t]{2}{*}{1998} & $\begin{array}{l}\text { Report of the Expert Group Meeting on Strategic Approaches to } \\
\text { Freshwater Management }\end{array}$ & Harare, Zimbabwe \\
\hline & Intl. Conference on Water and Sustainable Development & Paris, France \\
\hline \multirow{3}{*}{2000} & Second World Water Forum & The Hague, Netherlands \\
\hline & Intl. Year of Freshwater; UNGA Res. A/RES/55/196 & New York, USA \\
\hline & United Nations Millennium Declaration & New York, USA \\
\hline 2001 & Intl. Conference on Freshwater & Bonn, Germany \\
\hline 2002 & UN World Summit on Sustainable development $($ Rio +10$)$ & Johannesburg, S. Africa \\
\hline \multirow{3}{*}{2003} & Third World Water Forum & Kyoto, Japan \\
\hline & Dushanbe Water Appeal & Dushanbe, Tajikistan \\
\hline & International Water Year & Global \\
\hline $2005-2014$ & Decade of Education for Sustainable Development & Global \\
\hline $2005-2015$ & UN International Decade for Action "Water for Life" & Global \\
\hline 2006 & Fourth World Water Forum & Mexico City, Mexico \\
\hline 2009 & Fifth World Water Forum & Istanbul, Turkey \\
\hline \multirow{2}{*}{2012} & Sixth World Water Forum & Marseille, France \\
\hline & UN Conference on Sustainable Development $($ Rio +20$)$ & Rio de Janeiro, Brazil \\
\hline
\end{tabular}

\footnotetext{
${ }^{2}$ These are arranged in order of publication (articles and books) or latest access (websites).
} 
From this panoramic overview, based on the current literature ${ }^{3}$ as well as on relevant UN and NGO websites, it becomes clear that after the 1970s freshwater resources have been debated upon intensely in many different arenas and under several different headings. While few international meetings have focused entirely on water resources, many others have treated it as an important linked subject, e.g. the conferences on children, women and habitat and their close ties with questions of sanitation and drinking water supply.

A first trend follows the logic of progressive specialization; some of the foundational events were extremely broad, yet already touching on later specific themes. After a link made between water and the wider topic of the environment in Stockholm in 1972, further conferences were dedicated exclusively to aspects regarding freshwater, e.g. the 1977 Mar del Plata Conference but also the 1992 Dublin Conference. Over the course of time, several conferences were held with even more detailed and particular freshwater sub-issues, such as drinking water and sanitation, as well as international watercourses and transboundary conflicts and cooperation (c.f. chapter II). An exception to this pattern is the sub-topic of wetlands, which received considerable attention on its own very early on (even before UNCHE and Mar del Plata), leading to the Ramsar Convention in 1971.

Upon closer examination of Table 1, it is possible to distinguish another chronological pattern with regard to the types and quantity of water events on the international agenda. The year 1997 marks a decisive point, dividing the list of agenda items into two broader halves, which henceforth are referred to as emergence (pre-1997) and evolution (post1997) period in this thesis for two reasons.

Firstly, it is the year of the culmination of a long process of negotiations about international rivers, lakes and aquifers with the adoption of the most important freshwater treaty to date, the International Watercourses Convention (IWC). Together with the 1971 Ramsar Convention, these two international treaties form the central pillars of the current global freshwater governance structure and, thus, 1997 marks the year of their cogovernance of the issue area.

\footnotetext{
${ }^{3}$ Few authors - mainly Gleick and Lane (2005) but also Thomas and Howlett (1993) - provide an even more exhaustive list of conferences, which however includes many mostly technical meetings of experts. While this background is certainly interesting, these meetings do not have a direct impact on the international political agenda examined in this thesis, especially if there is no high-level political representation - such as ministerial meetings -, and are thus not included in the following. One can, however, assume that these experts and the knowledge of the respective epistemic communities form the scientific basis and a first substantive input to the other international conferences with more political character and decision powers.
} 
Secondly, in 1997, the first of several World Water Forums (WWFs) took place in Marrakesh, Morocco. While not resulting in greater efforts to create binding international rules through further agreements and conventions, this does mark the beginning of an important shift of importance within the institutional arenas and fora of global debates on freshwater resources as well as growth in event numbers, tipping away from big UN conferences (although there of course remains activity some continuity with the 2000 Millennium Summit, the 2002 Rio+10 and the 2012 Rio+20 conferences) and other events organized by UN agencies and programs, towards the WWFs with their backing institutions - the World Water Council (WWC) and the Global Water Partnership (GWP). In the words of Gleick and Lane (2005, p. 411), "the real profusion of large conferences, however, did not begin until the mid-1990s, when two new organizations were created by senior people in other water organizations and began to dominate global water discussions". This newer type of conference with its integrated ministerial meetings has changed the treatment of the freshwater issues on the international agenda and attracted both praise and criticism. However, it has not led to further international treaties and wider changes in global water governance. For these reasons and due to scope limitations, this thesis will focus on the emergence period of the freshwater topic on the international agenda from the early 1970 s to the late 1990 s.

Despite the elaboration of many high-level declarations and the negotiation of the two abovementioned important conventions on wetlands and on international watercourses (c.f. chapter III), these distinct sub-topics of international cooperation in the issue area have, to date, not been merged into one bigger, cohesive freshwater umbrella regime and global freshwater governance still remains highly fragmented. However, as chapter III will demonstrate, the existing sub-regimes regarding wetlands and international watercourses are not entirely isolated and mutually exclusive as might be assumed by their labels; they feature an overlap with regard to their rules and regulation matter and will thus be considered an emerging regime-complex. This, together with the progressive codification of international water law through additional regional and global agreements, perhaps in other sub-topics such as sanitation and access to potable water, is pointing in the direction of further institutional density, which in turn creates more potential to a reframing of the freshwater topic in the future. 


\section{Relevance and Justification}

Water ${ }^{4}$ is essential for life on earth and thus of greatest importance as a foundation for most other issues. In particular, freshwater ${ }^{5}$ is essential for the sustenance of human life and it is in mutual dependency with many ecosystems, thereby demonstrating its relevance for environmental concerns. The most readily available fresh water resources are found in the form of groundwater, whereas lakes and rivers, as the main source for direct human consumption, amount to only about a quarter of a percent of the total freshwater resources worldwide. The latter have always been central to the growth of societies all over the world due to easily accessible water for human consumption, agriculture and industry. Early civilizations succeeded or failed in large proportion in relation to their water access and management, most of them built near great watercourses, such as the famous example of the Nile. The process of industrialization and increasing global population increased the consumption of water immensely and resulted in water scarcity and water stress in some regions of the world.

With regard to international watercourses it is important to bear in mind that use of these waters in upstream countries, i.e. countries in the upper parts of where the river originates, can have detrimental effects for the downstream countries, referred to as negative externalities of upstream usage. Apart from water extraction and the construction of dams, leading to a problem of quantity in downstream countries, the problem of water pollution through industry and specific agricultural practices have become more and more apparent and urgent, thus raising questions and conflicts of water quality. However, as will become clearer in the course of this thesis, fresh water issues are not confined to rivers and lakes themselves. Groundwater plays a very important role with regard to fresh water provision, yet it was overlooked in water debates for many decades and it has only been recently that this element has found more public interest. Apart from issues related to these sources of freshwater on the supply side, i.e. the hydrosphere, there are important topics centered

\footnotetext{
${ }^{4}$ The world's total water resources amount to around 1.384 billion $\mathrm{km}^{3}$, which can be further subdivided into the two main groups of saltwater and fresh water. The former group represents the broad majority of world water resources with $97.47 \%$ (mostly ocean water but also a small amount of salty groundwater), whereas fresh water only makes up a total of $2.53 \%$. This can be further broken down into bound water $(1.76 \%$; mainly in the form of glaciers, permanent snow cover or ground ice) and liquid water $(0.77 \%)$. In turn, these $0.77 \%$ of liquid water are composed of fresh groundwater $(0.76 \%)$, lakes $(0.007 \%)$, rivers $(0.0002 \%)$ and others $(0.0028 \%$; mostly moisture of the soil, biological as well as atmospheric water) (SHIKLOMANOV, 1993).

${ }^{5}$ For this reason, saltwater resources will not be covered within this study despite their ecological link to freshwater via the hydrological cycle.
} 
around the demand side, with a broad array of water users with growing needs competing for this constant stock of water resources. While these latter issues are mostly dealt with at local or national level and are assumed to be of a more technical and managerial nature, they ultimately depend on overall freshwater availability in the specific regions and how said resources distributed, which is where politics and regulations enter the picture once again. Another connection between these more local and national levels and the global one is the importance of international norms, for example the human right to water, which requires a certain translation of the available freshwater into availability of potable water and sanitation facilities.

Since the mid-1990s, prominent public intellectual figures as well as some scholars have pointed to the possibility of increasing international conflict around issues of freshwater, which could result in so-called "water wars", due the ever increasing competition over this natural resource. Therefore, it is mandatory to study and better our understanding of water and especially fresh water related issues, such as the ones mentioned above, and how they are dealt with and regulated at the global level.

International Relations as a discipline has much to offer to such a study and to attempts to explain these kind of potential conflicts, as well as global cooperation on such issues. Whereas individual transboundary water disputes have long been studied due to the great number of shared international rivers, lakes and aquifers, the freshwater topic on a global scale has not attracted equal attention. However, with bodies of literature dedicated to international environmental politics, agenda setting as well as to the formation and evolution of specific topics and themes within regimes, current IR theory has the potential to be applied to this topic. This would advance IR scholarship in the light of global challenges, enabling a deeper understanding of the workings of the international agenda. This includes not just of the freshwater case, but also the genesis and evolution of other topics, particularly those that are understudied, complex and multifaceted. As will be shown in the next chapter, more recent scholarship on regime complexes offers a new perspective on the freshwater case, which in turn serves as a test case for the theories and assumptions of the former (c.f. section five on methodology in general and the hypotheses in particular). 


\section{Thesis Structure}

In this introduction, the thesis' thematic topic and universe of analysis are introduced, justified and delimited. For this purpose the emergence and evolution of the freshwater topic and its sub-issues are depicted, in a first moment, in a panoramic fashion to set the scene and provide the necessary background against which to subsequently cast the analysis of individual conferences, events and conventions.

The first chapter critically reviews previous scholarly attention to freshwater resources on the international agenda, drawing upon literature from several disciplines. Additionally, this chapter examines the core concepts and theories relevant to this thesis, which will be employed in the analysis of the empirical data. It also outlines the guiding research questions and the central hypotheses. These elements are gathered under the sections containing the theoretical backbone - which entails scholarship on international environmental politics, international agenda-setting as well as regime theory -, research design and methodology. The latter body of literature, especially elements of regimes formation and regime complexes, enables the study to analytically unpack the period of emergence of the freshwater topic in the form of conferences and conventions it has taken from the early 1970s to the mid- and late 1990s and the central hypothesis derives directly from it with its methodological consequences.

In chapter II, the first of two empirical chapters, key moments of the international agenda are analyzed individually from the above zoomed-out chronology of freshwater-related events and conferences in a second step, so as to show the fragmented treatment and the development of the broader debates on freshwater resources over the emergence time span. Following the choice of conferences and the respective justification in chapter I, this part takes a closer look at the origins, background, context, main countries and players as well as shortcomings, achievements and impact of the 1977 Mar del Plata Conference with the related 1980s International Drinking Water and Sanitation Decade as well as the 1992 Dublin and Rio Conferences, which are all considered milestones events for freshwater resources on the international agenda.

In a further step, chapter III features the analysis of the two sub-aspects of the freshwater issue area which have been negotiated and taken to the next level in the form of international treaties and conventions: wetlands of international importance and 
international watercourses. In a similar fashion to the study of the milestone conferences in chapter II, which have not resulted in new global governance structures, these two processes are traced back to their origins individually, with equal focus on the background and context of their respective conferences, their principal protagonists and coalitions where possible as well as their legacy.

In a final layer of analysis, the micro-level analyses of chapter II and of the first part of chapter III are woven together into a more macro study of the overall process of topic emergence and creation of global governance structures in the issue area of freshwater resources. From these analyses emanates the central argument of this thesis, namely that the existing structure of global governance in this issue area features an overlap in the regulation matter and thus comprises an emerging regime complex. In this section, the theoretical expectations of traditional regime theory, as well as the more specific and recent contemporary scholarship on regime complexes, which have inspired the central hypotheses of this work, are measured up with the empirical realities and put to the test. In both instances, it is shown that there is a lack of evidence to support the hypotheses, which implies, therefore, that the case of freshwater resources is not covered or explained sufficiently by current theories and that these require adaptation and reworking.

Finally, the conclusion summarizes the individual analyses of the chapters and makes some first attempts at discussing the wide-reaching implications and ramifications of the emerging freshwater regime complex, as well as highlighting the primary contributions of this thesis and pointing out future avenues for research in this area. 


\section{Chapter I}

\section{SCHOLARSHIP ON FRESHWATER, THEORETICAL FRAMEWORK AND METHODOLOGY}

\section{Academic Scholarship on Freshwater}

Academic scholarship directly dealing with the global emergence of the freshwater topic and its evolution on the international agenda has so far been quite scarce. Individual water conferences and conventions have been met with varying degrees of scholarly attention, most of it gravitating towards the conventions but with disregard for their links to each other and to broader freshwater issues (c.f. for example, BREITMEIER et al, 2006; SCHROEDER-WILDBERG, 2002).

Important institutions working on water topics, such as UN agencies or NGOs in the area, provide overviews, tables and chronologies of these events as background information, but with little to no added commentary (WWC, 2014; UNESCO, 2015; UND, 2015). Meanwhile, most existing analyses of development of international water meetings are carried out at the problem level or in a mostly technical fashion as to the outcomes of these events, their perceived impact on the management of the underlying resources or normative discussions as to how these longer-term debates ought to change or continue. Their authors are, in the largest part, members of the water professional community or interested policy makers, sometimes in co-authorship with scholars from international law or geography (SALMAN, 2003; BISWAS, 2004; GLEICK; LANE, 2005; GUPTA et al, 2013). Undoubtedly, these works are enriching and advance the understanding of the matter, particularly as they often come from the perspective of those who attended studied conferences and conventions, and who have unique insights into the processes and developments of these events from participant observation, as it were. However, in this kind of analysis there lies the danger of reducing the treatment of freshwater resources to a mere technical and managerial matter and thereby omitting or underplaying the political aspects and dynamics involved. Depending on the sub-issue at hand, the latter can be more or less important, but ignoring them certainly renders the overall analyses and conclusions partial and incomplete. Moreover, from an academic perspective, these articles often lack a 
theoretical base to explain outcomes and development and thus leave further room for discussion and analysis.

Ribeiro (2008), from the field of Political Geography, goes beyond the above contributions by offering a deeper, more complex analysis of freshwater resources, their distribution, related crises and links to human rights as well as to economic aspects. His depiction of these different dimensions is embedded into a powerful larger social and capitalist critique, which I will engage with through the examination of underlying political interests.

Within the discipline of International Relations, there has been a steadily growing body of literature concerning specific freshwater disputes as well as conflict and cooperation over transboundary water resources (c.f. LOWI, 1993; OHLSSON, 1995; CONCA et al (2006), ZEITOUN; WARNER, 2006; WARNER; ZEITOUN, 2008); nevertheless, the broader development of the overarching freshwater topic in all its dimensions at the global level has received little attention thus far. Back in the early 1990s, in their compiled edition of Resource Politics, the IR scholars Thomas and Howlett (1993, p.1) have pointed to this lacuna by stating that "a systematic study of the international politics of freshwater resources is long overdue". Unfortunately, neither their chapter "The Freshwater Issue in International Relations" and the remaining articles of their collection on regional water relations, nor Topaloglu's (2008) M.Sc. dissertation on the Integrated Water Resources Management (IWRM) approach and its chapter on water on the international agenda, are able to fully fill this gap since both feature a mostly descriptive account of the conferences and developments but fail to provide any kind of IR framework. Additionally, a justification of the choice of freshwater conferences and events is omitted and the later are portrayed in more historic character with little attention to political dynamics and context. In the case of Topaloglu this may be due to the author's overall research aim of tracing the specific norm of Integrated Water Resource Management regarding how to manage freshwater; nonetheless, it equally leaves gaps to be filled by future research such as this thesis.

The most notable contribution comes from Matilde de Souza's (2005) chapter article on the link between freshwater resources as an element of the environmental agenda, on the one hand, and the social agenda of International Relations, on the other. Her study stands out due to the fact that she makes an attempt to not only connect environmental and social aspects of the freshwater umbrella issue, but also to embed this within in more profound 
argument on the nature of the resource at hand. Having said that, Souza deals with the global emergence and evolution of the freshwater topic rather en passant and portrays individual conferences descriptively with regard to their content and outcomes in order to develop her key argument that freshwater is both a common-pool resource as well as a global public good. The author does not take a closer look at the political and interest constellations behind the conferences and leaves out the negotiation process(es). Moreover, Souza does not justify her choice of freshwater related events and omits several events, such as the 1971 Ramsar Convention and the 1997 International Watercourses Convention. All in all, this seeming lack of a theoretical framework with regard to freshwater emergence is explained by differing research questions and by her research goal of analyzing the duality of water being a common-pool resource and a global public good. Souza makes an important contribution by focusing mainly on the interaction of the freshwater topic with other issues. However, as a consequence, her article does not address political factors within the treatment of freshwater and thus leaves several research lacunae, which will be taken up and filled by this thesis.

On top of these issues related to theory, research techniques and methodology, there appears to be a lack of clarity over which should be considered the most important waterrelated events since the 1970s within the above-reviewed academic literature on freshwater on the international agenda. To illustrate this state of diverging emphasis put on the different data points of the international emergence of the issue, Table 2 below visually sums up the choices of the respective authors with reference to the main water related conferences, their respective year and brief description. 


\section{Table 2}

Scholarly consensus (or lack thereof) about important freshwater events on the international agenda (red = not mentioned/analyzed; green and tick = mentioned/analyzed by the respective source)

\section{Sources}

Elaborated by the author on the basis of reviewed literature ${ }^{6}$ as well as relevant UN and NGO's websites (in order of publication (articles and books) or last access (website) - 1: THOMAS; HOWLETT, 1993 ; 2 : SALMAN, 2003; 3: BISWAS, 2004; 4: SOUZA, 2005; 5: TOPALOGLU, 2008; 6: RIBEIRO, 2008; 7: GUPTA et al, 2013; 8: WWC, 2014; 9: UNESCO WWAP, 2015; 10: UND, 2015)

\begin{tabular}{|c|c|c|c|c|c|c|c|c|c|c|c|}
\hline Year & Event & 1 & 2 & 3 & 4 & 5 & 6 & 7 & 8 & 9 & 10 \\
\hline 1971 & Ramsar Convention on Wetlands & & & & & & & & & & \\
\hline 1972 & UN Conference on the Human Environment & & & & & & & & & & \\
\hline 1973 & Third UN Conference on the Law on the Sea & & & & & & & & & & \\
\hline 1976 & Habitat Conference & & & & & & & & & & \\
\hline 1977 & UN Conference on Water & & & & & & & & & & \\
\hline $\begin{array}{c}1981- \\
1990\end{array}$ & $\begin{array}{l}\text { UN International Drinking Water Supply and } \\
\text { Sanitation Decade }\end{array}$ & & & & & & & & & & \\
\hline \multirow[t]{2}{*}{1990} & $\begin{array}{l}\text { UNDP Global consultation on Safe Water and } \\
\text { Sanitation for the 1990's }\end{array}$ & & & & & & & & & & \\
\hline & World Summit for Children; Health, food supply & & & & & & & & & & \\
\hline $\begin{array}{l}1990- \\
2000\end{array}$ & International Decade for Natural Disaster Reduction & & & & & & & & & & \\
\hline \multirow[b]{2}{*}{1992} & Intl. Conference on Water and the Environment & & & & & & & & & & \\
\hline & $\begin{array}{l}\text { UN Conference on Environment and Development } \\
\text { (UNCED) }\end{array}$ & & & & & & & & & & \\
\hline \multirow[t]{2}{*}{1994} & $\begin{array}{l}\text { Ministerial Conference on Drinking Water Supply } \\
\text { and Environmental Sanitation }\end{array}$ & $x$ & & & & & & & & & \\
\hline & Intl. Conference on Population and Development & $x$ & & & & & & & & & \\
\hline \multirow{2}{*}{1995} & $\begin{array}{l}\text { World Summit for Social Development; Poverty, } \\
\text { water supply and sanitation }\end{array}$ & $x$ & & & & & & & & & \\
\hline & $\begin{array}{l}\text { Fourth UN World Conference on Women; Gender } \\
\text { Issues, water supply and sanitation }\end{array}$ & $\mathrm{x}$ & & & & & & & & & \\
\hline \multirow{3}{*}{1996} & UN Conference on Human Settlements (Habitat II) & $\mathrm{x}$ & & & & & & & & & \\
\hline & $\begin{array}{l}\text { World Food Summit; Food, Health, Water and } \\
\text { Sanitation }\end{array}$ & $x$ & & & & & & & & & \\
\hline & $\begin{array}{l}\text { Second Summit of the Americas, Sustainable } \\
\text { Development }\end{array}$ & $x$ & & & & & & & & & \\
\hline \multirow{3}{*}{1997} & Cape Town Declaration & $x$ & & & & & & & & & \\
\hline & International Watercourses Convention (IWC) & $\mathrm{x}$ & & & & & & & & & \\
\hline & First World Water Forum & $x$ & & & & & & & & & \\
\hline
\end{tabular}

The first observation to be made from Table 2 is that by adding up the events mentioned and analyzed by the above authors and institutions, it does not immediately become clear which elements should be included when studying the emergence of the freshwater topics

\footnotetext{
${ }^{6}$ The article of Gleick and Lane (2005) is not included in Table 1 despite dealing with the overall topic of large international water meetings; this is because they explicitly point to Salman $(2003$; 2004) for the history and background analysis of the conferences, while they themselves concentrate on the impact of global water conferences as well as offering suggestions and possible changes.

7 Since Thomas and Howlett's book was printed in 1993, the years after the year of publication are not counted as "not mentioned" (red) but rather as "not applicable" (x).
} 
since most sources differ in this regard, sometimes even strongly. Some authors include one set of conferences and even highlight their importance, whilst others omit them entirely and point to others; see for example the different perception of the Habitat I and II Conferences or the World Summits for Children as well as the one of Social Development. It can be assumed that the high variance in importance given to specific events can be attributed largely to the interests of the individual authors and their respective institutions, such as their relative proximity to organizing UN agencies and other water institutions in the case of water professionals and policy makers. For academic authors, the variation appears to co-vary with their overall research problem and goals. In either case, due to the broad disagreement noted in Table 2 , it is important to openly explain and justify the selection of events and conferences.

Having said that, one can also assume that the apparent lack of consensus above is most prominent with regard to conferences of minor to medium importance, whose inclusion (or not) for the study depends most on subjective evaluation. In contrast, the milestone events should be recognized and analyzed by most authors, if not all. A second, closer look at Table 2 indeed reveals that several events were chosen almost unanimously ${ }^{8}$, as in the cases of the 1977 Mar del Plata Conference, the 1980s UN International Drinking Water Supply and Sanitation Decade, the 1992 Dublin and Rio Conferences as well as the 1997 First World Water Forum. Additional, more detailed reading and analysis subsequently confirms the importance of these events and the scholarly consensus, which is the reason for their inclusion in the first empirical chapter of this thesis (c.f. chapter II).

A third and even less immediate observation can be made with regard to the conferences that have resulted most clearly resulted in binding results: the conventions. At the global level ${ }^{9}$, one can make out two such conventions; firstly, the 1971 Ramsar Convention on Wetlands of International Importance and, secondly, the 1997 International Watercourses

\footnotetext{
${ }^{8}$ To a lesser extent, this is true for the 1972 Stockholm UN Conference and the 1990 UNDP Global consultation on Safe Water and Sanitation for the 1990's. The former is often mentioned as the first big, environmental conferences and thus vital door-opener but not analyzed in more detail since it does not actually refer directly to freshwater resources; the latter does deal with freshwater, but actually consists of a the bringing together of prior regional consultations. Therefore, both will be included in this thesis but mainly as context for the other key events.

9 At the regional level, it is necessary to bear in mind the Convention on the Protection and Use of Transboundary Watercourses and International Lakes, adopted in the 1990s by the United Nations Economic Commission for Europe (UNECE, 1992; 1998). This treaty was signed in Helsinki on March $17^{\text {th }}$ March 1992, entered into force on October $6^{\text {th }} 1996$ and has since become known as the Helsinki Convention (not to be confused with the 1966 Helsinki Rules of the ILA; see chapter III, section 2.2). Since this convention only applies to the European and not the global context, it will not be included in the analysis of this thesis.
} 
Convention (IWC). Interestingly, most sources give priority to the conferences and omit the conventions, with the exceptions of UND (2015) - in the case of the Ramsar - and of Salman (2003), Ribeiro (2008) and Gupta et al (2013) - for the IWC. The reasons for this omission are not straightforwardly obvious and one can only make tentative explanations.

Regarding the Ramsar Convention, this may be the result of three developments: (1) initially it was a European project that only later expanded to the global level; (2) the origins of this project derived from concern not about freshwater resources but rather about migratory birds and wetlands as their habitat (it is sometimes even falsely referred to as the "migratory bird convention"); and (3), of the sub-issues of the freshwater topic, wetlands protection and regulation is often overlooked as a side-topic in comparison with transboundary water bodies or sanitation and water supply, which are considered more pressing issues and which receive more attention since they are more contentious.

The case of the IWC is somewhat different since it does deal with a very contentious and center-stage sub-topic of the freshwater issue, namely transboundary water conflict and cooperation, and was elaborated within the UN system. In comparison with Ramsar, it has received more relative attention from the sources studying freshwater resources on the international agenda and has also been analyzed more widely on its on by academic scholarship, see for example Conca et al (2006), McCaffrey (1993; 1995; and 1998 in coauthorship with Sinjela). Apart from the long from the long process of elaboration and negotiation of several decades, as well as its more legal and less technical nature in comparison to most other conferences, the main reason for the lack of attention might be for the fact that after its adoption in 1997 it did not immediately receive ample international recognition and support, quite the contrary. In the mid-2000s, Salman notes in this regard that:

The lack of political will is manifest in the failure of the world community to bring the United Nations Convention on the Law of the Non-Navigational Uses of International Watercourses into force and effect, more than six years after its adoption by the UN General Assembly (SALMAN, 2004, p. 18).

Instead, it was doubted whether it would even reach the status of hard law via ratification. Even in recent years, scholars and policy makers such as Gupta et al (2013) remained highly skeptical by stating that "the 1997 Watercourses Convention is not and may never enter into force". In late 2014, the IWC did finally enter into force; however, little time has passed since then, which to some extent explains the hitherto relatively scarce attention 
outside the legal sphere and, at the same time, makes it more likely that this trend will discontinue and reverse in favor of more awareness of the convention and its impact.

All in all, this review indicates several lacunae on theoretical and methodological grounds. While a first explanation for the varied selection of relevant conferences by the distinct authors and sources has been now made in the last paragraphs, it has not been thoroughly studied why the freshwater topic emerged on the international agenda in this form, which actors have pushed and backed the topic and which (political) processes led to the creation of these conferences and conventions. This thesis seeks to fill these gaps by analyzing the genesis of the freshwater umbrella issue on the international agenda - with regard to both the here identified key conferences and conventions - through the lens of regime theory. Rather than being concerned with technical aspects regarding efficient water management or with normative solutions on the direction that the global water dialogue should take, the primary goal is to unravel the political constellations behind the construction of the global freshwater governance structures that emerged between the early 1970s and late 1990s. In order to achieve these objectives, the following theories, concepts and methodology will be employed.

\section{Theoretical and Conceptual Framework}

The analysis of the chosen freshwater conferences and conventions in chapters II and III, respectively, as well as the central analytical argument of this thesis, rest firmly on regime theory. This choice of this theory suggests itself from the fact that its application has led to valuable insights with regard to other environmental topics and their emergence of the international agenda. Additionally, the literature on agenda-setting provides useful concepts and highlights specific elements and dimensions of the agenda-setting process which should be taken into consideration when analyzing the emergence of the particular issue area of freshwater resources. Due to the environmental character and importance of these resources and in order to highlight the links between the above two bodies of literature, this research project is located, in a first moment, within International Environmental Politics scholarship. In the next steps, the conceptual and theoretical tools derived from these literatures will be laid out. 


\subsection{International Environmental Politics}

In order to study the international interest and cooperation with regard to freshwater and its sub-topics, it is useful to place it within broader environmental debates and global governance. According to Zürn (1998), there are five dimensions which have sparked academic interest with regard to international environmental politics (IEP) ${ }^{10}: 1$ ) holistic perspectives; 2) agenda setting; 3) regime formation; 4) regime effectiveness; and 5) the role of transnational NGOs within regimes. The first four elements can be seen as progressive stages of academic interest in environmental topics, beginning with the general, comprehensive issue area and showing how it is important in relation to general IR literature. To this point, the same author goes on to explain that:

In the 1980s a first generation of studies identified the preeminence of the environment for the analysis of international relations. These early studies established international environmental policy as a core field that touches on all the major issues in the study of international politics, including peace and war, conflict and cooperation, international institutions, the comparison of foreign policies, and specific policy questions. (Zürn, 1998, p. 618).

As important exponents of this first generation, which put environmental concerns on research agendas, the author mentions David A. Kay and Harold K. Jacobson ${ }^{11}$, Oran Young $^{12}$ and Lynton Keith Caldwell ${ }^{13}$, amongst others. While of course these earlier contributions were important in their own right, it is particularly the second generation of IEP scholarship, which brought with it broadening of the scope of topics to be dealt with as well as increasing empirical application. Most importantly, this second generation not only covered the traditional policy areas with regard to environmental topics but transcended them by putting the spotlight on new questions and concepts, such as transnational and global networks as actors and epistemic communities. Through this extension of issues and concepts, IEP contributed by enabling the researcher to investigate topics of environmental concern, how they emerged on the international agenda, the process of regime formation, the influence of transnational actors on this process as well as regime effects in a new light.

\footnotetext{
${ }^{10}$ International Environmental Politics (IEP) is considered a policy area that began to emerge in the early 1970s and has since strongly increased its visibility and importance within broader literature of politics and international relations, going hand in hand with growing awareness and political, global campaigning with regard to ecological issues (O`NEILL, 2009).

${ }^{11}$ Both are editors of Environmental Protection: The International Dimension (1983).

${ }^{12}$ Zürn specifically cites International Cooperation: Building Regimes for Natural Resources (1989) but many other of his contributions could be mentioned instead with equal importance.

${ }^{13}$ International Environmental Policy: Emergence and Dimensions (1990).
} 
For the purpose of this study, items two (agenda setting) and three (regime formation) of Zürn's list are certainly of utmost interest and will thus be circumscribed in more detail in the following sections 2.2 and $2.3 .^{14}$

\subsection{Agenda-Setting}

The process of agenda-setting mainly consists of bringing certain topics and issues to the forefront of discussions so as to give priority to them vis-à-vis others, which remain in the background as a consequence. Evidently, this process features a strong political dimension since the definition of the agenda results in limiting or enabling potential action on a range of issues. For example, the removal of a topic like transboundary water conflict from the agenda or its omission in the first place, makes it hard, if not impossible, to gather political support amongst decision-makers to take action on the matter and to advance in the direction of agreements and regulation. On the other hand, once such a topic does arise on the agenda, the respective actors and decision-makers face pressure to negotiate and, at the very least, to position themselves with regard to the agenda item, thus making the achievement of potential agreements and regulation far more likely. This shows that the control of the agenda becomes vital for the actors, as "some issues are organized into politics while others are organized out" (SCHATTSCHNEIDER, 1960 apud LIVINGSTON, 1992, p. 313).

Much of the political science literature on the general agenda-setting process is focused on national agendas, mostly for the US case of the White House or Congress. It is worth mentioning that the traditional literature in this area stems from authors such as Schattschneider (1960), Bachrach and Baratz (1962), Cobb and Elder (1972), Cobb, Ross, and Ross (1976), Cobb and Elder (1981), Light (1982), Sinclair (1982), Kingdon (1995), Brady and McCubbins (2002) and Cox and McCubbins (2005), amongst others. In most cases, the agenda is conceptualized as a list of topics ranked in priority according to actors' preferences and their action within the given processes and institutions. In the words of one of the most well-known of these scholars, the agenda consists of a "list of subjects or

\footnotetext{
${ }^{14}$ Item five, the role of transnational actors, is more of a cross-cutting issue and will come to play a role as well with regard to particular conferences and conventions later on. However, it is relevant to a minor degree and will therefore be discussed only in the respective sections rather than as an element of the fundamental theoretical framework of the thesis.
} 
problems to which governmental officials, and people outside of government closely associated with those officials, are paying some serious attention at any given time" (KINGDON, 1995, p. 3). As becomes clear in this definition already, this author makes a distinction between two main types of relevant actors (or participants): (1) those within government, i.e. in the case of the US this includes the administration (the president and his political appointees in the White House staff), the Congress, bureaucrats in the executive branch and civil servants; and (2) those outside of it, including the media, interest groups, specialists in professional communities and the general public. It is important to underline that Kingdon differentiates, in contrast to other political scientists who subsume the following under agenda setting in the broader sense, between agenda setting in the narrow sense and alternatives specification as two separate steps in the process of public policy making. This subdivision is necessary due to the respective influence of the different abovementioned actors at specific stages of the overall process. The combination of these participants with three largely independent process streams (problems, policies and politics), which if joined at critical junctures can result in significant policy changes, lead the author to further develop the so-called "garbage can model"15 by the adaptation of earlier work by Cohen, March and Olsen (1972).

However, transferring these analyses and the models they are based on, onto the international agenda is a complicated and difficult task due to several key differences between both levels of analysis. Whereas national agendas - or equally the agendas of international agencies or organizations - have a clear physical place where the agenda is defined and controlled in form of a document, either publicly or not, this is not the case for the international agenda. While the broad division of direct and indirect agenda influence of actors can roughly be mirrored to fit the international level, one thus needs to be careful to apply the models as such since processes appear to be significantly harder to grasp and ambiguous than in the national case. Thus, a first necessary step is to try to identify how best to approximate the international agenda in order to analyze it later.

Scholarship on agenda-setting at the global level is restricted to several few major works. Whereas Mansbach and Vasquez (1981), Keohane and Nye (1989) and Livingston (1992) analyze it directly - albeit in a more general way by the former two - both Vasquez and

\footnotetext{
15 The garbage can refers to a choice opportunity, which consists of the leftovers of ideas floating in the community, existing policy solutions to related problems, current ideas which are in vogue as well as the priorities, personal convictions and resources of the respective participants involved.
} 
Mansbach (1983) as well as Peterson (1988) do so in a more indirect form via the lenses of "issue-cycles" and regime-formation, respectively. As the most recent contribution and by laying out his approach most tangibly, Livingston's approach appears to be the most promising and applicable to the topic of this thesis. For his analysis of North-South relations as an agenda topic during the Reagan administration in the 1980s, he enhances previous ideas and approaches to international agenda-setting. Rather than trying to transfer national models of agenda setting into the international sphere, the Livingston (1992, p. 315) states that "a better beginning is the recognition that agendas in other areas of politics are created through and embedded in the practices, i.e., the accustomed, rulegoverned behaviors, of actors within those areas of politics", and therefore it is important to develop "[...] an understanding that international agenda-formation is similarly embedded in the practices of international relations, allowing for the relative lack of formalization and 'fuzziness' of these practices". The author goes on to shift the focus from the general importance of specific actors in the agenda setting process towards an analysis of certain agenda access points, whose use he borrows from earlier scholarship by Mansbach and Vasquez (1981). They are defined by Livingston (1992, p. 315) as “[...] points from which an actor can, through some contextually appropriate and meaningful action, crystallize issue definition through compelling global attention to it". Examples of such access points include sites of global knowledge production, close ties (either formally or informally) with international institutions as well as transnational networks, or many other positions, from which actors can draw attention to their issue of interest. This approach, summarized in the following Table 3, provides a good starting point for the analysis of the freshwater topic by analyzing whether, how and by whom some or all of these access points were used. 
Table 3

International agenda-setting process through agenda access points

Source

Livingston, 1992

\begin{tabular}{|c|c|}
\hline Dimensions of interstate practice & Generic access points \\
\hline Knowledge & $\begin{array}{l}\text { 1) sites of global knowledge production } \\
\text { 2) supportive (employable) consensual knowledge }\end{array}$ \\
\hline Communication channels & $\begin{array}{l}\text { 1) linkages to transnational networks } \\
\text { 2) brokerage positions vis-à-vis other actors } \\
\text { 3) influential media }\end{array}$ \\
\hline Institutional loci & $\begin{array}{l}\text { 1) formal or information position in critical IO or regime } \\
\text { 2) "organizationally dependent capabilities" (KEOHANE; } \\
\text { NYE; 1989, p. 55) }\end{array}$ \\
\hline Diplomatic norms & $\begin{array}{l}\text { 1) legitimated "action-forcing" events (summits, conferences, } \\
\text { etc.) } \\
\text { 2) } \\
\text { differentiated status of great powers, "special } \\
\text { relationships", etc.) } \\
\text { 3) supportive (employable) general norms (law, reciprocity, } \\
\text { etc.) }\end{array}$ \\
\hline
\end{tabular}

These agenda access points help to structure thought and research around the freshwater issue emergence on the international agenda, and allow for easier comparisons between different conferences and conventions. From the item regarding diplomatic norms, particularly point (1) of "legitimated 'action-forcing' event (summits, conferences etc.)" one can derive the clear need to also make references to conferences, which have not resulted directly in conventions and, subsequently, regimes. Despite the fact that most of these conferences have not impacted in the global governance structures as such and, thus, cannot be regarded as part of an emerging regime complex (c.f. section 2.3 below), they do keep the topic visibly on the international agenda and extend the pressure on the international community to continue to seek cooperation on these issues.

The ideas and concepts developed by Livingston are useful for dissecting and studying the processes in and around the individual conferences and conventions as well as their sequence; for this reason they will be employed in the empirical chapters II and III. However, his approach does not consist of a fully-fledged agenda-setting theory in view of topic emergence and evolution, which could be applied to and tested with the freshwater case. Therefore, these concepts will be used in conjunction with regime theory, which does show the potential to fulfill these more sophisticated analytical functions. 


\subsection{Regime Theory}

When considering issue emergence on the international agenda we are essentially looking at states coming together at the global level to explore possible avenues of cooperation between them concerning the particular topic at hand; in this case, freshwater resources. In instances where these cooperation projects advance and move beyond the level of declarations and statements of intention, the consensus between the participants is often committed to written norms and rules in the form of agreements, treaties and conventions, which then acquire longer-term importance as regimes. Thus, along with the above academic treatises of agenda setting per se, this thesis will draw on scholarship about international regimes, broadly understood as rule-governed activity in specific issue-areas (LITTLE, 2011). Regime theory not only provides additional concepts to the ones of the agenda-setting literature but also entails assumptions and expectations with regard to its application to other topics, which can then be tested as hypotheses.

\section{Regimes: Terms and Definitions}

The origins of this body of literature can be traced back to the early 1970s when IR theorists were concerned with the potential loss of US hegemony, which had led to the creation and maintenance of many of the post-WW2 (economic) regimes. The concept "international regime" was introduced formally into IR and politics literature by John Ruggie (1975, p. 570) and defined as "a set of mutual expectations, rules and regulations, plans, organizational energies and financial commitments, which have been accepted by a group of states". Early literature on regimes was mainly interested in regime formation under hegemonic influence and, subsequently, regime change when this hegemonic influence declined. These studies were undertaken mainly with regard to economic and security regimes at the start but, coincidentally with the rise of IEP (see above), this issue focus was widened to include topics of the environment and human rights, amongst others.

It is important to point out that the 1980s, along with the first generation of IEP scholarship, also brought about the major definitions with regard to the concept of regimes, which are still widely used as the foundation framework in current times. The most wellknown and standard definition goes back to Stephen D. Krasner: 
Regimes can be defined as sets of implicit or explicit principles, norms, rules, and decision-making procedures around which actors' expectations converge in a given area of international relations. (KRASNER, 1983, p.2).

The author clarifies that in this definition the principles refer to "beliefs of fact, causation or rectitude", whereas the norms consist of "standards of behavior defined in terms of rights and obligations". These two, taken together, establish the fundamental characteristics of a given regime. Rules (specific prescriptions and/or proscriptions of action) as well as decision-making procedures ("prevailing practices for making and implementing collective choice") are less defining of a regime, in the sense that there can potentially be many different rules and decision-making procedures under the same principles and/or norms. Changing these need not necessarily alter the principal characteristics of a given regime, whereas a change in principles or norms surely does. Despite this elaboration on the terms of the definition, other scholars have pointed its weaknesses, particularly to ambiguity of norms as well as the potential overlap of norms and rules of a given regime (c.f. KEOHANE, 1984).

Another aspect of this definition, which has received lesser scholarly attention but which is central to the argument of this thesis, refers to the content of regimes, i.e. "the given area of international relations". How broad or narrow a specific area is and which scope of geographical delimitation is applied varies greatly from regime to regime. When comparing, for example, the regimes concerning non-proliferation, the ozone layer, global climate change, world trade and polar bears, the diverse nature of their content becomes evident. In the early 1980s, Keohane elaborated a first tentative distinction between issues and issue-areas (which possibly helps to illuminate the case of freshwater as shown later).

As our examples of money and oil suggest, we regard the scope of international regimes as corresponding, in general, to the boundaries of issue-areas, since governments establish regimes to deal with problems that they regard as so closely linked that they should be dealt with together. Issueareas are best defined as sets of issues that are in fact dealt with in common negotiations and by the same, or closely coordinated, bureaucracies, as opposed to issues that are dealt with separately and in uncoordinated fashion. Since issue-areas depend on actors' perceptions and behavior rather than on inherent qualities of the subject-matters, their boundaries change gradually over time...Issue-areas are defined and redefined by changing patterns of human intervention; so are international regimes (Keohane, 1984, p. 61).

The example of the issue-area of oceans is used to illustrate this difference between issues and issue-areas as well as to highlight a regime that has changed the functional scope it is dealing with (or has been replaced by a more encompassing one). 
Fifty years ago, for instance, there was no oceans issue-area, since particular questions now grouped under that heading were dealt with separately; but there was an international monetary issue-area even then (KEOHANE; NYE; 1977, ch.4 apud KEOHANE, 1984, p.61).

Following this logic, freshwater is (so far) considered an international issue but not necessarily an issue-area (yet), since its sub-issues are dealt with separately and in fragmented way. Governments have in fact come together and negotiated over some of these sub-issues, such as wetlands of international importance and international watercourses (see chapter II); however, the overarching issue of freshwater scarcity with regard to quantity as well as quality has been treated uncoordinatedly at separate conferences and has not been the content of a specific, cohesive negotiation process to date. It remains to be seen whether this persists or whether these sub-issues will be grouped together under the bigger heading of a freshwater issue-area, analogous to the logic of the ocean issue-area, which has also shown growth over time and incorporated sub-issues which had been dealt with separately before. Furthermore, it needs to be re-assessed whether this distinction of issue-area and issue still holds true in contemporary international relations, especially in view of the newer regime theoretical concepts and ideas such as the regime complex.

\section{Regime Formation}

American political science literature has focused on power-structural explanations, including hegemonic stability theory, and game-theoretic approaches for regime formation for topics which are high priorities for hegemonic actors such as the US; an often used example is the international monetary regime. However, issues of lower priority and socalled soft topics do not fit nearly in the realm of these theories and explanations, which is why alternative frameworks and theories are required. As Rittberger et al (1993) state, German scholarship has provided such a different academic perspective by not only modifying these power-related and game-theoretical hypotheses but, moreover, adding new theory-building blocks such as the problem-structural approach. The latter follows previous research lines (c.f. ROSENAU, 1966), which aims to explain countries' foreign policy according to inherent characteristics of the topics being dealt with. According to these authors, the topic of conflict or cooperation correlates with regimes conduciveness; i.e. some topics are more regime-conducive than others due to their given attributes. In a first step, the treatment of the issue is divided into two main modes: (a) consensual 
conflict, i.e. all parties agree in theory of how to resolve a certain issue or topic but cannot necessarily translate this theoretical consensus into practice; and, (b) dissensual conflict, where no such agreement exists. Within consensual cases, a second subdivision into (i) relatively and (ii) absolutely assessed goods is made, in which the latter are defined as being important independent of what other actors might have and, thus, solely of how they relate to one's own needs and interests. The example of food is given to illustrate such a case of a consensual, absolutely assessed good (RITTBERGER et al, 1993, pp. 13-15), and due to obvious parallels the freshwater topic is classified as pertaining to the same category in this thesis.

Figure 1

Issue treatment in the problem-structural approach

Source

Elaborated by the author on the basis of Rittberger et al, 1993

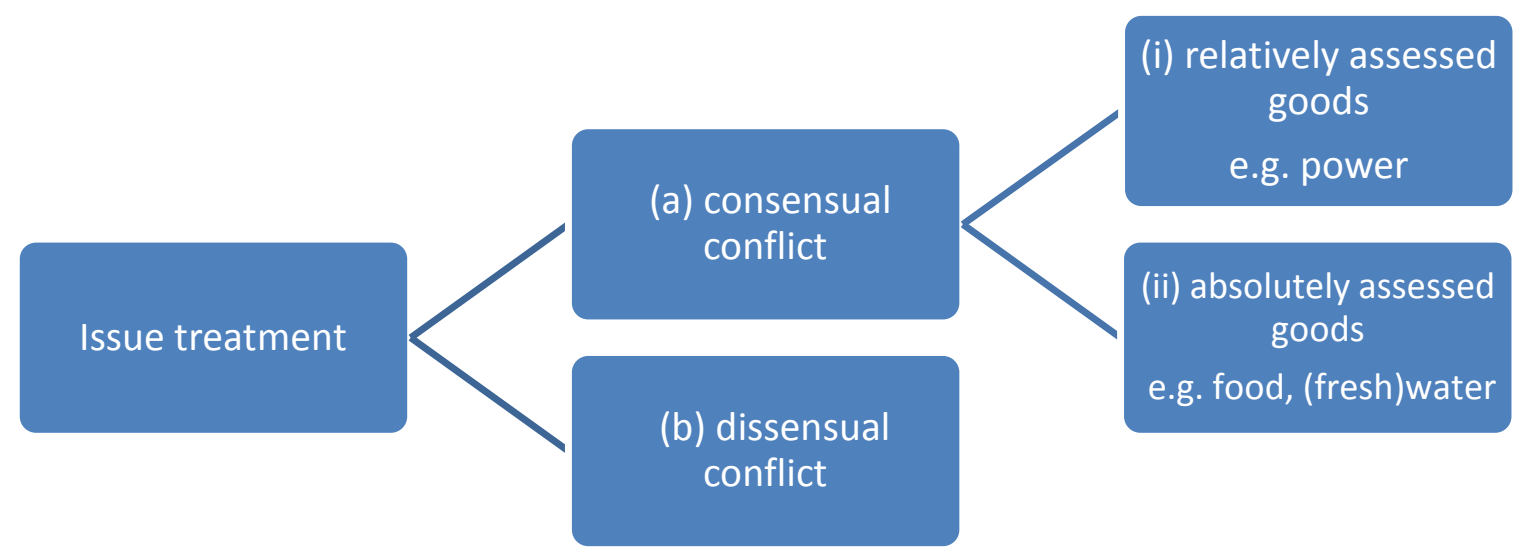

Based on this classification of issues, the problem-structural approach attributes different degrees of regime-conduciveness to them; in the case of (b, ii) the expectation for the treatment of these kinds of topics is a great likelihood of regime formation. This approach allows for analyzing the way a given topic with its particular characteristics is dealt with on the international agenda over a specific time-span; at the outset of this study, it therefore connects neatly with the treatment of the freshwater issue over the emergence period. 


\section{The Regime Complex}

From the first overviews of the topic emergence in Tables 1 and 2, one can observe at the outset of this research project that the freshwater issue and its sub-issues have been dealt with in several arenas and negotiation forums since the 1970s. In the emergence period (and also beyond) the international cooperation with regard to these resources has not lead to a cohesive, overarching freshwater regime; instead, one can note a substantial degree of fragmentation of the issue in that some sub-issues have turned into regimes, such as wetlands and transboundary water resources, whereas others have not moved beyond the level of declarations and statements of intent. Thus, traditional regime theory and the problem structural approach is taken only as a first attempt at theoretically explaining this particular case of topic emergence and evolution.

A newer strand of regime theory, involving the novel concept of the regime complex, focuses on cases of such fragmented treatment of topics on the international agenda as well as interplay and dynamics of loosely-connected individual regimes, which have so far escaped theoretical analysis in traditional regime scholarship. This concept was coined by Raustiala and Victor (2004) with reference to the case of how plant genetic resources came up as an issue on the international agenda, how they were framed differently in several forums and how regulation efforts in distinct institutions and regimes changed over time. As this literature evolved and matured, the concept was later applied to a broader range of issues, ranging from climate change (KEOHANE; VICTOR, 2010; 2011; VAN ASSELT, 2011) and energy (KEOHANE; VICTOR, 2013; VAN DE GRAAF, 2013a; 2013b), over health (MORSE; KEOHANE, 2014) and intellectual property (HELFER, 2009; MUZUKA, 2011), to trade and environment (GEHRING, 2011) as well as international security (HOFMANN, 2009; 2011); and, now, freshwater resources.

A regime complex is defined as "[...] an array of partially overlapping and nonhierarchical institutions governing a particular issue-area" (RAUSTIALA; VICTOR, 2004, p.279). The usefulness of this concept stems from its contrast to traditional regime theorists' narrower and isolated view of individual regimes, which are often based on a foundational international treaty or agreement (so-called "elemental regimes" in the authors' terminology). The added benefit of the regime complex approach is that it allows for the analysis of cases which do not fit so clearly into the cohesive regime framework but which feature several, distinct regulation attempts and to some extent overlapping regimes or 
institutions, involving more complicated dynamics within the issue area that do not follow only one direction but can result from several vantage points, which each claim legitimate authority over the treatment the issue.

Furthermore, it is important to differentiate a regime complex from hierarchically organized sub-regime elements, which can also entail an overlap. Such an institutional setup is a characteristic feature of the architecture of framework conventions with their following protocols, between which there is an established hierarchy and it is clear which rules have preference and priority over others. This kind of traditional regime formation and gradually increasing institutionalization in the form of hierarchically subordinate protocols is typical of environmental topics and, thus, in principal a possible model for the freshwater topic (c.f. above for the problem-structural-approach of conventional regime formation literature as well as section 3.2. for its analog hypothesis). However, it is important to point out that the freshwater issue emerged at the international level before this pattern emerged with regard to other topics such as the atmosphere and climate change ${ }^{16}$, which is a first indication that the freshwater case follows a different logic. The example of the protection of the ozone layer, now considered the standard case of a single, hierarchical regime, will shed light on both of these important differences with regard to overlap and hierarchy.

Following an a more generally worded framework convention in Vienna in 1985, which lay out the common interest of protecting the ozone layer and rather vague declarations of intent, later conferences of the parties (COPs) established more specific rules and regulations in protocols such as the Montreal Protocol in 1987, which explicitly laid out binding rules for the respective countries. This kind of institutional setup differs from cases consisting of only one foundational treaty, which are envisioned with no subsequent protocols. From the outset of the process, the member states foresaw an overlap with subsequent agreements; however, this overlap was an explicit aim at and it was subordinate to the framework convention. This type of gradually increasing specificity in the form of protocols was intentional in order to allow the negotiation process to first anchor the wider

\footnotetext{
${ }^{16}$ Even with issues, which follow the more classic framework-convention-and-protocol approach and thus entail hierarchically structured institutions creating rules in the issue area (such as the topic of climate change), a regime complex can still exist due to other, competing institutions, which do not fit in this hierarchy. As a matter of fact, earlier studies analyzed the climate change topic from the traditional regime theory perspective but later application of the regime complex concept revealed the weaknesses of this isolated study and outlined further, hitherto unknown dynamics (c.f. KEOHANE; VICTOR, 2010; 2011).
} 
intentions and then advance as permitted by the interests and positions of the individual countries towards specific obligations, rights and duties. Thus, the relation between the framework convention and the subsequent protocols takes into account previous efforts on the topic, but from the onset of negotiations, the hierarchy and boundaries of the institutional moments are clear. In a regime complex, in contrast, this is not given due to the existence of several institutions and forums involved in fragmented, overlapping, regulation attempts but without any clear hierarchy of rules in a given issue-area. Since these attempts often take part in several, diverse forums with different bureaucracies involved in the negotiation processes, the difference of issue-area vis-à-vis issue as elaborated by Keohane (1984) either become more fluid or even breaks down and ceases to exist at all within the concept of the regime complex. From this contrast to hierarchical regime rules, one can infer a first important implication of regime complexes, namely the possible clash of rules without clear indications over which specific rule has preference or priority over the other. In the most extreme cases, one can even envision contradicting rules of different treaties and agreements dealing with the same issue-area, thus leading to conflict over the course of action to take.

Apart from expanding the application of the regime complex concept to an increasing set of topics and fields, contemporary regime theory of this newer type has tended to focus mainly on the consequences of regime complexes, such as the possibilities of forumshopping (a state uses the most suitable forum, where it believes it can pursue its interest to the highest degree, in detriment of the other arenas; c.f. RAUSTIALA; VICTOR, 2004; BUSCH, 2007; JUPILLE et al, 2013) or regime shifting ("states and non-state actors relocate rulemaking processes to international venues whose mandates and priorities favor their concerns and interests", HELFER, 2009, p. 39; see also HELFER, 2004; MORSE; KEOHANE, 2014); however, on the flipside of these research developments, the origins of regime complexes have often remained an overlooked and understudied aspect.

The main literature concerning the emergence of regime complexes still finds itself in an embryonic stage and is characterized by a high level of consensus. It consists mainly of work by Morse and Keohane (2014) as well as Urpelainen and Van de Graaf (2014), who both underline intentional and strategic reasons for states to construct regime complexes. This scholarship is based on early and still rather vague ideas of so-called strategic inconsistency, defined as " [...] explicit efforts to create conflicts to force change in another 
regime [...]" (RAUSTIALA; VICTOR, 2004, p. 298). At its core, all these authors argue that, contrary to legal efforts at achieving increasing consistency at the global stage, states may consciously create new institutions with overlapping, contradicting rules and regulations to create inconsistency in order to challenge existing norms and trigger change.

Using the broader labelling of "contested multilateralism" for this phenomenon, Morse and Keohane (2014) directly focus on the aspect of political competition so as to challenge the status quo. They include two types of situations and strategies for states under this term: (1) either moving from one to another already existing regime in order to put pressure on existing practices and standards (so-called "regime shifting"), or (2) competitive regime creation, i.e. establishing an entirely new, previously non-existing institution with closer proximity to their interests. The former assumes a pre-existing regime complex, while the latter actively envisions the step from an elemental regime to a new regime complex (or adding a new unit to a regime complex). The authors point out two basic pathways to contested multilateralism, either (a) the dissatisfied coalition of states within an existing regime has outside options, i.e. using an existing or a new organization, but its threat lacks credibility and thus has to be acted out; or (b) the same coalition does have a credible threat but, nonetheless, powerful states in the focal regime use their vetoes to block international reform, which again leads to the need to make use of the outside options. With regard to competitive regime creation, which includes cases of the emergence of a new regime complex, the cases of the Proliferation Security Initiative (PSI), the International Renewable Energy Association (IRENA) and challenges of the WHO via the Global Alliance for Vaccines and Immunization (GAVI) or UNAIDs, amongst other, are analyzed.

In a more specific and narrower study, Urpelainen and Van de Graaf (2014) examine certain conditions of emergence of overlapping institutions - such as disagreement within an existing (elemental) regime, institutional capture and political pressure in the respective countries seeking reform - and develop a bargaining model on this basis. In short, their model posits that: 
[...] de novo [overlapping] institutional creation is likely when the challenger insists on reform but the defender's cost of conceding those reforms is high. This outcome can be expected when institutional capture has occurred and domestic political pressure is intense. (URPELAINEN; VAN DE GRAAF; 2014, p.3).

With the help of this bargaining approach the authors manage to explain case studies in the issues areas of energy, whaling and intellectual property. While stating that "it is the combination of the two conditions that is sufficient to explain de novo creation", they also concede that "[...] they are clearly no necessary, and other pathways to de novo creation offer exciting opportunities for future research in international relations" (URPELAINEN; VAN DE GRAAF; 2014, p. 35). This thesis seeks to continue these efforts and contribute to refining the existing theories, models and approaches in view of the case study of freshwater resources.

With the background of this theoretical framework, the methodology is developed in the following section around the central research questions and objectives. The hypotheses flow directly from the assumptions and expectations of the above IR theories, models and approaches.

\section{Methodology}

Along with the above theoretical framework, the following sub-sections on research questions, -problem and -objectives, hypotheses, data and methods will complete the research design of this thesis. This methodological part will clarify the objectives of this project as well as the tools employed for achieve them.

\subsection{Research Questions and -Objectives}

Within the wider topic of water in International Relations (IR) this thesis aims specifically at understanding the point in time and the conditions under which freshwater issues emerged on the international agenda and in which form it did so. In order to achieve this goal, the following three groups of main research questions will be considered and studied: 
- What was the temporal scope of the emergence of the freshwater topic on the international agenda? Which events and elements define the period of emergence?

- Which political processes and constellations underlie these developments? Who are the main actors and agents contributing to the prominence of freshwater issues internationally? Which are the key players and what are their principal interests? Did NGOs have an important role to play?

- How and in what form did the issue appear? What form of cooperation has been established (if any) and which regulation has been set up? Which institutions of global freshwater governance have been created? Is there a regime governing these resources or is this a case of a regime complex?

Through the thorough study and examination of these questions, this thesis will contribute to IR scholarship ${ }^{17}$ in several ways by adding to debates about the rise of so-called 'soft topics' (which concern the environment, human rights and other social issues) and by advancing the literature on (international) agenda-setting and regime theory. Firstly, a hitherto lacking systematic and comprehensive account of the global emergence of the freshwater issue will be developed from the perspective of international relations, with particular attention to the political dynamics of the events and processes. Secondly, theoretical propositions about specific global governance structures will be made and tested. To analyze the freshwater case through the lens of regime theory and applying the concept of the regime complex to it, is appealing due to the fragmented emergence of the topic on the international agenda and due to the existence of more than one convention in the issue area. It will be argued that in fact these resources are currently governed by a regime complex, which emerged between the 1970s and 1990s, thus adding another case study to test current theories in this regard. Particularly, the freshwater case can shed more light on the emergence of such regime complexes and contribute to developing and refining contemporary models and approaches.

\footnotetext{
${ }^{17}$ King et al (1994, p. 17) highlight the fact that one can make explicit contributions to literature in various forms. Among the options listed in the authors' chapter on research design, the contributions of this thesis sit most closely with points 5 ("Argue that an important topic has been overlooked in the literature and then proceed to contribute a systematic study to the area") and 2 ("Choose an accepted hypothesis that we suspect is false (or one we believe has not been adequately confirmed) and investigate whether it is indeed false or whether some other theory is correct"), but also entails elements of some others.
} 


\subsection{Hypotheses}

In order to investigate the above research questions, particularly the ones going beyond the systematic account of the case and in relation to the global governance structures, it is imperative to compare the emergence of the freshwater umbrella issue and its subtopics to other issues, as well as to theories of how the latter came about. Within IR, scholarship on international agenda setting and traditional regime literature (c.f. section 2 on theory) provide indications and prove relevant due to their focus on how international actors, mainly nation-states but often flanked by several important international IGOs and NGOs, come together to evaluate possibilities of cooperation with regard to certain topics of diverse urgency. Whereas Livingston's scheme of agenda access points provides a reference framework for analysis of the international genesis of the freshwater topic and will be employed for the systematic structuring of the conference and convention data, it does not represent a fully-fledged theory and thus cannot be used for hypothesis testing. Traditional regime theory literature on regime formation goes beyond this and does allow for such testing (see first hypothesis), although the preliminary data suggests that it is not sufficient to explain the case. A the newer strand of regime theory involving regime complexes appears more promising, in that it allows for closer analysis and hypothesis testing with regard to the regulations attempts in the area of freshwater resources (see second hypothesis).

The third group of research questions refers to the emergence of the international institutional architecture in the field of freshwater resources and it is here where regime theory proves most useful. Rather than just referring to negotiation constellations at specific points in time such as those of particular international agreements, conferences and conventions, a more promising approach for the study of the fragmented freshwater topic considers the issue-area at hand in relation to its particular characteristics and tries to infer consequences of these for its treatment in the emergence period. This so-called problem-structural-approach, which according to Rittberger et al (1993) has uniquely been introduced into German scholarship on regimes, entails expectations about certain characteristics. Figure 2 recalls these propositions. 


\section{Figure 2}

Expectations of issue treatment in the problem-structural approach Source

Elaborated by the author on the basis of Rittberger et al, 1993

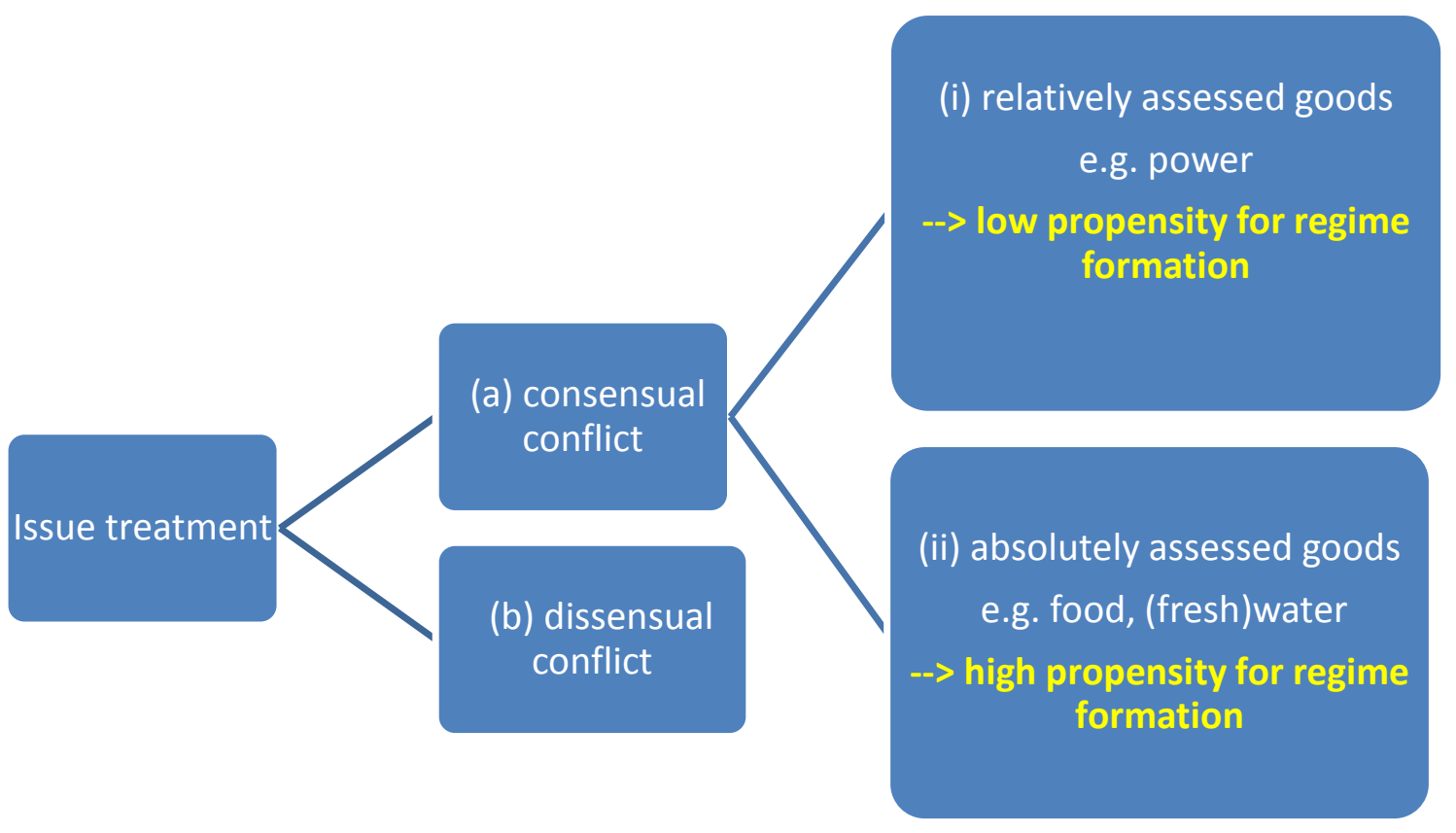

In the light of this approach on regime formation, the following hypothesis (H1) is derived, which will be tested along the course of the research project. It is hypothesized that issues, which are characterized by consensual conflict and which concern absolutely assessed goods, have a high propensity for regime formation. Since the freshwater case resembles the case of food and is classified as an issue of consensual conflict and an absolutely assessed good, the expectative derived from this theory is that it should show a high propensity for regime formation. According to this hypothesis, the emergence of the freshwater issues should not have encountered many obstacles in the path towards regime formation and should have shown a tendency to lead to international agreements and measures rather quickly. This hypothesis would be validated by observations of regime formation of the freshwater (umbrella) issue, whereas the lack of such regimes would indicate that the theory does not apply to the case and thus needs to be reconsidered and possibly adapted.

Already at the outset of this study, a first glance at international freshwater treatment on the international agenda does not provide evidence for the occurrence of an encompassing freshwater regime but rather more fragmentation and sub-regimes; thus, this hypothesis 
can most likely be dismissed on the basis of the rough data. Freshwater does not seem to follow a similar path as the case of food and other absolutely assessed goods and seems to belong to a different category of issues. Rather than being dealt with homogeneously, the freshwater topic appears to be more malleable to fragmented treatment of several of its constituting sub-elements in a first moment. However, this primary observation is further elaborated on in the empirical chapters and makes for an ideal starting point to challenge contemporary regime theory and this particular problem-structural-approach; in particular, it raises the questions as to why several sub-aspects have led to the creation of sub-regimes in their own right while others have not, as well as how these regimes relate to each other.

The shortcomings of the above theoretical model set the stage for the main argument and the principal hypothesis $(\mathrm{H} 2)$ of this thesis, which builds on the preliminary conclusion that the freshwater case is more malleable to fragmented treatment and sub-regimes. It will be argued that, through the application of newer strands of regime theory, the freshwater topic reveals itself as a case of a regime complex. With regard to the origins of such regime complexes, contemporary regime theory equally features clear expectations and assumptions, on which $\mathrm{H} 2$ is based. It is hypothesized that regime complexes are created for strategic reasons by states that are dissatisfied with the status quo. For this hypothesis to be validated, one must be able to observe dissatisfaction within the issue area, pro- and veto-coalitions with regard to rules and institutions existing prior to the regime complex and a link of these with the newly created institution, which leads to the establishment of the regime complex. Lack of such observations would indicate that this model is insufficient to explain the case and thus requires further improvement and reworking.

\subsection{Data and Methods}

A logical starting point for the study of the fresh water topic is the systematic analysis of the selected water events of the emergence period, especially through primary sources such as their proceedings and outputs, including key documents such as general statements, declarations of intent, action plans and actual treaties, if these were agreed upon. In many instances, these documents reveal insights regarding the main points of dissent and consensus of the discussions and negotiations, which input was considered and by whom it 
was produced, which processes took place until the final declaration or agreement as well as some first indications of the main actors. However, particularly with UN documents, the country-specific input and the general attendance of the event often remain nebulous since the wording of these sources in kept very general for political reasons and without clear references to the positions of the individual member states. Unfortunately, some of these documents are not readily available online and a few are not available at all anymore ${ }^{18}$; this information then had to be acquired from other sources.

In addition to these documents, the secretariats and main offices of selected conferences (e.g. the ones in Mar del Plata, Rio de Janeiro; especially those during the 1990s, which was the decade of conferences and in which new topics spread globally, for example due to UNCED) have been contacted and, in a more limited fashion, archives ${ }^{19}$ have been consulted in an attempt to identify key negotiators, otherwise elusive country positions and additional information about the topic and the event as such.

Furthermore, information revealed by insiders of these conferences and conventions - be it as key speakers, organizers or delegates - in the form of interviews, opinion pieces, newspaper or journal articles or analyses, was studied to complement the above data. Some of these materials might be regarded as secondary sources, however, they are more of a hybrid between primary and secondary in the sense that they, at times, provide some new information and their analyses are often made at a technical or problem level, which then require further "translation" into data to be used for theoretical analysis. In all cases, these kinds of sources have to be qualified and bear a word of caution. While, on the one hand, often providing interesting insights and otherwise elusive details and facts about specific events and processes, these sources might also entail certain biases and misrepresent some aspects. Through cross-checking of several of these types of sources and with the above primary data, this effect can be limited but must still be borne in mind when using this information.

Finally, this study also draws from prior secondary sources such as prior academic analyses of individual conferences. Due to the new approach and the application of the regime complex, the results of some of these studies are in fact input for the examination

\footnotetext{
${ }^{18}$ This is the case for most of the documentation of the 1992 Dublin Conference.

${ }^{19}$ Due to generally difficult access and only restricted online availability for most archives, this kind of data was only used from the Brazilian archives and merely for the earlier conferences, for which this type of information has been liberated.
} 
of the interaction of these conferences and conventions; this is particularly important for the Ramsar Convention and the International Watercourses Convention, which have been analyzed by several scholars but only on an individual basis without any recognition of their interplay and overlap as elemental regimes in the freshwater regime complex.

For the study of the emergence of a complex and fragmented issue such as freshwater resources, which connects several analyses of conferences with different formats, forums, participants and outcomes while at the same time mostly lacking quantifiable data, a qualitative research approach is most appropriate as opposed to quantitative modeling. Methodologically, this study is based on the method of case study in order to understand the inner logic of the emergence of the freshwater topic. Rather than developing a new theory and selecting cases to validate it, the emergence of the freshwater topic itself is considered a major case study here, which then serves to test hypotheses regarding contemporary regime-theoretic prepositions derived from the literature.

In the following empirical chapters, these methodological tools are employed in the study of the emergence of the freshwater issue on the international agenda. In a first moment, the conferences of the emergence period will be studied with a focus on agenda access points and the underlying political processes and actor constellations (chapter II); this will is followed up by a corresponding analysis of the two conventions in this issue area, which is then used to test the hypotheses laid out in the methodology section and to arrive at theoretical conclusions about the freshwater regime complex (chapter III). 


\section{Chapter II \\ IMPORTANT WATER CONFERENCES AND EVENTS}

Apart from the two conventions, which are examined separately and in-depth in chapter III, the scholarship of freshwater on the international agenda has identified around 30 international freshwater-related meetings and conferences since the 1970s. In this chapter, the major milestone events selected from this list (c.f. chapter I) are studied in more detail to acknowledge the ways in which they have been important for the overall emergence of the freshwater topic on the global agenda. Additional references are made to several of the remaining second- and third-tier conferences so as to make visible continuities as well as discontinuities in some of the sub-topics of the overall freshwater issue. While certain conferences have grabbed more interest of the international public and are thus more wellknown due to their high presence in the media (especially the "Earth Summit" in Rio de Janeiro, Brazil), others are equally important - if not more so - for the global emergence of the freshwater topic (here the Mar del Plata conference comes to mind ${ }^{20}$ ).

In chronological order, the analysis starts with (1) the 1977 UN Water Conference in Mar del Plata, Argentina, as well as (2) the resulting International Drinking Water Supply and Sanitation Decade (IDWSSD, also known as the first "International Decade of Water") from 1981-1990. Since the first International Decade of Water is a direct output of the Mar del Plata Conference, both are studied as a pair. The same procedure of coupled analysis is applied to (3) the 1992 International Conference on Water and the Environment (ICWE) in Dublin, Ireland, and (4) the UN Conference on Environment and Development (UNCED, commonly referred to as "Earth Summit" or "Rio-92") of the same year in Rio de Janeiro, Brazil. The relationship of the second pair is slightly different since the Dublin conference was envisioned as a preparatory meeting for the later Earth Summit.

These conferences and meetings did not result in negotiated international agreements in the form of conventions or treaties; rather, their output consisted of declarations, action plans and, most notably, the first International Water Decade for the case of the Mar del Plata Conference. Despite not resulting in direct regulation efforts, they have however played a vital pioneering role in bringing the freshwater topic to the forefront of international public

\footnotetext{
${ }^{20}$ This is even true for the 1971 Ramsar Convention and the 1997 International Watercourses Convention, which are both central to the global cooperation with regards to freshwater resources but have not found an equal international public echo as the 1992 UNCED.
} 
interest as well as attempting to keep it there over the course of time. Later conferences and global agreements pick up on several of the sub-issues, which were dealt with at these initial water events and over which consensus is built gradually over the course of the emergence period.

The application of the agenda-access-point approach enables a comparison across these events and provides a useful tool with a view to identifying the respective dimensions of interstate practice, which were important in bringing and keeping the freshwater topic on the international agenda.

\section{UN Conference on Water and First International Water Decade}

With regard to the surfacing of the freshwater topic on the international agenda ${ }^{21}$, the UN Conference on Water, held in 1977 in Mar del Plata, Argentina, stands out. While not being the very first event considered a milestone for the topic within this thesis - the Ramsar Conference preceded it by six years -, it does however receive near-universal recognition as being the first major conference with exclusive regard to freshwater resources (c.f. for example, BISWAS, 1988, 2004; SALMAN, 2003; GLEICK AND LANE, 2005; WWC, 2014), for some it is even the single most important water conference to date (particularly BISWAS; TORTAJEDA, 2005, 2009). Within the UN system, it was the first conference dealing exclusively with water, reuniting nearly 120 government representatives at the highest decision-making level alongside relevant UN agencies and organizations working in the water sector, international river commissions, IGOs and nearly 60 NGOs, inter alia, for an overall count of over 1500 participants. Central outcomes of the conference were the Mar del Plata Action Plan (MDPAP) as well as the recommendation to launch the International Drinking Water Supply and Sanitation Decade (UN, 1977). The importance of this conference for the international emergence of the freshwater topic in terms of its context, background, origins, focus, outcomes, background negotiations and evolution is laid out and analyzed in the following.

\footnotetext{
${ }^{21}$ Water, of course, has not just been important internationally since the early 1970 s. As pointed out in the introduction, this natural resource has been central to our development since the very beginnings of human settlement. While earlier cooperation does exist, it was unidimensional and only focused on navigation, thus this thesis therefore takes the 1970s as the starting point of the international consideration of the wider freshwater umbrella topic in its various dimensions.
} 


\subsection{Context and Background}

The Mar del Plata Conference did of course not occur in a vacuum, it was embedded in the context of its time and needs to be seen in connection with important preceding and following events. Since it took place within the structure of the UN, particular attention to developments and conferences with this system is due. First of all, one must bear in mind the role of the first big UN conference, the seminal 1972 Stockholm Conference on Human Environment (UNCHE), which established the United Nations Environmental Programme (UNEP) as well as triggering and setting in motion a whole wave of further UN conferences (RIBEIRO, 2008). In the aftermath of UNCHE, international interest was sparked in these types of intergovernmental conferences with a focus on specific topics. Apart from the conference on water in Mar del Plata in 1977, the UN had previously also organized conferences on a broad range of issues such as the law of the sea (UNCLOS III; New York, 1973), population (Bucharest, 1974), food (Rome, 1974) and on human settlements (Habitat; Vancouver, 1976), as well as subsequently launching conferences on desertification (Nairobi, 1977), science and technology for development (Vienna, 1979) and on new and renewable sources of energy (Nairobi, 1981). For its role as paving the way for these conferences and for putting wider environmental and social issues on the international agenda, UNCED is widely appreciated as a game changing event and catalyst. With regard to this pioneering role, O’Neill $(2009$, p. 8) states that "the 1972 Stockholm Conference ushered in a flurry of diplomatic activity coordinated by the new United Nations Environment Programme (UNEP)". From this we can gather that the water topic did not emerge as a stand-alone issue but in the context of other, also seemingly pressing topics of international importance. This becomes clear in the words of an attendant expert, who elaborates further on this connectivity with other issues.

In retrospect, as one of the three or four people who were privileged to attend all these world conferences, it is clear to the author that each conference was affected by those preceding it and each in turn had an impact on the conferences that followed. This, however, is proper since the primary foci of all the conferences were interrelated: environment, population, food, human settlement, water, desertification, science and technology, renewable energy. (BISWAS, 1988, p. 149).

Although freshwater resources were not mentioned directly at any point during UNCHE, the latter has to be seen as a critical, path-breaking event, which prepared the ground for their subsequent treatment on the international agenda. UNCLOS III came one notch closer in 1973 by dealing with close-related saltwater resources, particularly tied up with ideas of 
the Common Heritage of Mankind concept (c.f. SOUZA, 2005). At the Habitat Conference of 1976 a sub-topic of the broader freshwater issue was marginally dealt with, namely community water supplies for urban and rural areas, including the "[...] sweeping goal of safe water for all by 1990" (BISWAS, 1981, p. 154). However, it was not until the Mar del Plata Conference that freshwater moved into the foreground and focus, when these more general considerations were extended towards a more comprehensive treatment of the liquid resources per se. Thus, as a first observation, one can register that the water topic emerged within the realm of the $\mathrm{UN}^{22}$ together with a bundle of other, interrelated issues broadly concerning the interaction between human development and the environment, which were held to be of central significance for the global public in the 1970s.

\subsection{Origins, Process, Important Countries and Players}

While the actual water conference took place in 1977, the planning and organization of such an event, especially in the sphere of the rather gradually advancing UN, started significantly before. The origins of this specific conference can be traced back to 1971 , where the United Nations Committee on Natural Resources $(\mathrm{CNR})^{23}$ dealt with the issue of water as a critical resource in its $1^{\text {st }}$ session (aside energy and mineral resources as other priorities) and began to envision a big UN event dedicated to this topic, originally intended to be held in 1975 (UN, 1971, p. 325). Before taking a closer look at the content and proceedings of the conference, it is useful to adumbrate its context and background.

After the initial decision within the CNR to hold a UN conference dealing with freshwater, further steps were taken and the organization was carried out. The intention of organizing such a conference was to bring together water specialists from various parts of the world in order to establish a dialogue regarding current water problems and issues, existing technological solutions and future needs in the view of the global availability of water

\footnotetext{
${ }^{22}$ The only important exception is the 1971 Ramsar Convention, which has its roots outside the UN system and developed more bottom-up from the interests of European epistemic communities, mainly ornithologists. It was, however, later linked to the UNESCO as depository of convention and the same institution had funded earlier publications with regard to waterfowl and wetlands (c.f. chapter III).

${ }^{23}$ The CNR itself was created as a standing committee by the United Nations Economic and Social Council (ECOSOC) only a year before, in 1970, replacing the previously existing ad hoc Committee on the Survey Programme for the Development of Natural Resources. The CNR first consisted of 27 members, to be elected by the ECOSOC on the basis of equitable regional distribution (UN, 1970, pp. 459-460), but subsequently extended membership to 38 and, in 1972, to 54, respectively (SHRIJVER, 2008, p. 115).
} 
resources as well as initiating general cooperation in water management. In the following sessions two and three of the CNR, these objectives were extended to include the elaboration of national and international water policies, on the one hand, and an assessment of the economic impact of water demand and availability in the future, on the other. The intended target public of the conference were first of all water policy-makers and the thematic scope discussed was to go beyond detailed economic and administrative dimensions to also entail technical issues (BISWAS, 1988).

The work of the CNR was subsequently reviewed by the ECOSOC and in May 1973 the latter approved the realization of the water conference as well as confirming the draft agenda. In a further and final step, the UN General Assembly gave its support as well in December 1975 in Resolution 3513 (XXX) (UNGA, 1975). Thus, the holding of the UN water conference was confirmed and effectively took place from $14^{\text {th }}$ to $25^{\text {th }}$ March 1977 in Mar del Plata, Argentina, with a delay of 2 years to the original plan.

As expected for UN conferences, the process culminating with the final event is IGOdriven from within the UN system. Going beyond this general characterization of the internal path leading up to the Mar del Plata Conference is complicated as it is opaque and challenging to try to identify key individuals and tendencies within the UN "black box", which were at play to push or halt these developments. Rather than freely speculating in this regard, a slightly more promising route is to concentrate on the information available with regard to the behavior of particular countries during the process and at the final event in order to acquire clues about underlying political interest constellations. Even this task is not easy since conferences within the realm of the UN aim at reaching consensus over which topics to deal with, which decisions are to be taken and/or what is urged to be implemented by the part of the member states, and then fixate this consensus in final reports, declarations, resolutions and/or agreements as if speaking with only one voice. UN documents, especially the official conference documentation such as recommendations and resolutions, tend to use neutral form or generic plural in the official language, while individual country roles and contributions are not explicitly stated. They are only the polished and cleaned outer representation of the result of a more complex and heterogeneous process, which features many distinct country positions and voices that do not necessarily pull in the same direction. Therefore, it is notoriously hard to map out the behavior of all actors and their positions and intentions. However, even in the annexes of 
official documentation one can find first hints at country positions in the report on the conference background and several additional documents provide clues in this regard. Special relevance and attention needs to be given to the procedural and substantive processes before the actual event as well as during the event in terms of putting forward motions such as drafts and proposed amendments to these as well as voting patterns of these draft and later resolutions. In few cases, this information can be balanced and counterchecked with specific countries' national archives of the relevant time if these are openly accessible (usually after a certain minimum time buffer has elapsed).

In the present case of the UN water conference, the most explicitly mentioned country is Argentina. First mention of the country is made in the preparations of the CNR, when in its first session Argentina offers to host the proposed water conference in its country (UN, 1970). In order to try to better understand the specificities of Argentina's possible interests for this motion, one must bear in mind the situation of the country at the time. In the 1970s, Argentina faced turbulent and violent times under military rule with several changing heads of state, thus complicating a long- or even mid-term foreign policy with regard to non-priority topics, such as environmental ones, including most freshwater aspects. However, one dimension of the freshwater topic did in fact become a priority for the country, specifically with regard to its security, when Brazil and Paraguay began to construct the Itaipu power plant on the Paraná River in the 1970s after long negotiations the decade before. Argentina feared that Brazil, an important foreign political rival and opponent in the region at the time, could use the dam as a political weapon by threatening to open the floodgates, which would lead to the instant rising of the Rio de la Plata and, subsequently, to the possible flooding of its capital, Buenos Aires. This latent conflict was only settled with the 1979 Tripartite Agreement between Brazil, Paraguay and Argentina (QUEIROZ, 2012). The connection to the Itaipu conflict is likely to be linked with the country's motion to become the host of the water conference in the sense that it would have a strong interest to establish norms and rules with regard to freshwater use in the region's transboundary rivers. While this assumption on its own might be considered somewhat unsubstantiated, additional information acquired from the Brazilian Information System of the National Archive (SIAN) about Argentinian motions considering this topic provides further, albeit indirect, corroborating evidence along these lines. According to diplomatic sources, Argentina had unsuccessfully attempted to push its interests at first bilaterally with Brazil and then regionally within the realm of the Rio de la Plata Basin 
Treaty; only with a later international attempt at the UN Conference in Stockholm in 1972 had they been successful in recognition of their position (BRAZIL, 1976). This shows the history of regional rivalry over international rivers in the Southern Cone, which clearly played into the behavior of the Brazilian representation in the CNR and within the Mar del Plata process in general. An additional, yet more speculative factor would refer to the possible interest of the government to gain foreign recognition and enhanced status for the military regime as a result of hosting a prestigious event, such as a key UN conference. While this tactic has indeed been used by dictatorships and autocratic governments across the globe, this line of thought remains more speculative without further pieces of evidence to corroborate this idea. In either case, the most probable reasoning behind the motion to host the conference lies in contextual, political and strategic factors of that period, rather than an inherent interest in broader treatment of freshwater resources and, thus, mostly exogenous to the topic of the conference.

With regard to other countries, further important pieces of information are revealed from the accompanying documentation of the CNR meetings. Whereas the actual proposal for the realization of a water conference goes back to the Secretary General, in the form of a draft resolution within the CNR it was put forward by sextet of developing countries, namely Jamaica, Kenya, Pakistan, Sudan, Yugoslavia and Zaire (E/L.1411 apud UN, 1971). Particularly the African members of this group, most of all Kenya, are now either regarded as water scarce countries or highly water dependent on renewable freshwater resources from outside their territory (FALKENMARK, 1990), thus explaining a greater interest in freshwater conferences and cooperation in this area. The same is true of many countries of the former Yugoslavia, such as Serbia and Croatia, which are also highly water dependent, just as is the case with Pakistan (BLACK; KING, 2009), which additionally is concerned with a conflict over the region's international rivers. Thus, the composition of this group and its interest in carrying out a UN conference, which is dedicated to freshwater resources, appears understandable. Even more interesting than this small group are the two countries which put forward amendments (E/L.1413 apud UN, 1971) to this text, which were then voted upon and accepted by the CNR: Brazil and the USSR. In the first case, the desired and effected change in the proposal consisted in replacing the possibility of the Secretary General convening a group of experts to aid him with regard to the goals and targets of the conference by him having to prepare a report without further assistance. The second amendment resulted in the deletion of a part of the 
text which would have urged the CNR to deal with water resources as a priority in the following session in 1972. It is worth pointing out that these amendments were not passed unanimously but rather resulted from diverging positions since they were accepted by a vote of 16 to 7 with one abstention. After these changes were put in place, all the decisions were bundled in ECOSOC Resolution $1572 \mathrm{D}(\mathrm{L})$, which was adopted by a roll-call vote of 26 in favor, none against and one abstention by Brazil (UN, 1971). Having said that, one must be careful not to overstress the importance of which countries brought in the motion for a water conference since usually some other, possibly more powerful sponsors tend to have these motions brought in for them by their allies and partners and remain less visible in the back. It is however safe to assume that Brazil and the USSR, who tried successfully to put forward amendments, did not back the original draft proposal and were critical of it. For other players who did not make explicit any dissent to the draft resolutions this assumption is not as clear and must be borne in mind as a possibility, even if less likely.

With regard to the identifying key roles and processes of agenda-setting and issue definition in the case of the Mar del Plata Conference, the task remains challenging and the observations, as well as conclusions, are still preliminary since the agenda-access-point approach reaches some of its limits for this event. While the so far obtainable information has been able to shed some light on the positioning of some key countries, particularly Argentina and Brazil in the region where the conference was held, current lack of similar information from archives of other countries complicates the unravelling of the bigger, more complete picture. What has become clear though, is that the UN Water Conference is not seen as a merely technical event of exchange of best practices, in which ideas are shared and technology discussed with regard to freshwater management; particularly the Brazilian diplomatic material shows how security concerns and other political as well as strategic actions and motions must be considered as contextual variables and need to be borne in mind when analyzing these types of conferences. Therefore, it confirms the justification of the objectives of this thesis in attempting to delineate political constellation and actors interests beyond the technical dimension of cooperation over the matter at hand. For this kind of examination, the agenda-access-points approach provides a valuable framework of where to focus and locate the study. As an IGO-driven process, the dimensions of institutional loci (UN, more broadly, and the CNR, in the more specific sense) as well as of diplomatic norms (prior action-forcing dynamics of the 1972 UNCHE and the first wave of UN conferences) stand out with regard the Mar del Plata Conference. 


\subsection{Focus, Important Topics and Outputs}

The overarching concern of the conference was dedicated to the issue of ensuring that the world population was guaranteed an adequate supply of freshwater, both in terms of quantity and quality, while bearing in mind not only population growth as such but also rising levels of life style and accompanying search for enhanced economic and social conditions. The vision underlying the organization of the conference can be made clear by taking a look at the opening speech of the conference's Secretary General Yehia Abdel Mageed from Sudan:

It was hoped that the Water Conference would mark the beginning of a new era in the history of water development in the world and that it would engender an new spirit of dedication to the betterment of all people - creating a new climate for a wiser appreciation of these critical problems, generating a greater flow of funds through the channels of international financial assistance towards the cause of development and in general making a finer commitment, on the part of all concerned, to establish a real breakthrough, so that our planet would be a better place to live (MAGEED, 1977; apud BISWAS, 1988).

Thus, apart from the overarching goal of generating global awareness and establishing an important benchmark with regard to water, i.e. putting it firmly on the international agenda, financial support as well as achieving a general change of attitude were key hopes and aspirations. In addition to these, the conference's general rapporteur Malin Falkenmark mentions a few more concrete targets with regard to an impending world water crisis, providing safe access to drinking water and sanitation to the all individuals on the planet by 1990 as well as sufficiently well managed water for significantly raised food production to diminish global drought vulnerability. In order to combat these problems, " $[\ldots]$ the attention of the global community was directed to the need for immediate action to avoid a rapidly increasing water crisis and to find ways in which the earth's fixed stock of water could be used most wisely and efficiently" (FALKENMARK, 1977, p. 222). These goals and aspirations would later be taken up and reflected in the central outcomes.

Being the first big conference focusing on the topic of freshwater, it is natural that proper global assessment of water resources was a central objective and highlighted throughout the conference, since this is the basis for any action to follow. In preparation for the event, the conference secretariat had therefore prepared numerous documents, including the four main conference papers. It has been argued that two of them, "Resources and Needs: Assessment of the World Water Situation" (E/CONF. 70/CBP/1) and "Present and Future Activities of the United Nations System in Water Resources Development" (E/CONF. 
70/CBP/4), were of central importance because they - in the case of the former - provided a wide and encompassing up-to-date assessment of the global freshwater scenario at the time as well as - in the case of the latter - an analysis of the UN's work in the water sector including, inter alia, current hurdles, constraints, loss of effectiveness (BISWAS, 1988). On this basis, the conference dealt with several aspects of the freshwater topic and was able to advance the debates. Additionally, raising awareness amongst the world population for water related problems was also assigned great value in order to pave the way for subsequent programs and policy routes. Following these broader lines, priority was given to the topics of community water supplies and water for agriculture (FALKENMARK, 1977), the biggest user of water worldwide.

There were two main outputs of the Mar del Plata Conference: (1) an action plan and (2) the realization of the so-called International Drinking Water Supply and Sanitation Decade (IDWSSD) from 1981-1990. Upon conclusion of the event, the conference established consensus in several areas which were then molded into the so-called Mar del Plata Action Plan (MDPAP, 1977), which entailed a roadmap of which course of action to take to improve the world wide water scenario of the time. This action plan was divided into two parts: recommendation and resolutions. The former consisted of recommendations of the conference in the eight most important water management dimensions (assessment of water resources; water use and efficiency; environment, health and pollution control; policy, planning and management; natural hazards; public information, education training and research; regional co-operation as well as international cooperation) with an annex of specific regional recommendations, whereas the latter entailed twelve resolutions (ten for subject areas covering assessment of water resources, community water supply, agricultural water use, research and development of industrial technologies, the role of water in combating desertification, technical co-operation among developing countries in the water sector, river commissions, institutional arrangements for international cooperation in the water sector, financing arrangements for international co-operation in the water sector and water policies in the occupied territories; another two for special cases such as Panama Canal Zone as well as thanking the host country, Argentina; UN, 1977). Together, these recommendations and resolutions form the suggestions and plans of the conference as central output. From the outset of the conference, the assessment of water resources was seen as the basis for further debates and action, which is reflected in the fact that both the recommendations and the resolutions feature this item first. 
It is generally difficult to single out any particular recommendation or suggestion of the above action plan; however, a particularly important contribution of the 1977 UN Water Conference certainly lies in the fact that the underlying - but often implicit - consensus ${ }^{24}$ over the right of all people to adequate freshwater resources was made explicit in the MDPAP. In the accompanying text to the second resolution it is stated, that the United Nations Water Conference considers that "all peoples, whatever their stage of development and their social and economic conditions, have the right to have access to drinking water in quantities and of a quality equal to their basic needs" (MDPAP, 1977, p. 66). According to Gleick and Lane (2005), this is one of the earliest explicit affirmations of what would later become the human right to water, fully recognized as such in 2010. Finally, a second observation needs to be made with regard to another aspect of the freshwater topic and its role within the Mar del Plata Conference. While taking place six years after the 1971 Ramsar Convention on Wetlands, the extremely broad 1977 UN Water Conference and the resulting MDPAP hardly feature this subtopic at all. Over the entire document, only one minor reference is made regarding wetlands in the recommendations under the rubric $\mathrm{C}$ of "Environment and health", sub-point (m), which suggests that states "recognize that freshwater and coastal wetlands are among the most vital and productive of ecological systems because of their values for flood-water storage, as breeding grounds for fish and wildlife, and for their recreational and scientific use" (MDPAP, 1977, p. 26). The fact that this subtopic is hardly mentioned and that no reference at all is made to the 1971 Ramsar Convention, shows its more marginal perception within the greater freshwater topic as well as the misperception of the content of said convention (see chapter III).

Apart from this condensed form of written principal output, Biswas points to the fact, that the conference produced a wide range of information about water in many aspects and dimensions for both the individual countries as well as for regions and for the world. $\mathrm{He}$ underlines especially the action taken by the developing countries in order to prepare their respective inputs in the form of thematic papers at the conference, which has led to improvements on a bigger scale.

For the first time many countries prepared national reports on the availability and use of water as well as reviews of management practices. Several countries put in motion processes to assess the distribution of surface and groundwater resources, and patterns of water demand and use for various purposes, many of the which have continued ever since. (Biswas, 1988).

\footnotetext{
${ }^{24}$ For this reason the freshwater topic is classified as a consensual conflict issue over an absolutely assessed good (c.f. problem-structural-approach in chapter I).
} 
This country-specific input in form of thematic papers was bundled and turned into conference output for the other countries to share, compare and learn from. Finally, the purely technical aspects of water management were dealt with at a separate scientific meeting with experts on the different technologies and techniques involved (UN, 1977). This meeting's output along with reviews and analyses of NGOs added an additional informational layer to the official documents of the water conference.

The second major output of the Mar del Plata Conference was the subsequent International Decade of Water. As an ideational product, it is already envisioned in the MdPAP itself under its recommendation with regard to the section B on "water use and efficiency", subtopic "community water supply and water disposal", paragraph 15. The MdPAP text also established a direct link with an earlier recommendation of the 1976 Habitat Conference mentioned above.

In order to implement recommendation C.12 of Habitat (United Nations Conference on Human Settlements) the decade 1980-1990 should be designated the International Drinking Water Supply and Sanitation Decade and should be devoted to implementing the national plans for drinking water supply and sanitation in accordance with the plan of action contained in Resolution II below. (MdPAP, 1977, p. 14).

This recommendation was then followed up and implemented by the United Nations General Assembly in December 1979 and November 1980, respectively (UNGA, 1979, 1980). It came to be recognized as one of the successes of the UN Conference on Water.

\subsection{Evolution and Further Developments}

In general, it is not the aim of this thesis to measure the effectiveness of the UN Conference on Water in terms of achieving its goals, implementing the MdPAP and general impact; this has been attempted elsewhere (c.f. BISWAS; TORTAJEDA, 2009). However, where these coincide with the processes of international agenda-setting and topic emergence, it does indeed become significant for the overall aims of this research. Furthermore, the focus of this analysis will rest more on the global aspects rather than regional and national ones, thus touching impacts and behavioral patterns within specific 
countries or regions only tangentially, while concentrating on the issues that are of greater international relevance ${ }^{25}$.

Immediately after the conclusion of the event, the reception of the Mar del Plata Conference and its outputs were very positive. The general rapporteur praised the outcome and the process of achieving at the outputs in high words:

The Conference formulated an international consensus on a number of policy and operational measures contained in the Mar del Plata Action Plan. Its work was most constructive and successful and surprisingly free from contentious debate in spite of such controversial issues as the shared water resources of international river basins and the mobilization of financial resources to cover the almost gigantic costs involved if we are to reach the goals set up by the Conference: safe water for every individual by 1990 and a substantially increased food production in order to the increase selfsufficiency of developing countries and reduce the plague of starvation now affecting large parts of the present-day population (FALKENMARK, 1977, p.222).

While a stimulating and constructive conference atmosphere and work is certainly to be wished for, some of these evaluations and opinions need to be somewhat qualified in hindsight. In the end, the atmosphere and process are mostly important in being a means to progress and therefore more weight needs to be given to the actual outcome and impact of the conference.

With regard to the two controversial topics of transboundary water and financial support for the implementation of the conference, explicitly highlighted by Falkenmark, analysts and opinions partly diverge from the special rapporteur's roundabout optimism and appraisal. While there is consensus on the overall success of the event (e.g. SALMAN, 2003; BISWAS, 2004; GLEICK; LANE, 2005; WWC, 2014), the Secretary General of the UN Water Conference, Yehia Abdel Mageed, specifically addresses these two issues five years after the event by stating:

If time and budget had permitted, two other documents would have proved most useful in placing, more forcefully, before the Conference the questions of financial arrangement and shared water resources. It was felt that both these areas were not tackled satisfactorily at the Conference. (MAGEED, 1982; apud BISWAS, 1988, p. 154).

Certainly, both these topics are complex and multilayered, thus complicating possible progress. More importantly, they are politically loaded issues, which trigger strong

\footnotetext{
${ }^{25}$ This is an important distinction to be made. Whereas the Mar del Plata conference dealt with a huge array of topics at both levels (national and international) as well as from several angles (purely technical, environmental, social, political, and a mix thereof), the research interests of this thesis lay strongly on the international level, especially with a focus on how the conference and its treatment of several important topics effected the topic emergence on the international agenda, how the topic was framed, perceived and, ultimately, negotiated over and tackled as an issue of international importance.
} 
resistance by some countries as opposed to general consensus over freshwater cooperation in the bigger scheme. A closer look at both reveals interesting pointers as to why consensus and progress might have been out of reach in 1977.

The topic of funding and financial resources has historically been a primary complicating factor of many agreements and of the workings of the UN itself. To expect quick and effective contributions of the member states, mainly by developed countries, without clear conditions and targets is overly optimistic, especially at the beginning of intergovernmental treatment of topics, such as the case of water in 1977. A dividing line between developed and developing countries as potential givers and receivers, respectively, of these financial contributions was to be expected. While not making an agreement impossible, it certainly is understandable that this topic was left rather vague and forwarded to future meetings since there is not much political incentive for the potential givers to commit at these early stages.

For the topic of transboundary water resources, i.e. shared river, lakes and aquifers between particular countries and regions, it is also clear that this topic is more contentious than others because of its imminent political character of shared resources and the conflicting dimension of sovereignty over these national assets. Whereas, for example, national policies with regard to access to drinking water as well as sufficient sanitary facilities do not have much of an effect on other countries, the decision to build a dam on a river for the generation of hydroelectric energy or for freshwater extraction for direct human consumption or agricultural use, diminishes the on-flowing water resources that reach the neighboring states. The underlying political tensions with regard to the use of these resources is evident and well documented in the diplomatic material regard the Brazilian preparation for the Mar del Plata Conference (BRAZIL, 1976). Additionally, the pollution of shared rivers and lakes through industry can equally have effects on neighboring states through negative externalities and thus it becomes clear that there is imminent conflict in how states deal with transboundary water bodies. For many of these international waters, bilateral and plurilateral agreements exist and have been in place for quite some time; however, it is important to establish global norms for these shared freshwater resources as otherwise the more powerful riparian states can strongly influence the bilateral water situation without the shield of international law as protector of their 
rights (so-called hydro-hegemony) ${ }^{26}$. It is particularly due to these negative externalities that one should expect smaller and less powerful states as well as downstream countries to have a stronger incentive and impetus to negotiate international norms and treaties in this matter than the more powerful and upstream states (c.f. chapter III on the IWC). It is noteworthy, that the International Law Commission (ILC) ${ }^{27}$ provided a supporting document (E/CONF.70/A.12 apud UN, 1977) to the Mar del Plata Conference on its legal work in this regard; this shows the interaction of this topic between conference and later convention level within the IWC.

In relation to the first International Water Decade, the early optimism went a longer way but also reached certain limits. Whereas the explicit and numeric goals of providing safe access to drinking water and sanitation to all by 1990 were missed in the end, considerable progress was achieved. Falkenmark (1990, p. 185) notes that, according to figures of the World Health Organization, "the program was [...] a major success in that daily, over an eight-year period, almost 200, 000 additional people were supplied with water". Especially in urban areas of developing countries there was an improvement regarding water supply and sanitation due to low-cost technologies (THOMAS; HOWLETT, 1993) and Biswas (2004, p. 82) forcefully underlines that "[...] the Decade unquestionably changed the quality of life of millions of people all over the developing world". However, there is also the general consensus that rapid population growth reduced the impact of this progress significantly (THOMAS; HOWLETT, 1993; SALMAN, 2003; RIBEIRO, 2008).

\subsection{Summary}

The emergence of the water topic on the international agenda with the 1977 UN Conference on Water must be seen in the context of the 1970s first wave of UN megaconferences, which dealt with topics reaching from the environment, over desertification,

\footnotetext{
${ }^{26}$ Hydro-hegemony is defined as " $[\ldots]$ hegemony at the river basin level, achieved through water resource control strategies such as resource capture, integration and containment" (ZEITOUN; WARNER, 2006). This is particular relevant in the context of weak institutional frameworks, in which the more powerful actor is favored and can take advantage of these power asymmetries. See also Warner and Zeitoun (2008).

${ }^{27}$ This sub-issue of the freshwater topic was taken up by the ILC on behalf of the UN in the 1970s, and over several decades their work on this issue led to draft proposals on a law considering these water bodies, in a first step, and later a convention dedicated exclusively to it (see chapter III). However, even after partially resolving the differing interests after long and intense negotiations and finally finding a consensus, which could be laid down in formal international law as a convention, the slow ratification of the latter showed that this topic and its underlying conflict still bear considerable tension and are not entirely resolved.
} 
food and population to human settlement. Thus, the water topic did not emerge alone but in the context of other, seemingly pressing topics of international importance. While noting the variety of topics dealt with, it is also important to bear in mind which topics did not make it to the forefront of international attention, such as, for example, deforestation ${ }^{28}$.

While the overall event can be seen as a success story, which managed to put freshwater concerns as an important topic on the international agenda, some shortcomings can also be noted. Slowest progress was achieved on the most international topics, financing and shared water resources, which is explainable due to the strong political character of the issues. They are also the areas where the biggest contributions of the member states lie, directly affecting their positions and forcing them to act, whereas some more technical aspects are of more national interest and thus more easily sellable to the population.

Upon first inspection, the general atmosphere at the conference was friendly and productive and no substantial block-building along the lines of developing versus developed countries took place. This is especially interesting in comparison with the 1992 UNCED, where this form of coalitions began to play an increasingly important role in the intergovernmental negotiations. However, even in this seemingly straightforward positive environment of the Mar del Plata conference, some background negotiations and conflictual positioning can be perceived with regard to how certain topics are framed and given priority to (or not), most evidently in the case of international watercourses.

\section{International Conference on Water and the Environment (ICWE) and UN Conference on Environment and Development (UNCED)}

In 1992, two milestone events featured on the international agenda, which impacted on the way freshwater issues were perceived and dealt with globally. These two conferences were different in format - on exclusively dealing with freshwater; the other extremely broad with regard to the entire environment - but, at the same time, directly connected. The International Conference on Water and the Environment (ICWE) in Dublin, Ireland, was

\footnotetext{
${ }^{28}$ The debates on the protection of the ozone layer as well as the topic of climate change were discovered and began to be perceived as bigger threats only in the late 1980s and beyond and thus did not feature as possible topics for conference yet. They did however become important conference topics in the second wave of UN mega-conferences in the late 1980s and 1990s.
} 
planned as the preparatory meeting with regard to water resources for the subsequent UN Conference on Environment and Development (UNCED) in Rio de Janeiro, Brazil, which dealt with environmental topics on a much broader level. While the Dublin Conference is not well-known outside the water community, the contrary can be said about the Rio Conference. It is perhaps the most widely appreciated UN conference of all times under the label of "Earth Summit", in particular due to its enormous media attention, the signing of the UN Framework Convention on Climate Change and that of the Convention on Biological Diversity as well as the impact of the resulting action plan with regard to sustainable development, "Agenda 21". Having said that, both conferences are analyzed here with a view to how they relate to freshwater resources specifically. Since the two are thematically, administratively and chronologically linked, i.e. they took place shortly after each other, they will be dealt with within this thesis under the same section (albeit one after the other) and analyzed as a double unit of the international agenda.

\subsection{Context and Background}

The general context of the 1990s was quite different from that of the 1971 Ramsar Convention or that of the 1977 Mar del Plata Conference. In the 1980s, several important environmental conventions had been established, including the Convention on Long-Range Transboundary Air Pollution (CLRTAP; 1979/1983) ${ }^{29}$, the Vienna Convention for the Protection of the Ozone Layer (1985/1988) and the Basel Convention on the Control of Transboundary Movements of Hazardous Wastes and Their Disposal (1989/1992). With the help of the United Nations Environmental Programme (UNEP), the UN acquires an increasing role in the regulation of environmental tensions at the global level (RIBEIRO, 2001). After the end of the Cold War, this significant readjustment of topics on the international agenda - strongly influenced by NGOs and environmental issues - is accelerated and fills the voids left behind by the gradual loosening of global security concerns, finally culminating in the 1992 Earth Summit.

Freshwater resources, however, do not feature among the central environmental topics of that period as the originally strong impetus of the 1977 Mar del Plata began to wane. In contrast to topics of other UN conferences, which continued to receive global attention in

\footnotetext{
${ }^{29}$ The two numbers refer to the years of adoption as well as entering into force of the convention.
} 
the form of follow-up conferences, this was not the case for the Water Conference. According to Falkenmark (1990, p. 186) "the poor follow-up is partly attributable to the lack of a single action-oriented UN body with the responsibility for implementing the Action Plan adopted at Mar del Plata"; he goes on to lament that "[...] thirteen years after the Water Conference, the UN system is only now preparing a Strategy for the Implementation of the Mar del Plata Action Plan in the 1990s". In the bigger scheme of environmental debates, the priority of other topics vis-à-vis freshwater resources also became evident in the Brundtland Commission's 1987 report "Our Common Future", which otherwise played an important role for general environmental concerns but failed to address water at all. The water professional community has criticized the report severely for this omission, either as being "[...] remarkable for its total neglect of water issues [...]" (BISWAS, 1998) or as “[...] just another failure” (FALKENMARK, 1990). Unfortunately for the water topic, the Brundtland report set the tone for the 1992 events, which only gave freshwater resources a minor role.

In terms of water-relevant events on the international agenda preceding the $1992 \mathrm{UN}$ conferences, it is however worth briefly mentioning that safe water access was recognized as an important factor in diminishing child health risks and, ultimately, their mortality rates at the 1990 World Summit for Children in New York, USA (SOUZA, 2005). Whereas at that summit it was only treated as a side-issue, the parallel 1990 UNDP Global Consultations on Safe Water and Sanitation for the 1990s in New Delhi, India, featured freshwater more prominently. The latter brought together the results of previous regional consultations and resulted in the so-called New Delhi Principles; due to their high degree similarity with the Dublin Principles of the 1992 ICWE (SALMAN, 2003) they will be subsumed under the same examination.

\subsection{Origin, Process, Important Countries and Players; ICWE}

In the aftermath of the Mar del Plata Conference and after a longer omission of similar events and meetings, the International Conference on Water and the Environment (ICWE) was the next big water conference on the international agenda. It was organized through the UN system with the help of the World Meteorological Organization (WMO; c.f. WWC, 2014), and held in Dublin, Ireland, from the $26^{\text {th }}$ until the $31^{\text {st }}$ of January 1992. 
Furthermore, it was intended to link water to sustainable development as well as to produce policies and action plans for the following UNCED. In difference to the latter and as an input-pool for it, the ICWE was organized as a conference of experts and not of governments and their representatives, who only came for UNCED later (BISWAS, 2004). All in all, the conference gathered roughly 500 participants, consisting of water experts nominated by 100 different countries as well as members of 80 IOs, IGOs and NGOs (ICWE, 1992).

It is generally difficult to obtain information about country positions and important players as well as to trace back the international developments for IGO-driven processes, such as the ICWE. However, in this particular case it is nearly impossible due to an overall lack of information availability. Unlike for the 1997 Mar del Plata Conference, the UN official documentation does not retain much information for the Dublin Conference in terms of proceedings, participation and background of the event. With the exception of the final Dublin Declaration, which contains the oft-cited Dublin Principles, the entire conference material appears untraceable. To this point, Biswas (2004, p.83) states that "it is evident that the institutional memories of the United Nation System somehow disappeared during the preparatory process leading to Dublin and at Dublin itself'. Even the central outcome documents are either nowhere to be found (conference report) or only provided indirectly through the webpage of the World Meteorological Institute (WMO, 2015) or the UN documents webpage (UND, 2015). All authors referred to in chapter I, who examine the Dublin Conference, do so entirely with regard to its output in the form of the guiding principles. This of course not only complicates a more in-depth analysis of the background of the conference and related political constellations and processes in view of agendasetting and issue definition but renders the entire ICWE process a tightly sealed black box. The conference report is said to provide more detailed recommendations with regard to local, national and international spheres (ICWE, 1992), thus its study could further enrich the analysis. However, its absence as well as the general lack of documented sources raises important methodological questions. Having said that, it is worth remembering that the format of the ICWE was programmed to be a conference of experts, thus dealing with water issues from a merely technical and managerial point of view. If this was indeed the case, then one can expect a very low degree of political positioning, except for the nomination procedure of the individual experts. 


\subsection{Focus, Important Topics and Outputs; ICWE}

At the completion of the event - as already mentioned above - a final statement (henceforth labelled Dublin Statement or Dublin Principles) and a conference report were adopted and then forwarded to the participants of UNCED. While the sole reliance on experts for the preparation of content, guidelines and recommendations seemingly makes sense, it also leads to complications due to the norms and regulations of big UN conferences, as shall be discussed later (c.f section 2.4).

As can be seen from the title of the event, freshwater and its link to broader environmental aspects was the sole theme of the conference and thus it necessarily features high on the list of important water-related events the international agenda. However, since it was planned as a preparatory meeting for UNCED later that same year and thus functions as a building block, it does not carry the same weight as the 1977 Mar del Plata Conference, which stood alone without being part of any other meeting or conference nor fell under the global radar due to competing conferences of importance shortly before or after.

The central outcomes of the conferences were the Dublin Statement and a conference report, of which the former will be relied on in the most part for the following analysis. From its text and information one can draw conclusions on the focus of the conference, its aims, objectives and recommendations. The main intention and request of the conference is clearly stated in the introductory part of the Dublin Statement:

The Conference participants call for fundamental new approaches to the assessment, development and management of freshwater resources, which can only be brought about through political commitment and involvement from the highest levels of government to the smallest communities. Commitment will need to be backed by substantial and immediate investments, public awareness campaigns, legislative and institutional changes, technology development, and capacity building programmes. (ICWE, 1992).

This can be read as a reaction of the conference participants to the perceived lack of political commitment for water issues in the years following the Mar del Plata Conference up to the mid-1990s as well as an attempt to inject new impetus to the global debate on freshwater. Bearing in mind these developments (or lack of such), the text continues by underling that such political will needs to be supported by significant investments in terms of financial contributions for institutions and their reforms, campaigns and technologies but also in terms of what would later become labelled human capital, i.e. the investments in training and capacity building. Thus, as a first point, one can conclude that institutional 
reform and new approaches as well as financial assistance for this process are treated as proprietary topics by the conference participants.

The Dublin statement further contains four "guiding principles", which are then followed but the so-called "Action Agenda". The latter includes recommendations as well as references and explanations of expected benefits, which would derive from the suggestions stated in the conference report. In the water literature, the Dublin Conference is often reduced to just the four principles, for which the conference final statement is labelled (and thus reduced to) the Dublin Principles, underling the importance of these principles but also somewhat undermining the rest of the document. Due to this common treatment a closer examination of the principles is called for. In short, they read as follows:

1) Fresh water is a finite and vulnerable resource, essential to sustain life, development and the environment;

2) Water development and management should be based on a participatory approach, involving users, planners and policy-makers at all levels;

3) Women play a central part in the provision, management and safeguarding of water; and

4) Water has an economic value in all its competing uses and should be recognized as an economic good. (ICWE, 1992).

Each of the Dublin Principles consists of a central statement/principle (which has mostly been used exclusively in prior analyses); however, these are then further elaborated on in a following paragraph ${ }^{30}$. This distinction becomes relevant particularly for principles one and four, since they qualify and somewhat change their overall impact and meaning.

The first principle itself is only a statement about the importance of water and thus not really a principle, but in the full text the intention of the authors reveals itself more clearly. The centrality of water for life and the need for an effective management in general is linked directly to the principle of a holistic approach, i.e. not just economic development of the resource but this in combination with social and environmental concerns. The area of concern for this all-encompassing approach is not just the water body itself but the text explicitly includes land and water throughout either the catchment area (for the case of rivers and lakes) or the groundwater (aquifer). How this approach is to be carried out and

\footnotetext{
${ }^{30}$ The full text of the Dublin Statement can be found on the homepage of the WMO (2014).
} 
by whom is clarified in principle two (participatory approach with users, planners and policy makers at all levels abiding to the principle of subsidiarity $)^{31}$.

In contrast, principle four is indeed a principle in its own right and puts a large focus on the economic value of water, requesting it to be treated as an economic good. Whereas the principle itself is quite strong and only mentions the economic dimension of the resource, the explanatory paragraph, particularly the first sentence, qualifies this focus: "Within this principle, it is vital to recognize first the basic right of all human beings to have access to clean water and sanitation at an affordable price" (ICWE, 1992). Here, the explanation also reminds the reader of the social concerns ${ }^{32}$ yet, despite the linguistic preference supposedly given to these basic (human) rights, the overall message of the economic treatment of the resource still stands out due to it being the sole focus of the principle.

Thus, principle four and the related economic treatment of freshwater emerge as a second focal point of the Dublin statement along with the abovementioned holistic approach. Overall, the principles show a strong concern with the management of the resource rather than the related rights; the language of economics is preferred to that of social and political responsibilities and concerns. These aspects and the related linguistic treatment of the resource can be brought into connection with the interests of the more developed states, where freshwater is mostly dealt with regarding its quality and management, whereas developing countries often face questions and challenges related to water scarcity ${ }^{33}$.

According to Salman (2003), these principles are very similar and are indeed based largely on the output a previous conference, the 1990 New Delhi Statement. They are thus not new as such. However, this does not hold entirely true when actually comparing them and their exact wording. The most obvious parallel is the fact that both statements include a total number of four principles that deal with water and its management and that entail references to the broader environment, institutional reform, the role of gender and economic aspects. In their weighing of these elements, however, and in their concrete phrasing, both statements differ to quite some extent. Whereas the general importance of

\footnotetext{
${ }^{31}$ This and principle three, stating that women should be positively addressed by water policies, are selfevident in their message and thus will not be laid out in greater details here.

${ }^{32}$ After the above-mentioned inclusion of these concerns in the MdPAP, this explicit recognition of rights with regard to freshwater resources was important on the path the universal recognition of the human right to water in 2010.

${ }^{33}$ Of course, water scarcity also needs to be managed, i.e. the few resources need to be dealt with effectively so that, for example, human consumption is given preference over other uses, but just with management of the scarce resources several development questions cannot be resolved.
} 
water for the environment and for life in general is a basic and often-quoted truth in almost all water conferences, thus not entailing neither novelty nor leading to any kind of action or recommendation unique to any event, the broader issue of institutional reform does show more commonality between the two statements, especially with regard to participatory approaches and integrated water resource management. When tackling the role of gender, the differences become clearer. While the New Delhi statement includes the role of women within institutional reform and urges for their full participation, which indicates some form of discrimination needed to be remedied, Dublin goes beyond this by assigning a central role to women and thus places them far more into the focus of the statement. Similarly, the fourth New Delhi principle calls for better financial practices and improvement of current management in a more general form, whereas the fourth Dublin principle is far stronger by directly labelling water an economic good and urging for it to be recognized as such.

The latter point does not just serve to point out the differences between the two statements but also reveals a broader change in relation to the treatment of the freshwater resources. Whereas the Mar del Plata Conference treats water as a common good and merely states that it should be priced properly and with social objectives in mind (UN, 1977, p. 18), the label as economic good moves the focus onto the economic dimension and makes no mention anymore to social aspects. For this reason, the ICWE has been severely criticized as being in "[...] sharp contrast in comparison with the achievements of Mar del Plata", as well as that "[...] in several instances Dublin may even have been a retrogressive step [...]" (BISWAS, 2004, pp. 83; 84).

Finally, there is one last often overlooked contribution of the ICWE, which can be found in the follow-up section of the Dublin Statement. At the very end of its text, one can find the embryonic idea of an institution, which deals with freshwater issues and is more open and participatory by bringing together the private sector, NGOs and governments:

In addition, to involve private institutions, regional and non-governmental organizations along with all interested governments in the assessment and follow-up, the Conference proposes, for consideration by UNCED, a world water forum or council to which all such groups could adhere. (ICWE, 1992).

While these ideas are still presented in rudimentary form, the vision entailed in them would soon after be concretized by the establishment of the World Water Council (WWC) in the mid-1990s and the ensuing realization of triannual World Water Forums (WWF) after 1997. This institution, together with the Global Water Partnership (GWP), would later 
significantly change the dynamics of the freshwater topic treatment at the global level and thus marks the beginning of a new period, namely that of the post-1997 evolution.

When analyzing the topics dealt with at Dublin as a whole, the focus on a holistic, participatory approach (with a special, explicit mentioning of women) and the economic dimension stand out. Since the output of the conference is the result of the meeting of experts in the area, rather than government representatives, a broader consensus is to be expected due to a stronger focus on content rather than results for specific countries. However, Biswas (1998) raises an interesting point concerning the composition of these experts, namely an overrepresentation of professionals from the developed countries. While not necessarily taking strong political positions, these professionals tended to lay the focus on topics that are of greater concern in the countries they work in or of their region. They were mostly from Europe, North America, and in part, from Asia and South America. In this way, topics of greater interest to developing countries were not dealt with to the same extent. This fact was compounded by the differential availability of resources to different expert teams and delegations, once again favoring the priorities of developed countries.

Finally, in terms of substance, ICWE also met with criticism. While many authors, such as for example Salman (2003) or Souza (2005), take a rather neutral or slightly positive attitude towards the Dublin Principles, Biswas (1998) insists that no new ideas or programs resulted because of the meeting, while central issues, such as funding and implementation of the discussed programs, were largely omitted.

\subsection{Origin, Process, Important Countries and Players; UNCED}

The United Nations Conference on Environment and Development (UNCED) followed ICWE after an interval of about five months and was held at Rio de Janeiro, Brazil, from $3^{\text {rd }}$ to $14^{\text {th }}$ June 1992 . In contrast to the Dublin Conference, which had happened earlier in that same year, UNCED was set up as an intergovernmental meeting and also included a significant share of international observers and members of international civil society. Due to its wide focus on environmental and developmental concerns as well as the worldwide 
attraction of activist and media attention it was later referred to as the "Earth Summit" (or simply “Rio-92”).

Due to this broad character, there was an equally ample preparatory process over the course of several years - similar to that of the 1972 UNCHE or the 1977 Mar del Plata Conference - after the UN General Assembly decided in 1988 to convene such a conference dealing with the connection between the environment and the challenge of development (UNGA, 1988). In contrast to the extremely thorough examination of the entire preparatory process of the 1977 UN Conference on Water, which was dedicated exclusively to freshwater issues, the analysis of the broader environmental UNCED process will be restricted mainly to the treatment of the freshwater topic, with only tangential treatment of other topics as contextual variables. Since the earlier ICWE was set up as a preparatory event with exclusive attention to water for the Rio conference, the link between these two is the central focus of this analysis.

As already indicated above, the preceding ICWE process has been met with considerable criticism for its role in reframing freshwater resources in a more economic fashion. It is therefore surprising that UNCED and its resultant Agenda 21 action plan (see section 2.5) once more reconfigure this characterization by framing water as an explicitly social and economic good (SALMAN, 2003). This signals a weakness in the connection between the preparatory ICWE and UNCED due to obvious differences in such central aspects. Furthermore, while Agenda 21 features an entire chapter on water (c.f. UNCED, 1992a), it does not make any reference to Dublin although this was supposed to have been the preparatory event exclusively dedicated to this resource (BISWAS, 1998). This setting apart of both conferences and the complete omission of the Dublin conference in the official documentation of UNCED raises questions about the lack of organization and the failing dialogue between the two, which were meant to be complementary and supporting. Biswas (2004, p. 83) goes even further by stating that "in all probability, all the Chapter 18 of Agenda 21, which deals with water, would have been very similar, irrespective of whether the Dublin Conference had even been convened or not". The failure of the ICWE to act at as proper preparatory event for UNCED is principally attributed to two factors: (1) timing and (2) format. In the first place, ICWE was held in January 1992, roughly four months before UNCED, and so the period between its completion and the start of the bigger conference was extremely tight time-wise. This did not give enough time for 
UNCED to incorporate any of its results and outputs. This criticism has been voiced loudly by water professionals at the Third Stockholm Water Symposium (BISWAS, 1998). Secondly, and perhaps even more importantly, the format of ICWE directly impeded its inclusion into the UNCED process. In relation to this point, Biswas (2004) explains that, as a meeting of experts rather than an intergovernmental conference, ICWE did not meet the requirements of an event that can function as a direct input giver in the form of recommendations to world conferences such as UNCED. This had been the norm for all UN World Conferences in the 1970s and 1980s and because of this precedent, several countries objected to having references made to ICWE at Rio (BISWAS, 1998). As a result, the Dublin process was virtually ignored for reasons of timing and format at UNCED and found no inclusion in Agenda 21, thus contributing to the low importance of water at the event and to the vague and generalized recommendations made in this field in its chapter 18 .

In terms of key players and countries at UNCED, a key difference to be noted in comparison with UNCHE or the Mar del Plata Conference is open block-building along the North-South divide in the 1980s and 1990s (NAJAM, 2004; 2005b; WILLIAMS, 2005 apud O'NEILL, 2009). In the particular case of freshwater, Biswas (1998) explains that most governments of the developed countries employed specialists mainly in the areas of their interest, such as on climate change, biodiversity or reforestation, and generally lacked the political will to include water issues into their focus. The developing countries, on the other hand, which should inherently have a higher interest in freshwater issues due to their geographical conditions, are said to have featured lack of inter-ministerial coordination in determining their priorities, leaving water ministries excluded from this process. As a final point, Biswas adds that many developing countries had been overwhelmed by the importance of UNCED as it happened and were ill-prepared for its challenges and opportunities. From the input of this key author with regard to ICWE and UNCED, one can gather than the developed countries were able to exert greater agenda control regarding the wider UNCED conference and successfully managed to bring their topics of preference to the foreground, to which freshwater resources did not belong at the time. 


\subsection{Focus, Important Topics and Outputs; UNCED}

At a more general level, the focus of UNCED was the concept of sustainable development, which was intended to bridge the opposing issues of protecting the environment - on the one hand - and allowing for development through the use of natural resources - on the other. While this also applies to the use of water and high hopes were laid on the impact of the Rio Conference on freshwater treatment (GOLUBEV, 1996), the resource was in itself not a central concern at UNCED (THOMAS; HOWLETT, 1993). Other topics took centerstage, most of all the issues of climate change and biodiversity - whose treatment led to two conventions on these topics, the UN Framework Convention on Climate Change (UNFCCC) and the Convention on Biological Diversity (CBD), respectively - and, to a lesser degree, deforestation in the form of the additional principles regarding forestry (RIBEIRO, 2001).

The central outputs of UNCED consisted of the two already named conventions, two further declarations (one on the above-mentioned forestry principles and the central Rio Declaration) and “Agenda 21", UNCED's ambitious action plan (RIBEIRO, 2008). The role of water in these outputs was limited since the two conventions evidently deal with other topics altogether and the Rio Declaration also does not make any reference to freshwater resources (c.f. UNCED, 1992b), leaving only Agenda 21 with an explicit recognition their importance.

While several authors have pointed to the fact chapter 18, dealing exclusively with freshwater, is actually the longest chapter of Agenda 21 (SOUZA, 2005; RIBEIRO, 2008; even BISWAS, 1998) and that it entails a newly emerged consensus over the need for integrated management of freshwater resources (THOMAS; HOWLETT, 1993), Biswas is particularly critical of both ICWE and UNCED with regard to their role of placing freshwater resources on the international agenda, which he perceives to be marginal.

\footnotetext{
It was not by any plan or design that water did not have a higher priority at Rio. The UN system had banked on the Dublin Conference to make the difference. The failure of the Dublin Conference, the absence of any fall back strategy in the event of a failure, the very poor timing of ICWE which left only 4 months between the two events in Dublin and Rio, and the lack of interest by developing countries at high political levels, were all important contributory reasons, which did not strengthen the cause of water at Rio. (BISWAS, 1998, p.493).
}

When weighing these differing, even opposing, judgments of the diverse authors with regard to UNCED, Agenda 21 and particularly chapter 18, one needs to bear in mind that Biswas was actually directly involved in the developments around UNCED, not just as a 
participant but also as an advisor in the preparation of nearly 20 governments. Therefore, this particular author will have had very close contact with the respective decision-makers in many developing countries, which implies a greater wealth of information with regard to country positions and strategies but possibly also an alignment with their interests over time. While it is hard to assess many of his statements and conclusions without access to these sources, a more cautionary approach is to balance his strong criticism with the contributions of other senior water professionals that took part in these events, particularly M.A. Salman, who are more reservedly positive with regard to the role of ICWE and UNCED.

\subsection{Evolution, Further Developments}

Despite the relatively low weight given to freshwater resources in the overall UNCED context, it can be said that in terms of the follow-up more attention was paid to this aspect than was the case with Mar del Plata, which basically lacked such developments and stands alone. In June 1997, there was a special session (labelled as "Rio+5") in the UN General Assembly to review the progress made within the action plan (Agenda 21), which showed mixed results and led to a new resolution to ensure further advancing (A/RES/S-19/2). Additionally, there was a ten year follow-up conference in Johannesburg, South Africa, in 2002 (World Summit on Sustainable Development or, informally, Earth Summit 2002 or "Rio+10"), reaffirming the importance of the action plan and committing to its implementation and bringing it into relation with other important conferences and meetings that had taken place since the original Earth Summit in 1992, particularly the MillenniumDevelopment-Goals of 2000, which feature water-related aspects in several of their targets. Finally, in 2012, the UN Conference on Sustainable Development took place again in Rio de Janeiro, Brazil, thus termed "Rio+20" conference and, once again, the commitment to Agenda 21 was underlined, including freshwater resources.

While these conferences and meetings have been criticized for their slow progress, it does need to be stated that they show continued and renewed interest and commitment of the global community in relation to theme of sustainable development and, with it, the role that freshwater plays. In this sense, the conference in 1992 set in motion and larger, continued process and not only remained as peak meetings with scant attention before and after, thus keeping the issues, including freshwater, more visibly on the agenda since the mid-1990s. 


\subsection{Summary}

At first sight, water seems to feature in relative prominence at the ICWE and Rio Conferences. ICWE and chapter 18 of Agenda 21 are exclusively dedicated to its use and related aspects and chapter 18 is indeed the longest section of the extensive UNCED document. However, this seemingly important role needs to be qualified after closer examination. The declarations and recommendations have been criticized as weak, repetitious and merely expression political correctness (Biswas, 1998) and do not entail any form of action plan or program comparable to the outcome of the Mar del Plata conference $^{34}$. Whereas other topics, such as desertification and climate change, were dealt with more intensely, leading to two newly formed conventions in these areas, the freshwater topic did not advance at a similar speed.

\section{Key Freshwater Conferences during the Emergence Period}

After the Mar del Plata conference, a universally acknowledged focal point and key to the emergence of the freshwater topic on the international agenda in the 1970s, the Dublin and Rio conferences in 1992 were attempts to rekindle attention after the 1980s had witnessed waning support and interest in the topic at the global level. Moreover, there had not been a (ten year) follow-up conference for the UN water conference as had been the case with most other UN world conferences.

Dublin was intended as a preparatory meeting to UNCED with special and unique attention given to freshwater issues, with the aim of linking these with the broader UNCED theme of sustainable development, social objectives and environmental concerns. While it did bring out several interesting principles that have since been referred to as important steps in the development of global debates on freshwater aspects, the event has otherwise caught little interest of the broader public and went somewhat un(der)noticed in the near proximity of the Earth Summit, which dominated the headlines and public interest for the years to follow. Additional complicating factors were the short time span between the conclusion of

\footnotetext{
${ }^{34}$ Biswas criticism does not speak for all water professionals though and can be seen in the light of this own research interests. In personal communication with a senior water expert at FAO, the orientation role of Agenda 21 was highlighted and positively pointed out how it led to a wide spin-off formation in the form of local and regional "Agenda 21"s, which thus did have an important and lasting impact in water issues.
} 
the Dublin conference and UNCED with only four months, making an inclusion of its input into the broader Rio process nearly impossible, as well as the issue of format since Dublin was organized as a meeting of experts while UN world conferences such as UNCED only accept formal input and recommendations from intergovernmental conferences. The fact that the Dublin principles were not mentioned at all in the Rio process and some government representatives even objected to including references to it points to the fact that these two conferences, despite their supposed strong links of topic and preparation, were in fact quite different processes and the results and recommendation of Dublin were not seen as welcome by the participants of the Earth Summit.

In turn, the Rio conference did not only feature the water topic but the latter was part of the wider theme of sustainable development. When looking at Agenda 21, the central plan for action document of the Earth Summit, one could conclude that water did receive some distinctive attention and was in the spotlight since it was granted an entire chapter (i.e. chapter 18), which also turns out to be the longest. However, this attention needs to be qualified and contains several caveats.

First, the debates and negotiations on the topic of freshwater resources did not lead to the creation of a new regime or even an agreement in the form of a treaty with binding rules and targets, which contrasts with the treatment of the topics of desertification and climate change, both featuring prominently in the Earth Summit and resulting in two separate conventions as central outcomes of the event. While of course the issues of desertification and of climate change are connected to freshwater, either by lack of such or by changing precipitation patterns, they were not dealt with under the same topic umbrella and received far more attention in the negotiation process as well as the central outcomes of the events, showing that even this supposed prominence of the water topic in the form of written output does not reflect deeper substantive interest and that, indeed, other topics were given priority on the international agenda at that point.

As a second caveat, it needs to be mentioned that even within the freshwater topic the sheer amount of produced text cannot paint over the fact that little novelty is contained in chapter 18. The substantive content of this chapter rests largely on recalling previous agreements, guidelines and recommendations, while not containing a great deal of new metrics or tangible goals that can be monitored. 
Even though both Dublin and Rio conferences were organized within the UN system, a different attitude towards the freshwater topic can be appreciated. From the different results of both, and the lack of dialogue between them up to latent competition, one can conclude that different interests played out at both events. It is notable that certain countries and groups, mainly from developing countries, were either not present in Dublin or did not manage to convince the others of their perceived interests or suggested objectives and recommendations. Taking into account the observations of Biswas, who participated in the events and apart from his expertise in the issue matter can be taken as a witness of the events, it would stand to reason that there was a block-building and negotiation process, which saw a gap between developed vis-à-vis developing countries in terms of how to position freshwater on the international agenda. 


\section{Chapter III}

\section{FRESH WATER-RELATED CONVENTIONS}

The previous chapters have shown how a series of events have taken place since the 1970s in order to deal with challenges related to freshwater on a global level. While most treatments of the topic have remained at conference or meeting level, the main outcomes of which typically consist of declarations and statements that rarely lead to concrete activities and measurable improvements (with few exceptions, such as the 1977 Mar del Plata Conference and the resulting International Water Supply and Sanitation Decade; see chapter II), a select few have been taken beyond this stage by the establishment of concrete rules and norms in the form of negotiated international agreements. In this way they transcend the technical discussions and advancements of the other conferences by constructing global governance rules and institutions, i.e. regimes, which put in place or influence international regulation of freshwater resources for decades to follow. For this reason, these structures deserve special attention and are analyzed in the following separately from the rest of the conferences.

During the emergence period considered in this thesis, two ${ }^{35}$ such agreements stand out due to their overall significance within the global governance of freshwater resources, and will therefore be examined more closely: the 1971 Ramsar Wetlands Convention (section 1) and the 1997 International Watercourses Convention (IWC; section 2). While the former has often been overlooked with regard to its role $^{36}$ in contributing to the emergence of freshwater on the international agenda and thus stands under-analyzed in this regard, the

\footnotetext{
${ }^{35}$ It is debatable whether the UN Framework Convention on Climate Change of 1992 as well as the 1997 Kyoto Protocol should be included in this analysis since climate change features a link with water in the form of changing precipitation patterns, rising sea levels, melting glaciers and further effects on the distribution and availability of fresh water resources on a global level. It was opted against its inclusion since the issue of climate change goes far beyond the freshwater aspects and, in fact, has effects on these resources rather than regulating the resources themselves. Whereas the Ramsar Convention, which on the surface might seem to regulate only waterfowl but actually does provide rules and norms for wetlands and thus freshwater resources more directly, the discussions and actions of regulation of climate change center on $\mathrm{CO}^{2}$ emissions and therefore lie outside of the scope of this thesis. However, due to the above mentioned link it would be interesting future research avenue to focus on the interplay between regime complexes, such as the fresh water regime complex and the one of climate change in this case.

${ }^{36}$ It has thus far mainly been analyzed in its function of protecting the habitat of migratory bird species. While this was clearly the original motivation for this agreement, the actual convention goes beyond this aspect and includes regulations of wetlands for hydrological reasons as well as is demonstrated in more details in the next section.
} 
IWC is certainly the most widely known international agreement as well as the most farreaching one and therefore the central pillar of the current global water governance.

However, as already pointed out in the previous chapters of this thesis, it is interesting to recall that both conventions do not feature high on most accounts ${ }^{37}$ of the global emergence and evolution of the freshwater issue. On a general level ${ }^{38}$, this might have to do with the fact that the more technical discussions and advances - i.e. scientific progress in the management of the resources, so to speak - have a higher likelihood to occur at events, which foster the exchange of information and the open dialogue of experts regarding specific aspects of freshwater. This is the case of more technical meetings and conferences, which aim to achieve a form of joint scientific understanding over best practices, but which do not necessarily strive to put this kind of consensus into a binding agreement. While this thesis does not cover the conferences and meetings of an entirely scientific and technical nature, the level of inclusion of policy makers and political actors does vary. When the goal of a conference is set on achieving a binding international agreement with clear rules, duties and obligations for the respective member states on how to manage freshwater resources, the influence and power of legal and political actors increases. The negotiations leading up the adoption of international agreements and conventions do not necessarily stay in line with best technical solutions but are, depending on the urgency and importance attributed to the matter, more a function of power distributions between countries and coalitions as well as negotiations strategies. Under these conditions, it is not largely surprising that the water professional community gives priority to key conferences and their role in generating new knowledge and scientific insight, whereas legal and political scholars attribute higher importance to specific international agreements, their genesis and their impact on the regulation of the issue. However, for the complete picture on global freshwater emergence, a joint perspective is required since the sub-issues dealt with a the conferences can easily lead to further rules and regimes in those areas too and changing political interests of key states and actors may play a large role in determining whether, when and how this occurs.

\footnotetext{
${ }^{37}$ As a matter of fact, from analyses of water professionals and policy makers, only Salman (2003) and Gupta et al (2013) even mention one of them, the IWC; the Ramsar Convention only appears in connection with freshwater resources in a more recent account of an NGO close to the UN (UND, 2015).

${ }^{38}$ More specific reasons and possible explanations for either one of the conventions alone are given in the respective sections.
} 
After the individual examination of both conventions, section 3 focusses on the interplay between them, which is where the theoretical significance comes to full effect. It is shown that there is indeed an overlap between these two and that they thus form the nucleus of an emerging regime complex. The latter is then characterized further and allows for evaluating the employed hypotheses.

In order to subsequently establish and study this interaction, both processes and treaties are analyzed in more detail in the following two sections with regard to how agenda access points were used and the conventions' place in the overall emergence of the water topics.

\section{Ramsar Wetlands Convention}

\subsection{Context and Background}

The first event of international dimensions to touch upon water issues and create binding rules in this matter, was the "International Conference on Wetlands and Waterfowl", held in Ramsar, Iran. On February 2nd, 1971, representatives of 18 mostly European countries negotiated a convention text, which was signed on February 3rd and is known since as the Ramsar Convention ${ }^{39}$. Taking place one year before the United Nations Conference on Human Environment (UNCHE) of 1972, which is generally perceived as the first big event focusing on environmental issues on the international agenda, the Ramsar Conference equally lent its attention to ecological concerns. Before the creation of UNEP in 1972, UNESCO had been the primary UN agency to deal with environmental issues and the Ramsar Convention was one of its peak events ${ }^{40}$ (RIBEIRO, 2001). As indicated by the official name of the conference, its central objective was to conserve important international wetlands and their resources as well as to incentivize their sustainable use with particular attention given to their role as habitat of waterfowl. By the term "wetlands"

\footnotetext{
${ }^{39}$ In full, its original official name reads "The Convention on Wetlands of International Importance, especially as Waterfowl Habitat”.

${ }^{40}$ UNESCO, upon request of the MAR conference, provided support for earlier scientific contributions in the area of wetland and waterfowl protection, most notably for the important early work "Liquid Assets" by Atkinson-Willes (1964); after several back and forth motions, it was later also given the role of Depository of the Ramsar Convention. However, as shown later in this chapter, most of the negotiations leading up to the convention occurred outside the realm of UNESCO and its main function was and has been of backup support in terms of the budgetary and legal dimensions.
} 
one generally refers to land areas which are connected to and/or intersected by significant amounts of water, for example bogs, swamps and marshes. A more precise definition can be found in Article 1.1 of the Ramsar Convention in which they are described as

[...] Areas of marsh, fen, peatland or water, whether natural or artificial, permanent or temporary, with water that is static or flowing, fresh, brackish or salt, including areas of marine water the depth of which at low tide does not exceed six metres" (RAMSAR, 1971).

Interestingly, due to the conference's focus on such a sub-topic of the wider umbrella issue, freshwater thus surfaced on the international agenda in a very specific way, before the subsequent broader UN forums brought it to the forefront in a more encompassing style with the 1977 UN Conference on Water. Since the 1971 conference was not entirely about wetlands but, rather, about their connection with migratory birds, which use them as habitat, the Ramsar Convention's importance with regard to freshwater resources has often been overlooked. While featuring a high level of inclusion of epistemic communities, experts and information sharing - as will become apparent in the following - which should appeal to the water professional community, its omission from most accounts of freshwater on the international agenda clearly reveals this lack of recognition.

Within this thesis, the Ramsar Convention is examined as the first building block of global water governance structures since it consists of a legal instrument that regulates a sub-topic of freshwater, i.e. wetlands, which have important environmental functions in the hydrological system, such as being natural filters and thus ensuring good freshwater quality. In the words of Luc Hoffman, one of the so-called founding fathers of the convention

[...] It became more and more recognized that wetlands have a far greater importance for ground water protection, regulation of the water cycle, water storage, water purification, and as an ecological basis for many forms of life, especially for fish. In the Third World entire populations depend essentially upon wetlands. Thousands of millions, probably hundreds of thousands of millions of dollars, are spent each year in the industrialized world in order to restore the hydrological and biological functions - functions which would be free of charge if wet-lands had been conserved. Ground water protection and water purification measures, in particular, swallow enormous sums. (HOFFMANN, 1993, p. 3; highlighting added).

In the same vein, Black and King (2009, p. 38) point out the importance of wetlands by stating that "without wetlands, rivers flow too fast, lakes become overburdened with organic matter, and coastlines are eroded. Only recently has the ecological value of wetlands been recognized". From the first statement one can see the connection of wetlands with the provision of food, in particular of fish as important source of protein (if 
the areas in consideration are kept and protected ${ }^{41}$ ); however, for the discussion in this thesis, the hydrological functions of wetlands with regard to the availability of freshwater in good quantity and quality (such as groundwater protection; diminishing the effects of pollution; impact on river flow; general role in the hydrological cycle etc.) are more relevant. This is not simply a re-interpretation of the conferences aims, objectives and outcomes, as even the former Secretary General of the Ramsar Convention Bureau, Daniel Navid, who analyzed the development of the Ramsar process nearly 20 years after the signing of the treaty under the rubric of international law of migratory species, stresses "the necessity of wetland conservation for both biological and hydrological reasons" (NAVID, 1989; added emphasis).

Despite the conference's primary focus on the specific ecosystem of wetlands and related waterfowl habitats, it is nonetheless an important step in terms of being one of the first international agreements to deal with environmental topics that are in connection with fresh water in a more broad sense. It needs to be underlined that the Ramsar Convention was the "[...] first of the modern global nature conservation conventions" (for example, NAVID, 1993, p. 2; KUIJKEN, 2006, p. 55), thus playing a vital role as door opener not just for subsequent fresh water events but also other environmental conferences more generally. It set a precedent for demonstrating the transnational nature of environmental concerns and the crucial and increasing significance of environmental topics on the international agenda, and the need for international cooperation among states in this area. As a pioneering event in this regard, it could not fall back on existing agenda status; instead, several key players and organizations needed to play together in order to lift this issue onto the international agenda.

\footnotetext{
${ }^{41}$ Here it is necessary to point out that in the case of drainage of wetlands, the newly-"won" areas are not only used for settlement but can - and often are - used for agricultural production of other sorts. The tradeoff between these two sources of food, and thus how to treat the wetlands area of concern, needs to be evaluated by the policy-makers in the respective locality in conjunction with the concerned stakeholders. Unlike in the earlier half of the past century, it is no longer the case that drainage can be assumed to be the only and best way forward for development. In fact, "attempts have been made to estimate the economic values of wetlands. In many cases, their worth turns out to be higher than that of the drained land" (BLACK;KING, 2009, p. 38). For more detailed estimates and figures, see for example Constanza et al (1997).
} 


\subsection{Origin, Important Countries and Players}

In order to identify the main figures and organizations involved in the Ramsar Convention, one needs to analyze not just the final event but also the path leading up to the conference. These prior developments and processes, which culminated in the adoption of the convention and subsequent enlargement of membership, were recorded and recounted in great detail in 1993 by the later honorary director of IWRB, Professor G.V. T. Matthews, featuring several preparatory meetings as well as key players.

As a conservation and management response to the large-scale elimination of marshlands and wetlands, the so-called $\mathrm{MAR}^{42}$ project had been established in the early 1960 s by the hands of European epistemic communities, mainly British, Dutch and French ornithological circles (HOFFMANN, 1993). The bundling of scientific networks and their output led to the enhanced mapping of wetland deterioration and began to create consensual knowledge of which actions to take. The resulting MAR Conference in 1962 in Saintes Maries de la Mer, France, was largely perceived as a "[...] real turning point in the development of strategies and practices for the conservation of waterbirds and wetlands" (KUIJKEN, 2006, p. 54) since the project's motivation was publicly announced to be a future convention, whose text was then elaborated over the span of the following decade at diverse technical meetings at the international level. From this point onwards, the initial MAR conference acted as an action-forcing event and the MAR project, as well as the networks linked to it, ensured the continuity of the process. The main individuals responsible for the organization and the advancement of these meetings, later referred to as the "four founding fathers of the Ramsar Convention" (Ramsar, 2015), were Luc Hoffman (IWRB; WWF; IUCN), G.V.T. Matthews (IWRB) and Eric Carp (IWRB) with their respective institutions, in addition to Eskander Firouz (Iranian Undersecretary of the Ministry of Natural Resources as well as Director of the Game and Fish Department), who would later become the host of the 1971 Ramsar Conference. From this list, the crucial role of Luc Hoffman stands out. Not just his primordial role as organizer of the MAR conference, but even more his formal positions and close working ties within the IWRB, the WWF and IUCN, which connected the issue of wetland protection with the greater

\footnotetext{
42 The project was entitled "MAR" in reference to the word for wetland in many of the participating countries' languages; the name alludes to the first three letters of the respective words "MARsh" (English), "MARécages" (French) and "MARismas" (Spanish), amongst others (MATTHEWS, 1993).
} 
environmental and conservationist movement and secured institutional arenas as well as funding avenues for the Ramsar process. Due to these initial efforts of mainly ornithologists, the aim of the MAR conference and the following 1963 St. Andrews meeting lay almost entirely on the protection of the species in question.

This changed with the International Wildfowl Research Bureau's (IWRB) proposals of 1965, which moved the aspect of wetland conservation into the foreground and even drafted a first convention text. However, it was mainly through the intervention of IUCN legal consultant Cyrille de Klemm that this shift toward wetlands as wildfowl habitat was firmly established, thus extending and recalibrating the target of the convention while the original idea took second place (though in the end it appeared as appendage of the title $\mathrm{e}^{43}$ ). De Klemm argued in favor of pursuing two sequential ${ }^{44}$ and complementary conventions on the grounds that the conservation of wetlands would already function well with a limited numbers of members, whereas wildfowl preservation would only be achievable if all countries were included, in which the specific species lived and/or passed through. He envisioned, in the first place, a wetlands convention - as did occur with the 1971 Ramsar Convention - and, secondly, a wildfowl convention, which would later be realized in the form of the 1979 Convention on the Conservation of Migratory Species of Wild Animals in Bonn, Germany (MATTHEWS, 1993). This shift in focus was not merely of technical and/or strategic importance but one that in its consequences profoundly changed the nature of the Ramsar process with regard to the regulation matter; without it, the later outcome would indeed have been an exclusive migratory bird convention ${ }^{45}$ and the link with freshwater resources would have remained marginal at best. Due the refocussing, the convention was aimed at both wetlands and waterfowl protection, but the latter was to be achieved through the conservation of the former and as such providing valuable habitat; in this way, freshwater resources ${ }^{46}$ became the primary targeted regulation matter of the convention. This aspect of the Ramsar Convention has remained underappreciated in both

\footnotetext{
${ }^{43}$ In the 1969 Vienna meeting, the focus on wetlands, rather than waterfowl, was confirmed. While the resulting recommendations of this meeting envisioned the removal of any reference to waterfowl altogether, the insistence of Soviet delegates later reintroduced it (MATTHEWS, 1993).

${ }^{44}$ In the first place, a wetlands convention, as did occur with the 1971 Ramsar Convention; and, secondly, a wildfowl convention, which would later be realized in the form of the 1979 Convention on the Conservation of Migratory Species of Wild Animals in Bonn, Germany.

${ }^{45}$ This part was taken up in the end by the Bonn Convention of 1979 , which was dedicated exclusively to migratory species and did not entail much reference to wetlands.

${ }^{46}$ Due to the wide definition of wetlands in Article 1.1 of the convention, even brackish waters and specific coastal saltwater areas are covered under the Ramsar agreement.
} 
the public and academic perceptions; however, it is crucially important for the topic of this thesis.

An equally important dimension of the route to the Ramsar Conference was the increasing inclusion of governmental and political actors. Starting with the concerns, suggestions and actions of the scientific community and ornithologists in project MAR, it was pointed out early in the process by E.M. Nicholson - acting as Director General a British governmental body, the Nature Conservancy of Great Britain - that "[...] effective international cooperation would only come about if governments were directly involved in the conferences, along with experts and the representatives of international organizations" (MATTHEWS, 1993, p. 13). This was generally accepted and, subsequently, their presence and influence rose: the St Andrews meeting of 1963 already featured 10 governmental delegates (out of 17 countries represented) plus 7 international organizations, and by the time of the Noordwijk meeting in 1966, the number of government delegates had risen to 17 (out of 23). Furthermore, after the first draft proposals had still been prepared by the IWRB in 1965, a consensus emerged to leave this task in the hands of diplomats, so this function was transferred to the Dutch government in 1996.

With regard to these meetings and preparatory conferences, the role and importance of European epistemic communities and NGOs becomes clear and shows that this sub-aspect of the freshwater topic emerged bottom-up with strong participation of transnational networks, thus ensuring access to important communication channels for spreading their concerns and work as well as for generating support for these. In terms of the original participating countries of the Ramsar Convention, the majority of European representatives needs to brought to mind again. As mentioned above, of the 18 signatory countries of 1971, 11 came from Europe (Belgium, Denmark, Finland, France, Federal Republic of Germany, Ireland, Netherlands, Spain, Sweden, Switzerland, and the UK), whereas the other 7 were mainly Asian (India, Iran, Pakistan, Turkey, USSR) with the exception of Jordan and South Africa. When bearing in mind the nationalities of the founding fathers of the convention (Hoffmann: Switzerland; Matthews and Carp: UK; Firouz: Iran) as well as the host countries of the main organizations and NGOs involved (IWBR: UK and France, later Netherlands; IUCN: Switzerland; ICBP: UK; WWF: Switzerland) this regional distribution is not much surprising given the background of the relevant epistemic 
communities (mainly ornithologist circles) and the locations where the previous technical meetings had been held (see above). Furthermore, the scope of the convention's impact area was continuously expanded over time and from meeting to meeting, starting mainly within European geographical limits and rather scattered international ties in parts of Asia, Africa and the Middle East, until finally reaching global levels in the later stages.

It is worth noting that several internationally important countries were absent from the MAR meetings and the Ramsar talks, most notably the United States of America. Whereas content-wise the US and Canada had been leading with regard to mapping and fighting the loss of wet- and marshlands long before progress in this area occurred in Europe and other parts of the world (MATTHEWS, 1993), it is surprising that neither country was represented at the early and middle stages of the Ramsar process. This could be partially ${ }^{47}$ explained by the early inclusion and participation of the other hegemonic actor of the time: the USSR ${ }^{48}$. Despite the Eurocentric origins of the debates and negotiations with the Dutch government playing a key role in producing several drafts of the convention text, the 1966 technical meeting in Noordwijk an Zee, Netherlands, featured an important geographical extension by including for the first time areas of the Soviet Union. As Matthews explains,

A major enlargement of the scope of these meetings was provided by the attendance of a delegate and an expert from the Soviet Union. It is difficult to realize, in the 1990s, how politically remarkable this was. In bio-geographical terms, it meant that the major breeding grounds of the wildfowl wintering in Europe could now be included in the scope of the Convention. Since many other Soviet breeders migrated to South and East Asia, the whole Palearctic could now logically be considered covered. (MATTHEWS, 1993, p. 14).

However, this inclusion of the USSR might have impacted in the US not taking part in the Ramsar process until much later. For the sake of our discussion it is not so much the geographical expansion with related inclusion of hitherto unconsidered waterfowl species as such that is remarkable, but rather the fact that one of the two superpowers at the time of the Iron Curtain and the Cold War begins to get involved in the MAR process, both technically (expert) as well as politically (delegate). While the Soviet Union's role was seen as very cooperative in the initial stages in 1966, politics interfered at later meetings

\footnotetext{
${ }^{47}$ Two further possible factors are worth noting. Firstly, the already existing Migratory Birds Convention between the USA, Canada and, subsequently, Mexico, which by covering practically all of North America achieved continental dimensions. Secondly, another potential reason might lie in the fact that the basic concerns in the USA were related to hunting considerations to a greater degree than in the European case, though this reading of the developments of the time remains more speculative.

${ }^{48}$ Kuijken (2006) reminds us of the fact that in the former Russian Empire in the early 1900s Lenin initiated the transformation of the Volga Delta into a National Park, which reveals at least elements of a longerstanding conservationist interest in the region.
} 
due to the USSR's invasion of Czechoslovakia in 1968, which led to the USSR's temporary suspension from the talks due to pressure from the Netherlands and other European countries. However, the talks with Soviet Union's representatives were reinitiated in 1969 at a meeting in Moscow and it became a signatory member to the convention in 1972 (MATTHEWS, 1993).

\subsection{The Ramsar Regime: Rules, Norms and Wetlands Governance}

After having taken a closer look at the origins and the negotiation rounds leading to the 1971 agreement, a further step involves putting the spotlight on the resulting output, i.e. Ramsar regime itself. The rules and norms that have resulted from the Ramsar negotiation process were laid down in the original Ramsar Convention, which thus stands at the heart of the regime. It is therefore of utmost importance to analyze the individual clauses of this agreement and the obligations and duties for the member states therein. Due to the topical interest of this dissertation the focus will particularly be on water-related aspects and articles. However, it is worth mentioning that, due to the initial focus of the Ramsar process, the protection of the bird species that use wetlands as their habitat or stopover spots is also explicitly mentioned in the convention text and still dominates the public perception of the regime.

The preamble of the treaty ${ }^{49}$ (RAMSAR, 1971) points out "the fundamental ecological functions of wetlands as regulators of water regimes" (item 2) and underlines that they "constitute a resource of great economic, cultural, scientific and recreational value, the loss of which would be irreparable" (item 3), hereby echoing the concerns of Hoffmann as well as Black and King mentioned above. The importance of the preamble should not be underestimated as it sets the tone for the rest of the treaty; with the mentioned items wetlands and their role for water regimes are explicitly highlighted and thus form an important base for the following treaty text.

\footnotetext{
49 This analysis is carried out with regard to the original version of the Ramsar treaty, which was adopted in 1971 in the Final Act of the Ramsar conference and which still forms the core of the Ramsar regime itself. For subsequent developments of these rules and the amendments of the regime itself in the 1980s, c.f. section 1.3 of this chapter.
} 
The main obligations and duties of the contracting parties are contained in articles two through six, which consist mainly of designating particular wetlands within their respective territories (Art. 2), promoting their conservation and wise use ${ }^{50}$ (Art. 3 and 4), encouraging research, data exchange (Art. 4.3) as well as training of personnel (Art. 4.5), mutual consultation in the case of transboundary wetlands (Art. 5) and convening additional conferences if necessary (Art. 6). Within these, several aspects deserve further attention and are highlighted in more detail.

First of all, the criteria for the selection of a site for the list of wetlands of international importance are laid out in Art. 2.2 in such a way that they ought to be chosen "on account of their international significance in terms of ecology, botany, zoology, limnology or hydrology" (emphasis added), once again including freshwater-related dimensions among the principal outlined factors to be considered.

Furthermore, additional norms and rules concerning this list are particularly relevant and interesting for the discipline of international relations in how they explicitly safeguard the respective countries sovereignty in Art. $2.3^{51}$, Art. $2.5^{52}$ and Art. $4.2^{53}$. Especially the latter two with its reference to "urgent national interests" is a concession that illustrates how hard topics such as national security, military and economic interests clearly override the soft topics of wetlands conservation ${ }^{54}$. In order to understand this more fully, one needs to bear

\footnotetext{
${ }^{50}$ The elaboration of the concept of "wise use" in the Ramsar treaty is highlighted by Kuijken (2006), who maintains that it not only served as the basis for the later UN efforts in the area of biodiversity but that actually the term "sustainable use" is almost entirely a synonym and thus more of a re-branding or relabelling that innovation at UNCED in 1992 and within the Convention on Biological Diversity (CBD), in particular.

${ }^{51}$ Article 2.3 in its entirety reads as follows: "The inclusion of a wetland in the List does not prejudice the exclusive sovereign right of the Contracting Party in whose territory the wetland is situated" (emphasis added).

${ }^{52}$ The complete text of Article 2.5 states that "Any Contracting Party shall have the right to add to the List further wetlands situated within in territory, to extend the boundaries of those wetlands already included by it in the list, or, because of its urgent national interests, to delete or restrict the boundaries of wetlands already included by it in the List and shall, at the earliest possible time, inform the organization or government responsible for the continuing bureau duties specified in Article 8 of any such changes" (emphasis added).

${ }^{53}$ Article 4.2 reads in full: "Where a Contracting Party in its urgent national interest, deletes or restricts the boundaries of a wetland included in the List, it should as far as possible compensate for any loss of wetland resources, and in particular it should create additional nature reserves for waterfowl and for the protection, either in the same area or elsewhere, of an adequate portion of the original habitat" (emphasis added).

${ }^{54}$ However, in reality the member states have seldom made use of these clauses. This is not to say that the above mentioned hierarchy of topics does not exist, since the mere existence of the clauses always allows for the potential reconsideration of designated wetlands, but it does hint at a growing power of soft topics such as wetland and general water conservation which elevate the price of openly putting other interests higher. The only cited example for the use of Article 4 refers to a Belgian case in the late 1980s, in which the economic interests (the construction of a new container terminal) led to a diminishing of the Ramsar site of Galgonschoor followed by a compensatory measure of adding a vastly superior newly designated site near the River Ijzer (KUIJKEN, 2006).
} 
in mind and recall the international tensions of the time, particularly the era of the Cold War. By including such clauses of predominance of sovereignty and national interests in explicit terms the convention is weakened on the one hand since it places itself in a lower step of hierarchy of interests; on the other, bearing in mind the geopolitical tensions of the time of elaboration of this treaty text, this awareness proves a great amount of realism and certainly facilities the acceptance of the convention on the part of the member states due to the easy opt-out routes laid on in these articles. A stronger wording and an omission of these clauses might have compromised the willingness of particular countries, particularly the USSR at the time and later the US, to join and remain member of the convention.

Finally, Art. 5 deals with transboundary issues and urges the contracting parties to consult with each other in the case of shared wetlands or shared water systems. In this way, it becomes clear that the obligations and duties arising out of the convention are not purely national whereas international coordination were only required with regard to the norms but, rather, that in specific instances the regulated matter itself is de facto transboundary and requires cooperation. However, the overall articles remains extremely general and does not entail any further recommendations, suggestions or obligations with regard to the type of consultation or cooperation, thus leaving the latter almost unregulated and entirely up to the contracting parties. From this we can see that agenda setting on soft and transboundary topics in the 1970s was still quite limited in its influence and constrained by geopolitical or national security concerns.

The remainder of the treaty deals with the representation of the member states and voting rules for recommendation (Art. 7), the establishment of the bureau and its functions (Art. 8) as well as clauses related to the states and entering into force of the convention (Art. 912). While some of the latter articles consist mostly of technical formalities, several of the former are worth a closer look. With regard to the voting procedures on recommendations elaborated at additional conferences, the treaty text establishes a level playing field with equal voting power with one vote per represented contracting party as well as a simple majority of the votes required for the adoption of such recommendations, subject to the minimum voting percentage of $50 \%$ of the members ${ }^{55}$.

\footnotetext{
${ }^{55}$ This minimum hurdle was later removed in the 1987 Regina Amendments, thus facilitating the adoption of recommendations and making the regime more flexible to take action.
} 
More surprising and equally relevant to the discipline of IR are the clauses subsumed under Article 8 related to the bureau duties of the Ramsar Convention, which were to be carried out by an $\mathrm{NGO}^{56}$, namely the International Union for the Conservation of Nature and Natural Resources (IUCN). This fact is quite remarkable since the standard procedure is to create a new institution which then performs bureau tasks and deals with administrative matters. In this case, however, it was decided to delegate this to an NGO which already held significant expertise in the matter and which was subsequently to act as a connecting point between the member states for information exchange, organizing follow-up conferences wherever necessary and maintaining the list of wetlands judged to be the most important internationally. This decision was extraordinary since at the time, in the early 1970s, the role of NGOs was still quite marginal on the global agenda ${ }^{57}$, thus giving the Ramsar process and the activities of the IUCN within it a pioneering role.

Lastly, Article 9.3 establishes the United Nations Educational, Scientific and Cultural Organization (UNESCO) as depository ${ }^{58}$ for the treaty and Article 10 states that seven states had to become contracting parties for the convention to enter into force, which in the end happened only a few years after.

Seen as a whole, the Ramsar treaty stands out as being one of the first international environmental agreements and features important novelties; on top of the content this includes the activities of the IUCN as an NGO carrying out an important function. In hindsight and when compared to later conventions, the wording of the treaty text appears quite tentative, without strong obligations and containing no metrics or specific quantifiable measures to be taken by the member states. It thus made it relatively easy for countries to join and become members at a not very high cost and with clear escape valves in the form of sovereignty and national interest clauses as well as national observation of the wetlands under concern and the omission of an explicit sanctions catalog in the convention for the case of non-compliance.

\footnotetext{
${ }^{56}$ This was later changed by the Regina Amendments of 1987 and since then the Ramsar Bureau is now an independent institution at the service of the contracting parties, while still residing on the premises of IUCN in Switzerland (RAMSAR, 1987).

${ }^{57}$ This only began to change significantly in the early 1990s after the end of the Cold War, a period after which a series of studies has noted an increase in the role and influence of so-called "new actors" in the global arena, namely NGOs but also big international companies.

${ }^{58}$ Initially, this role was envisioned to be fulfilled by the government of the Netherlands; later drafts foresaw a co-depository of the Netherlands and the USSR (MATTHEWS, 1993).
} 


\subsection{Evolution, Further Developments and Current State}

The Ramsar Convention eventually entered into force in 1975 with the deposit of an instrument of ratification by Greece, herewith fulfilling the minimum requirement of seven countries becoming members of the treaty as set out its Article 10. Subsequently, periodical $^{59}$ gatherings took place in the form of meetings of the Conference of the Contracting Parties ${ }^{60}$ (COPs) since 1980 to discuss the further development of the convention and related issues. Over time, the number of member states (see Table 4) as well as the area of impact (see Figure 3) has increased substantially, and it is generally considered one of the most successful international agreements.

\section{Table 4}

Development of membership to the Ramsar Convention

\section{Sources}

Listed individually after the respective year and membership numbers

1971: 18 signatories (RAMSAR, 1971)

1989: 52 contracting parties (NAVID, 1989)

1993: 75 member states (NAVID, 1993, p.2)

2006: 152 contracting parties (KUIJKEN, 2006)

2009: 158 signatory states (BLACK; KING, 2009)

\footnotetext{
${ }^{59}$ This was later fixated in written form in the 1987 Regina Amendments to happen on a triennial basis and continued as such thereafter.

${ }^{60}$ As exceptions to these regular meetings of the member states three additional conferences occurred. In 1974, a conference of the parties' event was realized in Heiligenhafen, Germany one year before the entering into force of the Ramsar Convention; and in 1982 and 1987, two Extraordinary Conferences of the Contracting Parties were held in Paris, France and Regina, Canada, respectively.
} 
Fig. 3

Evolution of the geographical scope of the Ramsar Convention

Source

Kuijken, 2006

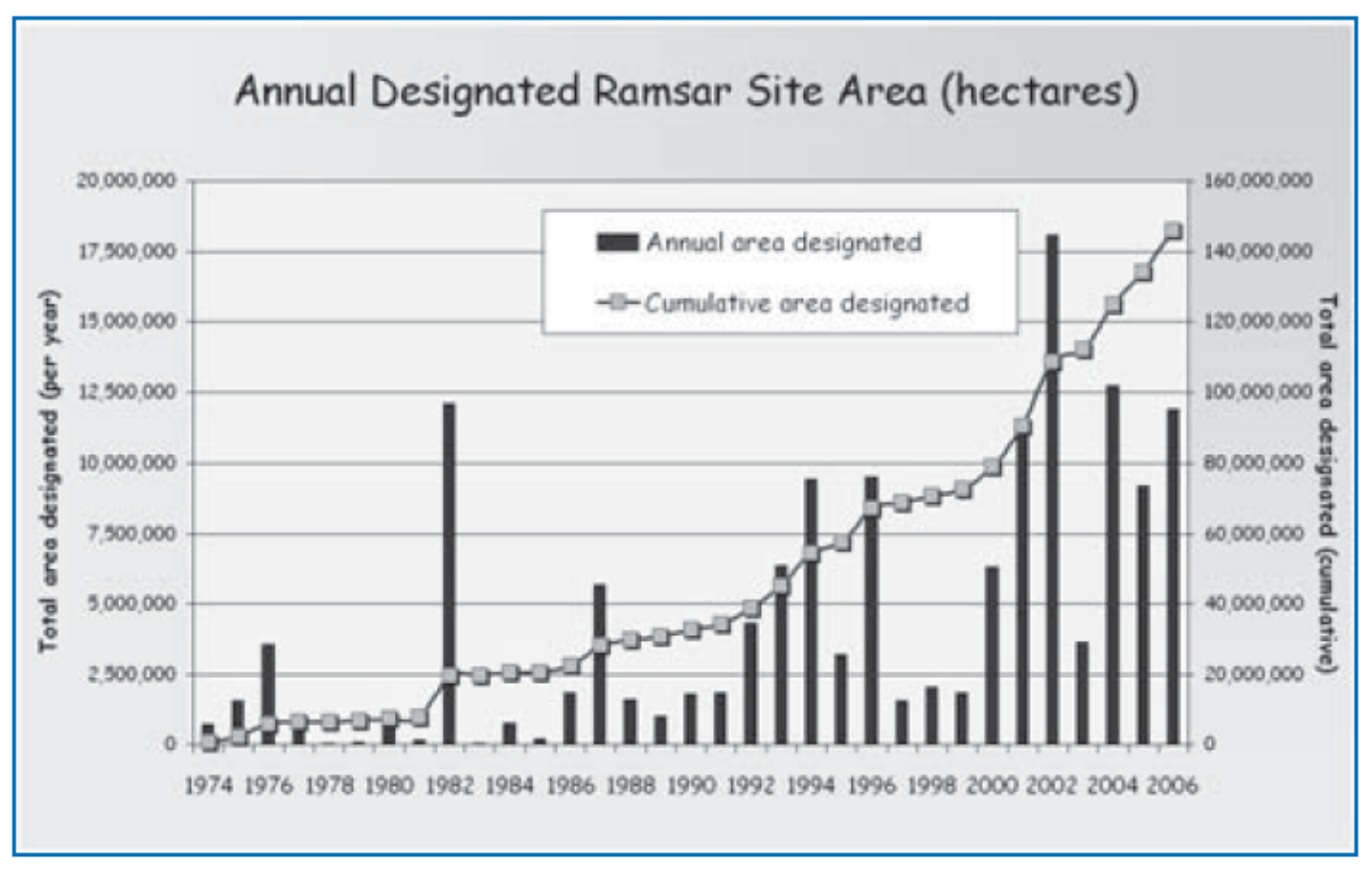

It is worthwhile to trace changes in the names and general terminology within the Ramsar process over time since they prove revealing with regard to the weight and importance granted to environmental concerns and the recognition of broader ecological problems and challenges related to the convention's topic. As mentioned in section 1.2, the primary interest of the groups and people involved in the MAR project lay in the protection of migratory bird species ${ }^{61}$ but was extended to wetlands as their habitat for legal and strategic reasons, thus leading to the inclusion of wetlands in the original title of the convention (while still giving equal semantic weight to the birds) in 1971. Over time, however, the importance and focus given to the wetlands gradually increased within the Ramsar process up to nowadays, where "[...] the working title of the Convention (Ramsar Convention on Wetlands) no longer recalls its relationship with waterfowl habitat" (KUIJKEN, 2006, p.55). While this is of course not to say that the conservationist interest in the waterbird protection part has vanished, it does reveal that, after entering the

\footnotetext{
${ }^{61}$ At the same time, the labels given to these animals developed from "wildfowl" (used in the first European meetings in the UK and the Netherlands in the 1960s), via "wildfowl resources" (employed at the meeting in the former USSR in 1970) to "waterfowl" at the Ramsar Conferences in the early 1970s. The former terms resonate more with the hunting interests and resource exploitation, whereas subsequently a trend toward actual eco- and biological concerns (endangered species, habitats under threat etc.) is reflected. As shown by Kuijken (2006), this evolution runs parallel in the names of the concerned NGOs and institutions, for example the former IWRB.
} 
convention through the back door - so to speak -, the role and importance of the wetlands themselves with all their vital eco- and hydrological functions has emancipated and taken the foreground.

In the context of the COPs, the convention has been altered on two occasions at Extraordinary Conferences of the Contracting Parties (COPs). While the substantive content of the Ramsar Convention stands almost unaltered over time, in 1993 the Secretary General at the time underlines "[...] tremendous changes in the Convention" (NAVID, 1993, p.2); this refers mainly to the fact that some of the convention's earlier weaknesses of administrative and functional nature have been remedied through progressive amendments of the contracting parties and it now stands as a positive example to follow. In 1982, the 19 members present at the COP in France adopted the so-called Paris protocol containing an amendment procedure to the treaty in the new Article 10bis (RAMSAR, 1982), based on which changes to procedural and financial aspects of the Ramsar Convention were made in 1987 at the COP in Canada by the attending 33 delegations (RAMSAR, 1987). The latter, henceforth known as "Regina Amendments", included revised Articles 6 (new budgetary consideration and duties as well as new rules of procedure for meetings) and 7 (removal of the minimum of votes cast of $50 \%$ of the contracting parties). These amendments entered into force in 1994 and made the convention stronger in giving it new competencies and potential as well as flexibilizing its conditions for recommendations and voting. While still not containing many strongly worded clauses, negative incentives in the form of sanctions nor a great many metrical obligations - thus classifiable as a softer treaty - this more general open approach is perceived to have had a positive influence on the developments and growth of the Ramsar Convention. According to Kuijken (2006, p. 56), it is "[...] recognized as a most dynamic and functional treaty, having opened the way for wetland conservation, especially in many developing countries".

\subsection{Summary}

As shown in the above analysis, the Ramsar process was in large part driven by European epistemic communities and a select group of committed individuals with their corresponding institutions and NGOs, thus essentially a bottom-up movement. After the 
scientific community and concerned ornithologists had alerted to the dramatic losses of wetlands and their effect on migratory birds, this movement began creating a broader base of detailed data and developed publicly available information and action programs, such as the MAR project, leading to an international consensus on the issue upon which subsequent action and negotiations between the corresponding countries could be built on. After the 1962 MAR conference was realized and a convention was called out as the ultimate objective of the process, it acted as an "action-forcing" event, which gave momentum to the movement and laid out a clear path to follow. However, without the personal commitment of the so-called founding fathers of the convention - using their influential positions within their institutions and NGOs, mainly the IWRB, IUCN, ICBP and the WWF, in order to spread their concerns and ideas, secure important arenas and links with the broader environmental and conservationist movement as well as bringing in political and diplomatic actors, the process to the final Ramsar Convention would have far more difficult to bring to conclusion. In summary, one can state that through the lens of the agenda access approach it becomes clear that access and control within the interstate dimensions of knowledge, communication channels and institutional loci - diplomatic norms to a far lesser extent -, was vital to the success of the Ramsar process.

\section{International Watercourses Convention}

\subsection{Context and Background}

Apart from the 1971 Ramsar Convention, the genesis of the freshwater topic on the international agenda features only one additional global binding agreement, which also marks the end of the emergence period. Surfacing on the global forefront almost 30 years after the former, and taking place in the aftermath of the majority of the most important water conferences of the 1970s, 1980s and 1990s (see chapter II), the adoption of the 1997 Convention on the Law of the Non-Navigational Uses of International ${ }^{62}$ Watercourses,

\footnotetext{
${ }^{62}$ It is useful to underline the specific wording of the convention, referring to "international watercourses" and avoiding the word "global" due to inexistence of truly global rivers. Instead, there are many watercourses that run between several countries, even reaching regional/continental dimension in few cases (e.g. Rhine, Danube, Nile and Amazon). What is global about these rivers and lakes and the convention that governs them, is the fact that global norms and rules are created that are supposed apply everywhere; even in the case of prior transboundary agreements between specific riparian countries, which regulate water bodies shared
} 
often referred to as International Watercourses Convention (IWC), is the single most important event concerning international environmental cooperation on the topic of fresh water during that period. Already in its name one can appreciate the contrast to previous, mostly bilateral or regional, freshwater treaties and agreements, which had mostly dealt with navigation and had left environmental and other related aspects on the side ${ }^{63}$. With the IWC this treaty approach changes and marks the beginning of a more holistic dealing with international transboundary water resources and their regulation between the countries that share them.

The clear target matter of this agreement refers to water bodies divided between two or more countries and, therefore, a subject much more in the focus of states, organizations and the public in comparison to the more marginally noticed subject of wetlands. In order to get a feeling for the scope of transboundary freshwater it is useful to bear in mind some basic figures and their worldwide distribution.

Globally, there are just over 260 river basins shared by several countries, which encompass around half of our planet's land surface and on which around $40 \%$ of the global population rely (WOLF et al, 1999); 13 of them are even shared by five or more countries, which further complicates their management and regulation (BLACK; KING, 2009). Though sometimes connected to rivers and lakes, aquifers are often "overseen" and their role in the provision of freshwater is generally underestimated; however, one must highlight that nearly all of our accessible freshwater, around $98.7 \%$ according to figures from Shiklomanov and Rodda (2003), is withdrawn from them. With 269 shared groundwater basins, a number slightly higher than those of international river basins, UNESCO (2009) estimates that nearly 2 billion people depend on these sources alone for the provision of water. Table 5 breaks these figures down by continent and, in the case of international river basins, presents the percentages of surface area the cover.

\footnotetext{
between them, these treaties are urged to be changed, updated and/or harmonized to the greatest extent possible.

${ }^{63}$ The obvious exception is of course the Ramsar Convention (see section 1), which carried forth and is strongly motivated by many environmental concerns. As shown previously, these were originally mostly related to avifauna, however, and not to freshwater resources. Only due to legal and strategic reasons this balance ended up more favorable to wetlands but, importantly, these are treated as vital ecological and biological resources to be protected and conserved.
} 
Table 5

Worldwide shared river and groundwater basins by continent

Source

Gleick et al (2012)

\begin{tabular}{|c|c|c|c|}
\hline \multirow{2}{*}{ Continent } & \multicolumn{2}{|c|}{ Transboundary River Basins } & Transboundary Aquifers \\
\cline { 2 - 4 } & Nr. & Percent of Area in International Basins & Number \\
\hline Africa & 59 & $62 \%$ & 40 \\
\hline Asia & 57 & $40 \%$ & 70 \\
\hline Europe & 69 & $55 \%$ & 89 \\
\hline $\begin{array}{c}\text { North and } \\
\text { Central America }\end{array}$ & 40 & $37 \%$ & 41 \\
\hline South America & 38 & $59 \%$ & 29 \\
\hline Total (global) & 263 & $48 \%$ & 269 \\
\hline
\end{tabular}

These figures already make clear why this aspect of the freshwater topic has received most attention, both scholarly as well as from the public and from states. Due to these numbers and the importance of international transboundary freshwater conveyed by them, one can easily understand that it is a topic which receives much less "soft" treatment than other sub-issues of the freshwater umbrella topic such as wetlands. The way it is dealt with is often permeated not just by environmental but also industrial, agricultural and powerpolitical concerns, as will become evident in the negotiations leading up to the final convention text.

Since the mid-1980s, a consensus has emerged in the water professional community that the river basin is the best place for governance and resolution of issues with regard to specific rivers, thus favoring the creation of river-basin authorities and commissions (c.f. Falkenmark, 1985). In the words of Hoekstra (2011, p.22), "it has therefore been widely acknowledged that...the river basin is the most appropriate unit for analysis, planning and institutional arrangements". However, this is mainly true for technical regards and some more localized power-related issues; since big rivers are so important for entire countries, it is an illusion to believe that higher-level interest will remain in the observer role. To this point, Gleick (2012, p.1) underscores that "political borders and boundaries rarely coincide with borders of watersheds, ensuring that politics inevitably intrude on water policy". For this reason, it is vital that in addition to the river-basin authorities between the riparian states of a particular river, there are international norms and guidelines, which take into 
account these particular situations but also create overarching rights and obligations for the parties involved to create more effective and just governance.

Apart from a greater display of interest by the water professional community and policy makers (for example, c.f. SALMAN, 2003; GUPTA et al, 2013), the IWC process has received considerable scholarly attention, mostly from the legal perspective (CHENEVERT, 1992; MCCAFFREY, 1993，1995，1996，1997; FITZMAURICE，1997; TANZI, 1997, 2000; BARANDAT; KAPLAN, 1998; MCCAFFREY; SINJELA, 1998; SCHROEDER-WILDBERG, 2002), some from the field of political geography (RIBEIRO, 2008) but also partially by the IR community (CONCA et al, 2006). However, and rather surprisingly, most of the sources dealing with the broader development of freshwater resources on the international agenda do not analyze or even makes references to this convention (such as, for example, BISWAS, 2004; SOUZA, 2005; and TOPALOGLU, 2008; the WWWC (2014), UND (2015) and the UNESCO WWAP (2015) websites omit this convention completely). Thus, one of the objectives of this thesis is to connect and integrate these different analyses within a broader framework of analyzing the emergence of the freshwater topic on the international agenda.

Concerning its place within this thesis, the IWC is considered a second regime of a subissue of the freshwater umbrella topic, in this case regulating transboundary rivers, lakes and hydrologically connected aquifers. It stands as the central pillar of the global water governance structure, along with the previously examined Ramsar Convention. In comparison with the latter, the IWC's link to freshwater resources is self-evident since the convention entirely deals with these and only these; furthermore, their regulation is not intended as a means to another end ${ }^{64}$ - this is at least partially the case with the Ramsar Convention and the protection of migratory species through wetlands regulation. Having said that, the IWC can however not be considered a cohesive, overarching freshwater regime on its own since it does not cover all of the main issues of the freshwater umbrella topic; apart from the non-coverage of certain types of groundwater, on the supply side, it also does not deal with many urgent demand and usage aspect, such as access to potable water and sanitation. Therefore, it still needs to be considered as another building block,

\footnotetext{
${ }^{64}$ Ultimately, of course, all of these conventions' regulation efforts are in view of sustaining human and other life on earth as the broadest of all goals.
} 
even though by far the most important one ${ }^{65}$ within the global freshwater governance architecture that was constructed in the emergence period of the freshwater topic.

\subsection{Origins, Important Countries and Players}

Transboundary waters and externalities resulting from their use have been contentious for a long time. However, at the global level - as opposed to the many bilateral or regional agreements - this this topic was not met with any regulation efforts for a long time and was only guided by customary international water law, i.e. unwritten rules, which developed over time through the practice of states. This changed in 1966 with the publication of the so-called "Helsinki Rules" by the International Law Association (ILA), through which "the codification of the customary international law took a major step forward [...]" (DELLAPENNA; GUPTA, 2013, p.13). However, these rules only elaborated principles to be used in other agreements and were not negotiated formally into international agreements at that point, thus representing only "soft law", i.e. being non-binding. According to legal experts, their acceptance is thus strongly dependent on the reputation of the organization that develops them (CANO, 1989, p. 167) and "although these principles are widely recognized and have greatly influenced subsequent agreements, there is no mechanism in place to enforce them" (GLEICK, 2012, p. 4).

To fill this gap and with the aim of possibly arriving at a global convention, a process was initiated from within the $\mathrm{UN}^{67}$ system to seek further codification of the law on

\footnotetext{
${ }^{65}$ One could argue that the most fundamental element of global freshwater governance does not consist of an international institution, such as the two abovementioned conventions and their regimes, but that this role is rather played by the human right to water as the ultimate basis for almost all other international cooperation with regard to freshwater. Thus, this thesis speaks more of global governance structures or architecture versus the concept of global governance on its own. Since the human right to water was officially only codified into written law, formally introduced and confirmed in 2002 and 2010, respectively, a deeper discussion of the interaction of these elements of global freshwater governance falls outside of the scope of this thesis but is certainly relevant to the main argument concerning an emerging freshwater regime complex. ${ }^{66}$ Whereas the abovementioned "Helsinki rules" were non-binding, a posterior regional convention went a step further. In the form of the so-called "Helsinki Convention" of 1992, a later attempt at regulation became binding. However, its scope is limited to Europe since it was elaborated by the United Nations Economic Commission for Europe (UNECE, 1992;1998) and will thus not be included in this analysis of the global level; with regard to future, more in-depth studies of the freshwater regime complex and its regional elements this convention should be considered as well.

${ }^{67}$ For the sake of completeness, a quick reference should be made to the 1959 GA resolution 1401 (XIV) of November $21^{\text {st }}$, in which the UNGA first recognized the importance of the issue of transboundary water by stating that "it is desirable to initiate preliminary studies on the legal problems relating to the utilization and
} 
transboundary water resources; it is important to stress that this was not an effort to create a great set of innovative regulatory guidelines, instead - as McCaffrey (2008) points out this process was strongly influenced by existing state practice. This can be seen in the 1963 legislative series produced by the UN secretariat (UN, 1963) - which featured the gathering of the then available water agreements - and its update of 1974 (UN, 1974) which had been requested by the UN General Assembly (UNGA) in 1970 (KEARNEY, 1975) - as well as the fact that the ILC contacted the UN members states' and asked for their opinions on the matter via a survey when it later began its work in 1974 (MCCAFFREY, 2008). In parallel, the GA also adopted resolution 2669 (XXV) with the title "Progressive Development and Codification of the Rules of International Law Relating to International Watercourses" on December $8^{\text {th }}$ of 1970 , which recommended that the International Law Committee (ILC) study the matter and work with the goal of codifying relevant norms and principles into formal international law (UNGA, 1970). The ILC made this task part of its program as of 1971 at its $23^{\text {rd }}$ session, initiated it in 1974 and developed its input over the course of 20 years until finally submitting a bundle of over 30 draft articles for a convention on watercourses ${ }^{68}$ back to the UNGA in 1994 (ILC, 1994a). What is important about the work of the ILC for this thesis is not so much the historic detail and the chronology in that 20 year period, but rather an idea of the process that lead to the drafts. A subcommittee of the ILC was created and a sequence of five so-called special rapporteurs (Richard D. Kearney, Stephen M. Schwebel, Jens Evensen, Stephen McCaffrey, and Robert Rosenstock) produced detailed reports on the matter, which were then considered as a whole and crystallized into the draft articles (MCCAFFREY, 2008a). During this period of drafting a future convention, the ILC focused on codifying customary international water law of the time as well as bearing in mind general state practice and input by the UN member states; as such, the main drivers of this were almost entirely ${ }^{69}$ by legal experts.

\footnotetext{
use of international rivers with a view to determining whether the subject is appropriate for codification" (UNGA, 1959, p. 55). However, this was only followed up on as of 1963.

68 Furthermore, the ICL equally adopted a so-called companion resolution with regard to confined groundwater (ILC, 1994b), suggesting that it be guided by the same principles as the ones applying to watercourses; however, this resolution was not picked up by the UNGA in 1994 and, thus, confined groundwater is not covered by the later 1997 IWC.

69 There was additional feedback from the UN member states on a 1974 report of the Subcommittee (A/CN.4.283) as well as on preliminary set of draft articles of 1991 (A/CN.4/L.458) but this was not directly introduced into the drafts but rather mediated by the work of the ILC, unlike the later negotiations of the working group of the GA.
} 
The most interesting parts of the IWC process for this thesis are, nonetheless, (1) the actual negotiations within the GA and its $6^{\text {th }}$ Committee (dealing with legal issues), convened as a Working Group of the Whole (WG) from 1996-1997, as well (2) the final voting on the IWC, since this is where politics enters the stage and the political positions of the UN members are most clearly revealed.

Upon receiving the draft articles from the ILC, the UNGA decided on December $9^{\text {th }} 1994$ to pass the matter to the $6^{\text {th }}$ (Legal) Committee through resolution 49/52, which would then convene as a Working Group of the Whole (WG) at its $51^{\text {st }}$ session, open to UN members states and those of specialized agencies (UNGA, 1994; a second session was later recommended, c.f. UNGA, 1996b). The WG then carried out these two sessions in October 1996 and March/April 1997 and issued reports A/51/624 (UNGA, 1996a) and A/51/869 (UNGA, 1997a), respectively; the latter contained the final text recommendations, which were later to be adopted as the International Watercourses Convention by the GA. While most of the draft articles remained almost unchanged throughout the negotiation process, the final convention thus resembling the preparatory work of the ILC to a high extent, some clauses received very detailed attention and were modified significantly, in particular Article 7 regarding the principle not to cause significant harm (MCCAFFREY, 2008a).

In addition to the negotiations in the WG of the GA $6^{\text {th }}$ Committee, the voting on the elaborated convention text, as well as the explanation of several countries with regard to their vote, give final clues as to the key players/countries and important groups. When the final text of the IWC was considered and, in the end, adopted by the General Assembly on $21^{\text {st }}$ May 1997 (UNGA, 1997b), all present countries cast their votes; upon request of Turkey, the modality was a recorded vote, resulting in the following voting pattern (SCHROEDER-WILDBERG, 2002):

In favor: 103 (incl. Bangladesh, Czech Rep., Greece, Hungary, Mexico, NL, Portugal, Slovakia, Sudan, Syria, USA)

Abstentions: 27 (incl. Egypt, Ethiopia, France, India, Israel, Rwanda, Spain) Against: 3 (Burundi, China, Turkey)

Absent: 33

The voting pattern can begin to elucidate the pro- and veto-coalitions within the UN General Assembly with regard to the IWC, with China and Turkey as powerful upstream countries clearly opposed to the Convention. A further analysis of the pre-negotiations and 
within the UN GA $6^{\text {th }}$ Committee and its working group shows the positions of the most important nation states and their preferences even more clearly (Table 6).

Table 6

Most important countries participating in GA and GA $6^{\text {th }}$ Committee

Source

Schroeder-Wildberg, 2002 (added color-coding)

\begin{tabular}{|c|c|c|c|c|c|}
\hline \multirow[b]{2}{*}{ Country } & \multirow{2}{*}{$\begin{array}{l}\text { Rip. } \\
\text { Pos. }\end{array}$} & \multirow[b]{2}{*}{ Watercourse(s) } & \multicolumn{3}{|c|}{ Voting pattern (topic; forum) } \\
\hline & & & $\begin{array}{l}\text { Art. 5-7; } \\
\text { WG }\end{array}$ & all; WG & all; GA \\
\hline Bangladesh & Down & Ganges & in favor & in favor & in favor \\
\hline Egypt & Down & Nile & abstaining & Abstaining & Abstaining \\
\hline Greece & Down & Several & abstaining & in favor & in favor \\
\hline Hungary & Down & Danube & in favor & in favor & in favor \\
\hline Iraq & Down & Euphrates-Tigris & in favor & in favor & ---- \\
\hline Mexico & Down & $\begin{array}{l}\text { Colorado/ Rio } \\
\text { Grande }\end{array}$ & in favor & in favor & in favor \\
\hline Netherlands & Down & Rhine & in favor & in favor & in favor \\
\hline Portugal & Down & e.g. Tejo & in favor & in favor & in favor \\
\hline Syria & Down & Euphrates-Tigris & in favor & in favor & in favor \\
\hline Canada & Both & $\begin{array}{l}\text { Great Lakes/ } \\
\text { Mississippi }\end{array}$ & in favor & in favor & in favor \\
\hline Finland & Both & Several & in favor & in favor & in favor \\
\hline Germany & Both & $\begin{array}{l}\text { Rhine/ Danube/ } \\
\text { Elbe }\end{array}$ & in favor & in favor & in favor \\
\hline USA & Both & $\begin{array}{l}\text { Colorado/ } \\
\text { Mississippi }\end{array}$ & in favor & in favor & in favor \\
\hline South Africa & Both & $\begin{array}{l}\text { Lower Orange } \\
\text { River }\end{array}$ & abstaining & in favor & in favor \\
\hline Brazil & Both & Paraná/ Amazon & in favor & in favor & in favor \\
\hline Israel & Both & Jordan & in favor & Abstaining & Abstaining \\
\hline Burundi & Up & Nile & --- & --- & Against \\
\hline China & Up & Mekong/ Amur & against & Against & Against \\
\hline Czech Rep. & Up & Elbe & abstaining & in favor & in favor \\
\hline Ethiopia & Up & Nile & abstaining & in favor & Abstaining \\
\hline France & Up & Rhine & against & Against & Abstaining \\
\hline India & Up & Indus/ Ganges & abstaining & Abstaining & Abstaining \\
\hline Slovakia & Up & Danube & abstaining & Abstaining & in favor \\
\hline Spain & Up & e.g. Tejo & abstaining & Abstaining & Abstaining \\
\hline Switzerland & Up & Rhine/ Po & in favor & in favor & ---- \\
\hline Tanzania & Up & Nile & against & Abstaining & Abstaining \\
\hline Turkey & Up & Euphrates-Tigris & against & Against & Against \\
\hline
\end{tabular}


The author of the above table concludes generally that "[...] the riparian position of a country along a river is the main factor determining the international positioning of states but that other factors of political, economic or historical nature also play a role in certain cases" (SCHROEDER-WILDBERG, 2002, p. 35). In short, upstream countries tend to favor either a weak or non-existing regulation on transboundary freshwater courses since this gives them the liberty to use them more freely without paying too much attention to negative externalities caused by pollution through industry for the downstream countries; downstream countries, in turn, favor strong regulation and pushed the IWC process to conclusion along with some mixed-motive countries, which are both down- and upstream with regard to different water courses.

\subsection{The IWC Regime: Rules, Norms and Transboundary Water Governance}

The long process of codification efforts in the area of transboundary freshwater finally culminated in the adoption of the International Watercourses Convention (IWC) in 1997, whose content and provisions sit at the center of the transboundary freshwater regulation regime at the global level ${ }^{70}$. Stephen McCaffrey $(2008 \mathrm{~b}$, p. 1), the second of ILC's five socalled Special Rapporteurs for the Law on the Non-Navigational Uses of International Watercourses, clarifies this by underscoring that it "[...] is the only treaty governing shared freshwater resources that is of universal applicability. It is a framework convention, in the sense that it provides a framework of principles and rules that may be applied and adjusted to suit the characteristics of particular international watercourses". In the following, the treaty text of the IWC regime will be analyzed, highlighting its key provisions, in the form that they resulted from the negotiation process within the GA $6^{\text {th }}$ Committee and its WG (see above for the negotiation dynamics).

The final version of the treaty is composed of a preamble, a main body of 37 articles, which are divided into seven main parts (I: Introduction; II: General Principles; III: Planned Measures; IV: Protection, Preservation and Management; V: Harmful Conditions and Emergency Situations; VI: Miscellaneous Provisions; and VII: Final Clauses), as well as an annex of another 14 articles regarding arbitration. While not all articles and parts are

\footnotetext{
${ }^{70}$ As mentioned before, it does not replace local, bilateral or regional agreements and institutions; rather, it is intended to function as part of a multi-level governance structure.
} 
equally important, a quick overview of each section is due, in particular with regard to environmental considerations, before a more restricted analysis of the main clauses and key provisions.

The preamble sets the tone for the rest of the convention text and makes references to the origins of the process as well as to its motivations and its place in global governance. Three elements deserve particular attention. Firstly, the reference to Article 13, paragraph 1 (a) ${ }^{71}$ of the UN Charter as well as its connection to Articles 1 and 2 of the Charter, legitimizes the IWC process, which started from an impetus from within the UN system and was catalyzed by the work of the ILC before the multilateral negotiations. Secondly, the preamble features important environmental concerns by specifically mentioning pollution as a key threat (along with increasing demands) to international watercourses, and by making clear its conviction that the IWC will strengthen the "[...] conservation"[,]...protection of international watercourses and the promotion of the optimal and sustainable utilization thereof for present and future generations" (IWC, 1997, preamble). Despite not being an environmental treaty per se and without featuring the discernible role of environmental activists in the IWC process, the preamble does contain significant ecological concerns in stark contrast to previous regulation attempts at the global and many regional freshwater agreements. Thirdly, and finally, it is important to point out that the preamble relates to the general treatment of freshwater and related developmental topics on the international agenda. However, it is very selective in doing so by only pointing to the role of developing countries and their special needs as established at the 1992 Earth Summit in the Rio Declaration as well as Agenda 21 (see chapter II analysis of this conference and its relation to freshwater issues). This referencing of a single event is understandable when bearing mind that the IWC originated from within the UN system, for which the 1992 UNCED was a key event, as well as the fact that the 1991 and 1994 ILC draft articles and the negotiations in 1996-1997 were only a few years after said event and probably still highly under its influence and repercussions at many levels.

As expected due to its introductory label, most of Part I is dedicated to delimiting the scope of the convention (specifically excluding navigation), vital definitions, its relation to previous watercourses agreements as well as issues of membership to such agreements. It

\footnotetext{
71 Article 13, paragraph 1 (a) provides that "the General Assembly shall initiate studies and make recommendations for the purpose of encouraging the progressive development of international law and its codification"; the alluded Articles 1 and 2 refer to the UN goals.
} 
its worth pointing out that watercourse is defined in Article 2 (a) as "[...] a system of surface waters and ground waters constituting by virtue of their physical relationship a unitary whole and normally flowing into a common terminus" (IWC, 1997); hereby it includes not just rivers and lakes but also non-confined groundwater, which according to McCaffrey (2008a) covers the majority of the world's groundwater, although this has been questions subsequently by other authors.

With regard to previously existing and future watercourse agreements between riparian states, Article 3 - especially paragraphs one through three - sets out interesting provisions. While on the one hand stating that it intends to leave previous watercourse agreements intact and untouched (par.1), it immediately qualifies this by asking the concerned riparian states to potentially harmonize these agreements with the basic principles of the IWC (par.2). Finally, it opens possibilities of subsequent watercourse treaties to the contracting parties, by which the provisions of the IWC could again be adjusted and adapted in accordance with the special features of particular watercourse realities. What is important to keep from this section is that, despite the framework character, which sets out guiding principles, no specific hierarchy is established between these agreements and the IWC. They can potentially affect each other and their respective provisions can turn out to outweigh either the convention's provisions (in future cases) or vice-versa (in the case of existing ones), thus providing a flexible and dynamic structure.

The third part of the conventions contains its general principles and, thus, consists of the heart of the watercourses regime, establishing the central norms, rights and duties of the contracting parties. While the general obligation to cooperate in good faith (Art. 8) and regular exchange of data and information (Art.9), which form the most fundamental base upon which any cooperation in this issue rests, are pretty much self-explicatory and standard provisions, articles five through seven are widely considered the cornerstones of the convention (MCCAFFREY, 2008a) and require further analysis and commentary.

As already mentioned in the section on the origins and negotiations of the IWC (see above), these articles also proved to be the most contentious ones and featured heated arguments and, in particular with regard to Art. 7, significant alterations to the $1994 \mathrm{draft}$ articles of the ILC. In Article 5, the principle of equitable and reasonable utilization as well as participation is introduced, stating that the respective riparian states of a particular watercourse should use and develop it "with a view to attaining optimal and sustainable 
utilization thereof and benefits there from, taking into account the interests of the watercourse States concerned" (par. 1). The following paragraph then strengthens the overarching cornerstone principle by adding the innovative dimension of equitable and reasonable manner, including " [...] both the right to utilize the watercourse and the duty to cooperate in the protection and development thereof" (par. 2). To this effect, Article 6 provides an indicative, non-exhaustive list of factors to consider in such a judgment; for the sake of our research matter, it should be noted that environmental and social concerns are mentioned explicitly right at the top in points (a) and (b) as well as (f), thereby once again paying testimony/testament/due to the more holistic treatment of the freshwater topic by including these "softer" dimensions. Article 7 is then devoted to the no-harm-principle, the second most important element of the IWC, which requires that in their use of a particular watercourse the concerned states should "[...] take all appropriate measures to prevent the causing of significant harm to other watercourse States" (par. 1). If, however, significant harm is caused by a state's actions, the next paragraph further elaborates that the responsible state shall "[...] take all appropriate measures, having due regard for the provisions of articles 5 and 6 , in consultation with the affected State, to eliminate or mitigate such harm and, where appropriate, to discuss the questions of compensation" (par. 2). From their content and from the preceding negotiations, it becomes clear that the noharm principle is mainly a defensive one, thus practically favoring downstream (or midstream) countries vis-à-vis upstream countries; whereas the latter generally prefer the equitable and reasonable utilization norm from which they derive the highest expectation of freedom in their use of the watercourse resources. The final text of the IWC represents a somewhat mid-way meeting between both of these positions and preferences by including both principles without an explicit ${ }^{72}$ priority of one over the other. Rather, as McCaffrey (2008a) sees this as a success of the IWC when he underscores, "this compromise language reflects the reality that the two principles are not actually at odds with each other but are in fact complementary, with equitable utilization serving as the overarching principle". On the other hand, Schroeder-Wildberg (2002, p. 46) reaches the conclusion that this compromise in the IWC “[...] does not represent a final solution because possibly conflicts about transboundary watercourses have not been successfully resolved by the text.

\footnotetext{
${ }^{72}$ Both principles are in fact intertwined but mutually dependent; however, they are still not fully at equal importance, as the next quote shows, since the principle of equitable utilization is implicitly regarded as the broader, more encompassing principle. This slightly higher status of the principle in Article 5 can also be seen in the International Court of Justice's (ICJ) exclusively reference to it in the Gabcikovo-Nagymaros case, while not making an equal motion for the no-harm principle (see section 2.4).
} 
However, ambiguity was the key to its success since the states would most probably not have adopted an unambiguous solution". When bringing both these judgments together, one can state that, one the one hand, the compromise inherent in the reformulation of Article 5 and 7 might not have been enough to provide a lasting international norm set in stone; however, on the other, this midway meeting of the two opposing positions seems to have been the only feasible political solution at all at the time and that the conclusion of the IWC with these clauses can be seen as substantive progress.

Finally, a last important provision of Part II is found in Article 10, which posits that "no use of an international watercourse enjoys inherent priority over other uses" (par. 1) but, once again, this presumed parity is slight broken in the following, since the same article also requests that in case of conflicts of uses "[...] special regard [be] given to the requirements of vital human needs" (par.2). This is another important reference to the general freshwater debates on the international agenda, in that it signals certain minimum human standards, which are to be given absolute priority. Although using a different language and terminology, this paragraph basically refers to what would later become the human right to water ${ }^{73}$.

Part III goes into detail regarding planned measures on a watercourse and the obligations, rights and duties of the respective riparians for these cases. In so doing, it makes the two core principles of the conventions more concrete by translating them into a usage manual with regard to specific planned activities; for this reason, it refers back to the principles of equitable utilization and that of no-harm in the Articles 15, 16, 17 and 19. It is the longest and most detailed part with 9 articles; however, its main logic and structure of its clauses is not very complex and can be analyzed relatively quickly.

In summary, these articles require states to notify the other and exchange information with regard to action they are planning to undertake on a specific watercourse that could cause significant harm, consult with each other considering their effects and, in the last instance, begin negotiations on the matter if no previous agreement can be achieved (Articles 11; 12; 15 and 16). Specific timeframes are given for these steps, mostly consisting of a six months period (Articles 13; 17, par. 3; 18, par.3), during which no further advancement of the measures should be carried out in order to enable mutual appreciation of the situation

\footnotetext{
${ }^{73}$ See the later discussion on the human right to water as an important norm in the emerging freshwater regime complex.
} 
or negotiations (Articles 14; 17, par. 3; 18, par. 3); the exception from these rules, namely urgent measures, is laid down in Article 19, which allows for immediate advancement if accompanied by equally immediate notification and start of consultations and/or negotiations. It is important to underline that these provisions do not represent a veto-right for the affected states (MCCAFFREY, 2008a), thus allowing the upstream states considerable freedom in their equitable utilization of the transboundary waters; at the same time, the obligations for notification, consultation and eventually negotiations, if necessary, raises the costs of unilateral action, does limit their freedoms and protects the downstream states from significant harm without compensation for most cases.

The fourth part is entitled "Protection, Preservation and Management" and entails important provisions with regard to environmental considerations. As the second longest part with its seven articles, it elaborates in more detail on specific environmental matters such as the protection and preservation of ecosystems (Art. 20), prevention, reduction and control of pollution (Art. 21), the prevention of introducing alien or new species (Art. 22) and the general protection and preservation of the marine environment (Art. 23). By singling out these important issues, the convention goes beyond merely paying lip service to environmental debates and expectations; it establishes clear guidelines and thus features a strong environmental dimension, aware of the fact that the proper functioning of the transboundary water ecosystems is fundamental to most other uses and derivable benefits. Even Article 24 with the less obviously "soft" title "Management" defined the latter from an environmental and social point of view in line with the 1992 UNCED concept of sustainable development; Articles 25 and 26 deal with flow regulation and the maintenance of installations along the watercourse, respectively. As is explicitly mentioned in almost all of these clauses, the link of these environmental concerns is very strong with the principle of no-harm, and in line with the interests of downstream countries as well as environmentalists. At the same time, all of these clauses basically remained untouched during negotiations and reflected the original ILC drafts, therefore showing that these provisions and clauses are internationally accepted to a very high degree.

Parts V (2 articles on human and natural disasters), VI (5 miscellaneous provisions), VII (4 clauses regarding legal status and entry into force) as well as the annex (14 articles on arbitration) are directed at specific conditions, exceptions and legal issues regarding the convention and thus, for the most part, do not entail anymore key provisions. The most 
important exception is found in Part VI, where Article 33 deals with dispute settlement. Composed of ten paragraphs, it is the most detailed article of the convention and establishes procedures in the case of enduring conflict between riparians over the application of the IWC, such as negotiations, mediation or conciliation by a third party or joint institutions and/or submitting the dispute to arbitration (further elaborated on in the annex) or the International Court of Justice (ICJ) (par. 1-2). Paragraphs three through nine cover the case of lacking success of the previous measures and introduces a process of impartial compulsory fact-finding through a small commission, which McCarthy (2008a) praises as a significant innovation of the convention in so far as it is a means to reconcile the involved parties before the conflicts reach a stage of being nearly irresolvable.

From this textual analysis of the final written IWC, it can be seen that the transboundary water regime is indeed based upon an extremely wide-reaching convention, codifying the most important principles (equitable utilization; no-harm) of hitherto customary into formal international law and dealing with a broad array of topics, with substantial attention to environmental concerns. Having said that, it does not cover all aspects of the freshwater umbrella topic; on the supply side, confined groundwater is not covered by the IWC and many aspects are only hinted at (e.g. ecosystem protection), whereas on the demand/uses side, some are even omitted almost entirely (e.g. access to freshwater and sanitation ${ }^{74}$ ). All in all, it does represent the most advanced and far-reaching regulation effort with regard to international freshwater.

\subsection{Evolution, Further developments and Current State}

After the long period of several decades of evaluation within the UN, elaboration of draft articles by the ILC and, finally, negotiations within the GA $6^{\text {th }}$ Committee, the influence of the IWC remained unclear for quite some time. With regard to coming into effect, Article 36, paragraph 1 of the convention states that "the present Convention shall enter into force on the ninetieth day following the date of deposit of the thirty-fifth instrument of ratification, acceptance, approval or accession with the Secretary-General of the United Nations" (IWC, 1997), therefore requiring 35 countries to agree to its terms. From $21^{\text {st }}$

\footnotetext{
${ }^{74}$ These are only covered very indirectly under the notion of "vital human needs" in Part II, Article 10, paragraph 2.
} 
May 1997 until 20 $0^{\text {th }}$ May 2000, the IWC was opened for signature (c.f. Article 34) and 17 countries did so before the end of this period. However, this deadline is somewhat of symbolic nature since non-signatory countries can later accede to the convention indefinitely (SCHROEDER-WILDBERG, 2002; TANZI, 2000). This has in fact been the case and to date (March, 2015), the IWC process has completed the necessary 35 countries requested by Article 36, par. 1, with the ratification by Ivory Coast on $25^{\text {th }}$ February 2014 and the accession by Vietnam on the $19^{\text {th }}$ May 2014 (IWLP, 2015). After the procedurally required 90 days, the International Watercourses Convention entered into force on $17^{\text {th }}$ August 2014 and has now turned from soft law into binding international hard law, almost two decades after its adoption in the UNGA.

Even during its phase of soft law status, both IR as well as legal scholars have analyzed its influence at the global level. Conca et al (2006, p. 280) concentrate on the convention's impact in terms of how its key principles are or become reflected at basin-levelagreements, obtaining mixed results; however, their results come with the caveat that the IWC is relatively young in comparison to the long process of norm development in the area generally and they acknowledge that "these principles may yet take root at the basin level". From a legal point of view, McCaffrey (2008b) refers to the significant influence of the convention, which can be derived from the fact that only few months after the adoption of the IWC, the International Court of Justice (ICJ) directly cited from it, especially with regard to the principle of equitable utilization contained in Article 5, in its judgment of the Gabcikovo-Nagymaros case. Furthermore, McCaffrey (2008a) points to some more recent watercourse agreements, on which the IWC and its ILC draft article forerunners have had a clearly discernible influence, including the Agreement on the Cooperation for the Sustainable Development of the Mekong River Basin of 1995, the Revised Protocol on Shared Watercourses of the Southern African Development Community (SADC) of 2000 and the Senegal Water Charter of 2002. Thus, even while still at the level of soft law, the convention can be regarded as having been more or less influential, depending on the aspect under analysis, but with its entering into force in 2014 it is very likely to play an increasingly more influential role globally. 


\subsection{Summary}

The analysis of the IWC process has identified five main stages: (1) its early beginnings from within the UN system in 1959 and 1963 until the early 1970s; (2) the work of the ILC, starting in 1974 and resulting in the 1991 preliminary as well as the 1994 final draft articles; (3) the return of these draft articles to the UNGA and the negotiations therein from 1996-1997; (4) the adoption of the IWC in the UNGA in 1997 and the subsequent period as important source of soft law; and, finally, (5) the entering into force of the convention in 2014, turning it into formal, hard law. This segregated process has implications with regard to the use and control of important agenda access points.

In contrast to the Ramsar case, the IWC process is not characterized by a bottom-up approach from several key members of an epistemic community or NGOs of specific countries but is rather IGO-driven, as it originates from within the realm of the UN. However, once this process is ignited, it is passed on to the International Law Commission, which then acts as a driver and catalyst by producing an almost complete convention in the form of draft articles based on state practice, customary law and input from the countries as well as legal sources. For this stage, the work of the IWC's special rapporteurs - Richard D. Kearney, Stephen M. Schwebel, Jens Evensen, Stephen McCaffrey, and Robert Rosenstock - is of utmost importance in advancing the process, particularly McCaffrey, for the crucial period of producing the first set of draft articles, as well as Rosenstock, for the period of the second draft articles and for participating as a catalyst in the final negotiations in the UNGA $6^{\text {th }}$ Committee. Yet, however positively influential these key figures might have been, they are far from being as central to the IWC as the founding fathers of the Ramsar Convention were to its respective process. The latter acted as "policy entrepreneurs", who not only managed the negotiations and the elaboration of the convention from a legal and managerial perspective but also were key experts and renowned scholars with a direct link to the bottom-up approach and in charge of important NGOs in the field who would directly impact on the implementation and observation of the convention. While of course bearing in mind the focus on states' practice, it still must be stressed that after the UNGA referral to the ILC, this process until 1994 was driven almost exclusively ${ }^{75}$ by legal experts and, thus, it represents a strong contrast to the bottom-up,

\footnotetext{
75 There was additional feedback from the UN member states on a 1974 report of the Subcommittee (A/CN.4.283) as well as on preliminary set of draft articles of 1991 (A/CN.4/L.458) but this was not directly
} 
scientific and activist based-approach of the Ramsar Convention, which included legal and political actors only at the middle and later stages of the process. As such, the initial period which put the IWC process in motion was concentrated on the interstate dimension of diplomatic norms, mostly the principles of law, but not drawn up and championed by a specific country or group of activists but rather from within the UN as an intergovernmental organization, which equally served as the important institutional locus for it.

Furthermore, as tends to be the case with these kinds of UN processes, but also for more broader and encompassing projects, the IWC project developed over the chronological scope of several decades; from the very first UN reports in 1959 and 1963 until the entering into force of the convention itself in 2014, it took more than 50 years ${ }^{76}$. Compared to the Ramsar process, which developed for around 15 years from the beginning until the entering into force of its Convention, the IWC took over three times as long. Particularly outstanding is the fact that the process of draft article elaboration by the ILC lasted at least five years longer than the entire Ramsar process. Apart from the greater depth and degree of holistic treatment of freshwater resources, this can quite likely be attributed to the underlying stronger conflict potential between groups of countries, particularly the said dichotomy of up- and downstream countries. Once this process was jumpstarted and put into the UN's institutional framework with assistance of the ILC, no further agenda control or use of agenda access points was necessary to keep it going. However, the interest and influence of a "political entrepreneur" (as in the case of the founding fathers of the Ramsar Convention; here, for example in the figure of the Secretary General of the UN or likewise important individuals) might have sped up the process along the way.

In terms of the main players and countries, there is also a stark difference to be noted when compared to the Ramsar convention. Whereas in the case of the latter cooperation seems more clear-cut from the beginning and a general consensus was achieved rather quickly in the form of a binding treaty and, later, additional structures and finance, the IWC negotiations reveal a stronger political rift between clearly identifiable veto- and pro-

introduced into the drafts but rather mediated by the work of the ILC, unlike the later negotiations of the working group of the GA.

${ }^{76}$ However, it must be said once more that before this latter step was finally achieved in 2014, the IWC - and even the draft articles it was based upon - has already played an important international role as soft law. 
groups $^{77}$ in the form of up- and downstream (together with environmentally-minded) countries respectively. Prominent representatives of the upstream states were Turkey, China, France but also Ethiopia, the Czech Republic and Burundi (at least in the final voting), whereas the most important downstream contributions and voicing came from Egypt, Hungary and Portugal. In addition, the negotiations featured several mixed motive countries (such as Canada, USA, Germany) that do not fall easily into either one of these dichotomies in terms of their negotiation behavior and support of the IWC. While Schroeder-Wildberg's in-depth analysis of the negotiations has revealed that this division into up- and downstream countries is too simplistic to cover all aspects regarding the respective countries' positions over certain clauses and issues, one can nonetheless see this factor as the far most important one, while bearing further political, military, historical and economic reasons in mind with regard to a few exceptions, most notably the role of Egypt and - to a lesser extent - Syria and Iraq.

Despite these different processes and scopes in terms of subject matter, both conventions share the common link with the freshwater umbrella topic, which goes beyond the more narrowly regulated matter of the two respective treaties. Additionally, their rules, norms, obligations and duties overlap to a certain extent, most clearly for international rivers connected to wetlands. It is this overlap and the potential application of either one of these bodies of international water law to specific cases within and between the contracting parties, which gives way to treating the dealing of freshwater on the international agenda, mostly clearly in the form of these two conventions, as an emerging regime complex as is discussed in more detail in the next section.

\footnotetext{
77 This term avoids the use of the word "coalition", since one of the final conclusions of an earlier comprehensive study of the negotiations (SCHROEDER-WILDBERG, 2002) was that there were no open pro- or veto-coalitions as such. However, it is insisted here on this broad two-fold division of the negotiating countries since it clearly reflects their underlying priorities and preferences. Furthermore, due to lack of access on internal diplomatic documents of the respective countries in those groups for the time being, it is not possible to fully exclude the explicit coalition-building; implicit coalition behavior based on common preferences is even quite likely without the need to formally discuss and even fix this in any form of agreement between the members of each of these broader groups.
} 
This section brings the analyses of the previous chapter together with the conclusions regard the two conventions and their ensuing regimes. It follows the three-step overall logic of this thesis. In the first place, the emergence of the freshwater topic in the format of both conferences and conventions is brought together in view of evaluating the first, more cursory hypothesis. The second and third steps then consist of analyzing the interaction and interplay between the two conventions and their regimes in order to assess the possible formation of a freshwater regime complex; particular attention is paid to the origins and emergence of this global governance structure so as to assess the second and central hypothesis of this thesis.

\subsection{Freshwater Related (Sub-)Regimes on the International Agenda}

Summarizing the above, one can state that the Ramsar Convention and the IWC played an important part in the emergence of the water topic on the international agenda, but in very different ways. The preparation and negotiating processes leading to both these conventions date back to the $1960 \mathrm{~s}^{78}$ but both sub-topics surfaced on the international agenda at different points in time (the early 1970s and the late 1990s respectively). Additionally, both were dealt with in separate forums, featured different important actors and, more generally, consist of different types of processes.

On the one side, the protection of wetlands was an issue pushed for initially by European epistemic communities (mainly ornithological circles from the UK and the Netherlands) and NGOs, outside of a global institution and from the concerned people dealing directly at the grassroots level with challenges, thus a bottom-up process. In its development, this process only became institutional at a later stage when the newly established norms and rules were crystalized into an international agreement with its own bodies responsible for its oversight and further development as of the 1970s. At the time of the conclusion of the

\footnotetext{
${ }^{78}$ It is important to note that both processes that led to conventions on freshwater sub-topics began before the 1972 UN Conference on the Human Environment (UNCED), which is generally perceived to be the key moment of emergence for environmental topics on the international agenda (see for example, O'NEILL, 2009). While the Ramsar negation process was also concluded one year before UNCED took place, the IWC was only established nearly 30 years later.
} 
IWC negotiation process and the signing of respective convention in 1997, the Ramsar process had grown from the 18 signatories, showing strong international interest and progress in scope.

This contrasts with the IWC process, on the other side, which from the onset was undertaken from within the realm of the UN and thus IGO-driven. The UN General Assembly authorized the ILC in the 1970s to begin working on the development of draft principles on the matter with the aim of establishing a convention in the mid to long run. The fact that this process was very slow and only led to a global agreement in the later 1990s is a sign of/statement/testimony of its institutional nature but also to the strong opposing of veto and pro-groups, principally upstream versus downstream (plus environmentally-minded) countries. The latter is also reflected in the slow ratification processes in the different countries after the formal signing of the IWC, which only recently entered into force in late 2014 and thus shows a continuing division. Table 7 sums up the most important dimensions of this comparison between the two processes/(sub-) regimes.

Table 7

Summary of the Ramsar and IWC processes/(sub-)regimes Source

Elaborated by the author

\begin{tabular}{|l|c|c|}
\cline { 2 - 3 } \multicolumn{1}{c|}{} & \multicolumn{1}{c|}{ Ramsar } & \multicolumn{1}{c|}{ IWC } \\
\hline (Sub-)Issue & Wetlands & International Watercourses \\
\hline Origins & Early 1960s & 1959,1963 \\
\hline Convention & 1971 & 1997 \\
\hline Entry into Force & 1975 & 51-55 years \\
\hline $\begin{array}{l}\text { Total Duration } \\
\text { of Process }\end{array}$ & 15 years & $\begin{array}{l}\text { IGO-driven from within the UN } \\
\text { bottom-up process; (European) } \\
\text { epistemic communities, } \\
\text { ornithologists; NGOs; "political } \\
\text { entrepreneurs"; broader } \\
\text { consensus; quick development }\end{array}$ \\
\hline $\begin{array}{l}\text { Main } \\
\text { Characteristics } \\
\text { and Drivers }\end{array}$ & $\begin{array}{l}\text { system, legal experts as catalysts } \\
\text { and drivers; intense negotiations; } \\
\text { smaller consensus; slow } \\
\text { development }\end{array}$ \\
\hline
\end{tabular}

By bringing together the analyses and results of chapter II with the information contained in Table 7, one can also begin to more fully evaluate the first cursory hypothesis 
concerning the possible regime formation with regard to freshwater, set out in the methodological section of chapter II. Based on the problem-structural-approach to regime formation, advocated by Rittberger et al (1993), it was hypothesized that issues, which are characterized by consensual conflict and which concern absolutely assessed goods, have a high propensity for regime formation. Due to strong parallels between the topics of food and of freshwater and, thus, its classification as an issue of consensual conflict regarding an absolutely assessed good, this hypothesis boiled down to the theoretical expectation that this topic should also show a high propensity for regime formation, i.e. rather quick development of a regime concerning these resources. When considering the deeper analysis of the various conferences as well as the Ramsar and IWC conventions, it becomes clear that during the emergence period, no such encompassing, overarching freshwater regime has been established, as was already indicated at the outset of the study in a more superficial analysis of Table 1 (see Introduction).

While the Ramsar process has in fact led to a very successful regime within a reasonably short period of time of only 15 years, this is confined to the sub-issue of wetlands and does not relate to a great many other sub-issues of the overarching freshwater topic; it thus represents a sub-regime. The IWC process already presents a more complicated case. While it is a lot broader and more encompassing, it still leaves out some aspects of the freshwater umbrella topic and can thus only be considered another partial or sub-regime, although far closer to a truly holistic freshwater regime than in the case of Ramsar. At the same time, its extremely long development process as well as the persisting divide between up- and downstream (plus environmentally-minded) countries, shows that even as a subtopic, it does not feature a high-propensity for regime formation and was only concluded after some 50 years. In contrast to other regimes that follow the framework-protocolapproach in the order of its label, such as in the case of the protection of the ozone layer (Vienna Convention, 1985/88 ${ }^{79}$; Montreal Protocol, 1987/89) or climate change (UNFCC, 1992/1994; Kyoto Protocol, 1997/2005), the IWC was established as a framework convention at the global level at a time where a great amount of bi-, tri-lateral and plurilateral agreements concerning international watercourses had already been put into place in many parts of the world. Furthermore, future meetings of the contracting parties (COPs) were not envisioned in the IWC process and no additional protocol has been created. Therefore, its nature is somewhat different to those of other framework

\footnotetext{
${ }^{79}$ The two numbers refer to the dates of agreement and of entry into force to the respective treaties.
} 
conventions and it presents a less clear-cut version of a regime. Conca et al's (2006, p. 263) analysis of the principle content of international river agreements ultimately leads them to state that "if joint articulation of common principles is necessary for regime formation, then there is only weak evidence for a global rivers regime"; however, this extremely decisive conclusion is based on the analysis of a group as big as nine principles, which the authors perceive as the main provisions of the IWC. This number is far greater than those mentioned by other scholars and experts, who usually consider three ${ }^{80}$ key provisions as being the cornerstones of the IWC and thus the transboundary rivers regime: (1) the principle of equitable and reasonable utilization and participation ${ }^{81}$, (2) the obligation not to cause significant harm, and (3) the principle of prior notification of planned measure. Even in the very high standards considering all these nine principles, Conca et al do find evidence of a global river regime, albeit a weak one. However, if considering only the provisions that are widely accepted as the cornerstones of the convention, the evidence of a global regime for transboundary freshwater resources becomes stronger.

As a result of this assessment, the first hypothesis can therefore not be validated since there is no evidence of a cohesive, overarching freshwater regime during the emergence period of the freshwater topic on the international agenda from the 1970s until the 1990s (and, as a matter of fact, neither after that period when including the information on the entering into force of these conventions). Instead, the analysis has shown and proven that the freshwater topic has largely emerged in a heterogeneous and fragmented way through the treatment of several of its sub-issues, of which some (wetlands and transboundary water bodies) have reached regime-level on their own.

It is interesting to note that the sub-topic of wetlands, rather than the broader freshwater topic itself, follows the logic of the problem-structural-approach quite neatly. In concluding the full process within 15 years and showing a high degree of consensus between the members, the Ramsar process and the sup-topic of wetlands did indeed have a

\footnotetext{
${ }^{80}$ Others go as far as reducing this number to only two principles by omitting or at least downgrading the importance of the principle of prior notification of planned measures. Either way, the provisions regarded as most important almost always range from two to three and in no other case include as many as in the study of Conca et al.

${ }^{81}$ In order to increase the number of principles, one could consider the principle of equitable and reasonable participation as a separate one from the one of utilization; this would add one additional principle. However, the element of participation is best seen as a strengthening of the overarching principle of equitable and reasonable utilization or an addition of another dimension to it.
} 
high propensity for regime creation. On the other hand, the IWC process on its own proved more difficult and only reached conclusion in the sense of entering into force after a more than 50 year period. While it can be considered a regime - or better a sub-regime - in the end, the long period of development and continuing underlying conflict between the contracting parties characterizes a process with low propensity of regime formation, even if ultimately successful. From all of the above, one can conclude that the freshwater umbrella topic does not seem malleable to being treated as one big block because its subissues have differing dynamics that pull in different directions. Global governance in this area does not seem possible - or at least not very likely for the time being - in the same way this has been done for more clearly defined topics such as the protection of the ozone layer.

After the completion of the analysis regarding a cohesive global freshwater regime, which has not materialized as seen above, the empirical data can furthermore be used with a view to determining the relationship between the two sub-regimes, which is the matter of the next section.

\subsection{Emergence of a Freshwater Regime Complex}

After establishing the existence of two individual regimes - one for wetlands (Ramsar) and one for international watercourses (IWC) - the next and final step of this research consists of assessing their relationship. Two main, mutually exclusive scenarios are to be considered: (a) parallel regimes governing distinct aspects of the overall freshwater umbrella topic and/or with mutually exclusive membership; or (b) overlapping regimes, i.e. a freshwater regime complex.

In terms of the chronological dimension, this analysis only makes sense once there are in fact at least two regimes at one given time, since this is the prerequisite for any kind of interference. Therefore, the considered time frame begins at the point when the IWC emerges on the international agenda in the form of draft articles in the early $1990 \mathrm{~s}^{82}-$

\footnotetext{
${ }^{82}$ The exact point in time is of course debatable, one could also prefer for it to be the year of adoption (1997) or even as late as the year of entry into force of the IWC (2014); ultimately however, this is not particularly
} 
since, as seen above, this is the earliest point when the IWC process begins to influence other agreements as well as negotiations, and can thus be regarded to set norms and to start behaving like a regime.

Moreover, there needs to be an overlap in membership of the respective regimes, because otherwise they would merely be parallel institutions, although governing the same issuearea. A quick comparison of the lists of the member states (RAMSAR, 2015b; IWLP, 2015) of both regimes sheds light on this dimension. As early as 1998 and 1999 there was in fact the situation of having dual members: Finland $\left(1975 / 1998^{83}\right)$, South Africa (1975/1998), Syria (1998-1998), Jordan (1977/1999) and Lebanon (1999/1999), to name but a few; this numbers has grown further since the 2000s.

Finally, and most importantly, there must be at least a partial functional overlap between the two regimes, i.e. their norms and rules must be theoretically ${ }^{84}$ applicable to the same matter or object. In order to evaluate this factor, one needs to return to the actual regime norms and rules contained in the two conventions. Since the objective here is to show that there is in fact an overlap, this can be done - in the first place - by going back to the definition of the regulation matter the respective regimes apply to. The starting is the IWC - since it applies to the broader scope of all international watercourses, i.e. rivers, lakes and hydrologically connected groundwater -, which then is compared with the Ramsar case. Bearing in mind the exact definition of wetlands in the convention text as "areas of marsh, fen, peatland or water, whether natural or artificial, permanent or temporary, with water that is static or flowing, fresh, brackish or salt, including areas of marine water the depth of which at low tide does not exceed six metres" (RAMSAR, 1971), one can state that the broad definition of the Ramsar Convention actually does entail not only wetlands in the narrower sense but also applies to connected rivers, lakes and aquifers, i.e. groundwater, since these are implicitly included within "static or flowing waters". The website of the Ramsar Convention further elaborates on this point and makes this fact even more explicit by stating that "the Convention uses a broad definition of wetlands. It includes all lakes and rivers, underground aquifers, swamps and marshes, wet grasslands,

relevant for the overall argument of the existence of two regimes with an overlap as long as it is clear that both do co-exist after some point in time, which is the case here.

${ }^{83}$ The first number refers to the year of membership of the Ramsar regime, the second to that of the IWC.

${ }^{84}$ This condition does not require that the application and conflict of norms actually has to have occurred in practice; mostly this refers to the potential of either applying the rules and norms of regime A or B without clear guidelines over which takes precedence. 
peatlands, oases, estuaries, deltas and tidal flats, mangroves and other coastal areas, coral reefs, and all human-made sites such as fish ponds, rice paddies, reservoirs and salt pans" (RAMSAR, 2015c). In the end, it is somewhat surprising to note that the Ramsar scope is actually wider in terms of the regulation matter of freshwater resources since it is not confined to international waters that cross borders but also within national territories. However, with regard to the international freshwater bodies there is a clear overlap between the two regimes. Secondly, the functional overlap continues with regard to the regimes' rules; here, the more fundamentally environmental character of the Ramsar regime is evident throughout its provisions, thus favoring stricter preservation of the freshwater resources - one could speak of a no-significant harm obligation not towards another state, but rather towards nature itself -, whereas the IWC balances environmental concerns with those of equitable and reasonable utilization by the riparian states. Depending on the choice of which of these rules to apply to a specific international river, lake and/or hydrologically connected groundwater, the functional overlap of norms could become conflictual if there is no agreement on this aspect between the concerned states.

Having demonstrated functional overlap between the two sub-regimes, one can now assert that both are elemental regimes of the overarching freshwater umbrella topic, which in fact co-govern freshwater resources in the form of an emerging regime complex ${ }^{85}$. Figure 4 illustrates this conclusion with regard to the case of freshwater and its place in a regime pyramid, consisting of the poles "no regime", "(cohesive) regime" and, finally, "regime complex.

\footnotetext{
${ }^{85}$ Due to the focus of this thesis on the global treatment of the freshwater topic within its emergence period, the analysis of the freshwater regime complex is still preliminary since it does not include regional or bilateral agreements of the same period nor any sort of regime, institutions or norm established after 1997. There may well be further components of the freshwater regime complex, which require further study of the topic.
} 


\section{Figure 4}

Regime pyramid (red dot $=$ freshwater case)

Source

Elaborated by the author ${ }^{86}$

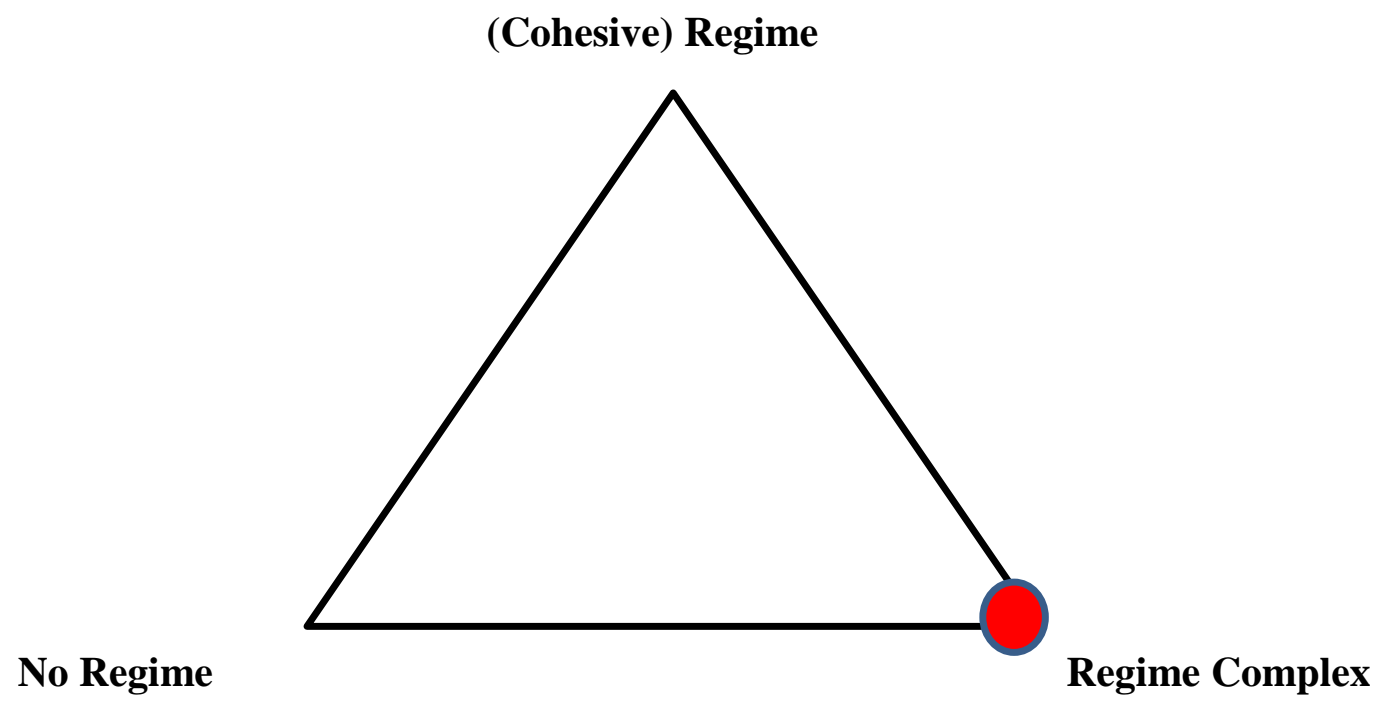

Since the global governance architecture of freshwater resources has not been couched in the terms of the regime complex approach nor analyzed with regard to its parameters, it is opportune to quickly relate it to other cases of regime complexes. Raustiala and Victor (2004, p. 306) have enunciated in their original article that "it might be useful to develop a typology of regime complexes that spans from tightly bound arrangements (for example, chemicals) to the very loose (for example, energy)". Given that the above analysis deals with only two elemental regimes and thus does not represent a very dense and deep regime complex, it makes sense to place it towards the looser end of a spectrum of regime complexes. When taking into the account that the energy regime complex, which Raustiala and Victor place at the loose end of the typology, mainly consists of two elemental regimes as well - namely OPEC and the IEA (c.f. VICTOR et al, 2006), a preliminary classification based on the studied global level and emergence period time frame would indicate a place equally close towards the end of said spectrum (see Figure 5).

\footnotetext{
${ }^{86}$ The author wishes to thank Michael Zürn for discussing ideas about regime formation and regime complexes, especially regarding their representation, at a student workshop at the University of São Paulo in September 2013.
} 
Figure 5

Regime complex spectrum and typology (red dot $=$ freshwater case)

Source

Elaborated by the author based on ideas from Raustiala and Victor (2004)

Tightly-bound

Regime Complex

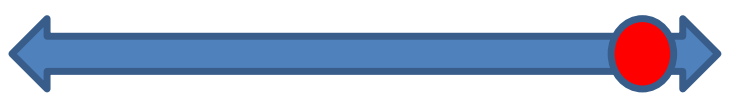

Very Loose

Regime Complex

\subsection{Origins of the Freshwater Regime Complex}

With regard to this emerging, loose regime complex for freshwater resources, a final question arises with regard to its establishment and coming into place. This final analytical step allows for the assessment of the second and central hypothesis of this thesis. Derived from most recent IR scholarship and the newest strand of contemporary regime theory (c.f. MORSE; KEOHANE, 2014; URPELAINEN; VAN DE GRAAF, 2014), it was hypothesized that regime complexes are created for strategic reasons by states that are dissatisfied with the status quo. In order to test whether this expectation holds true for the case of the freshwater, one needs to examine the dynamics of the regime formation of second regime (i.e. the IWC) to see (i) whether there are any clear links to the Ramsar regime and, if the result is positive, (ii) whether these links feature an observable dissatisfaction of a significant group of states with regard to the status quo entailed in it before the creation of the IWC led to the recurrence to the outside option of creation a new institution for strategic reasons. As mentioned in the methodological section of this thesis, a lack of such observations and, therefore, the inexistence of a strong link between the existence of one regime and then establishment of the other, would indicate that the creation of the freshwater regime complex did not occur for strategic reasons - such as weakening the status quo rules and norms of the time before the regime complex and future opportunities of forum shopping and/or regime shifting.

As was laid out in detail in the above sections, the development of the norms and rules of the IWC, first in the form as draft articles and later as the final convention body, did not feature any contact with the Ramsar process. As a matter of fact - and is still the case in large parts of the literature on the emergence of the freshwater topic on the international 
agenda -, both processes were perceived as entirely independent of each other since the Ramsar Convention had acquired the label of a "migratory birds regime". Whereas this was certainly the original intention that initiated the process, a critical but often overseen shift occurred within the development of the Ramsar regime towards wetlands protection for its own sake as well (see section 1.2). As a result, the regulation of the final regime is in fact done through wetlands, which in turn are so broadly defined that the regulations in the end applies to nearly all freshwater bodies, both nationally and internationally. However, this was not considered within the IWC process, which began at a similar point in time but concentrated on the already huge number of agreements explicitly dealing with bi-, tri- and plurilateral regulation of rivers, lakes and aquifers and acquired a dynamic of its own with references to the Ramsar regime.

From this parallel - and later sequential - development of the Ramsar and IWC regimes, which occurred independent of each other, one can conclude that the ensuing functional overlap did not result from strategic reasoning and calculations as has been the case with many other regime complexes. As shown above in Table 7, both processes were indeed characterized by quite different dynamics, dealt with in distinct forums, with varying time frames and driven by diverse actors. Of particular importance is the nature of the IWC regime formation, which was not triggered by the action of specific UN member states but rather from within the more politically neutral UN system and ILC, making it less likely to intentionally undermine the Ramsar process. The resulting functional overlap occurred unintentionally as a side product of the independent regime formations and not because of member states of the Ramsar regime potentially dissatisfied with the status quo. With this conclusion, hypothesis two can also not be validated and this indicates that current models of regime complex emergence are insufficient to explain the freshwater case and possibly require further adaptation to also cover non-intentional processes. Figure 6 visualizes these final results. 


\section{Figure 6}

Regime complex emergence

\section{Source}

Elaborated by the author

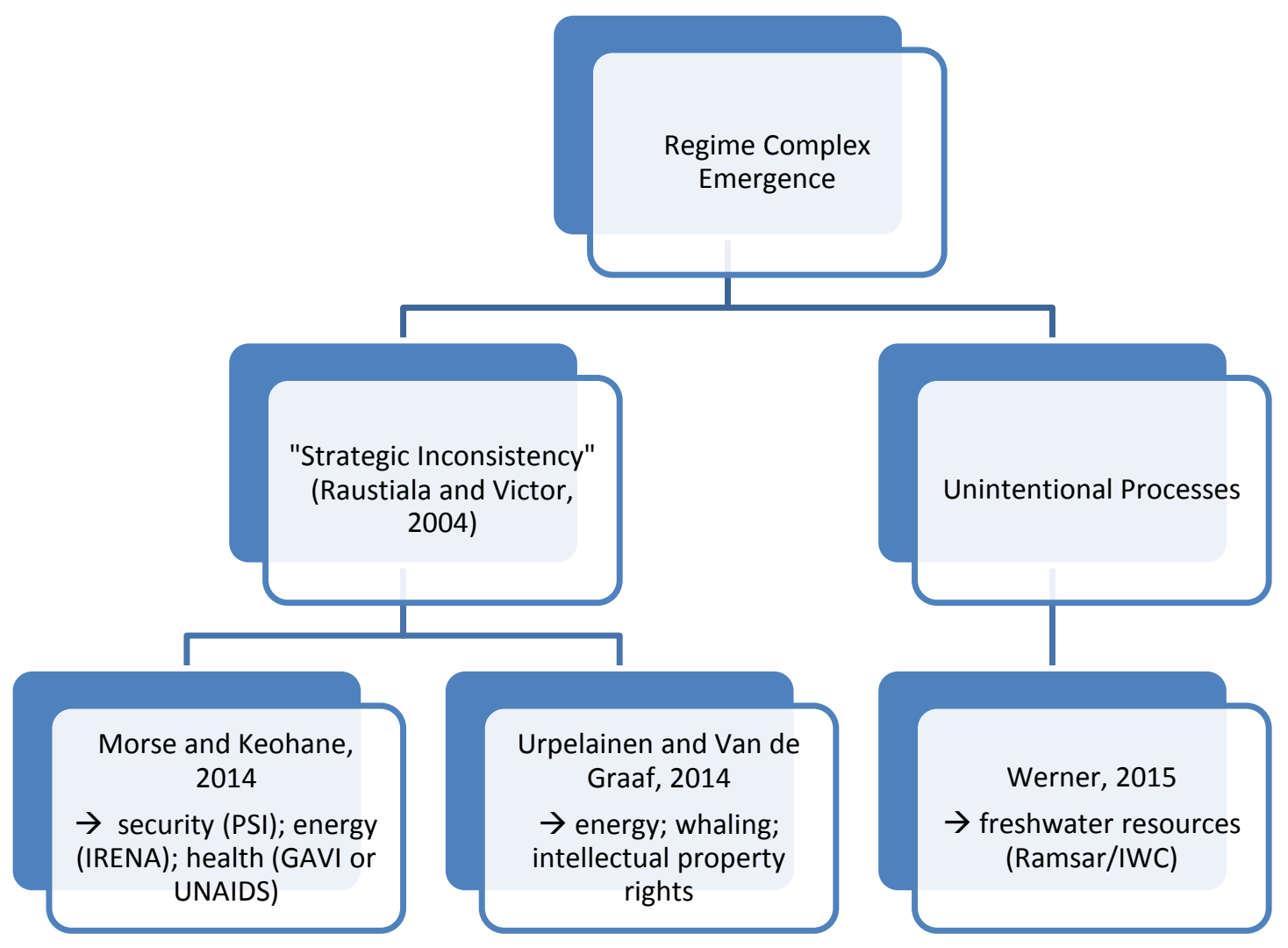

In summary, this chapter has demonstrated the existence of a freshwater regime complex and has argued that its emergence is due to unintentional processes rather than for strategic reasons, thereby challenging current regime theory and IR scholarship on regime complexes. This should not be understood as falsifying these theories and approaches, since they clearly cover a whole range of other issues. Rather, the above analysis has revealed weaknesses and shortcomings of contemporary regime theories as well as adding another case to the array of regime complex examples. The examination of the freshwater regime complex is based on the appreciation of freshwater related events, meetings and conventions of its global emergence period from the early 1970s until the later 1990s, which is enough to demonstrate its existence. However, the regime complex concept can also entail sub-global elements as well as further development after the late 1990s, and thus the conclusions regarding the freshwater regime complex must be seen as preliminary and pave the way for further research in this important field. 


\section{CONCLUSION}

Freshwater resources, dealt with not merely as a means of navigation but more broadly with the consideration of environmental and social aspects, surfaced on the international agenda in the early 1970 s and have since taken up an increasingly important role globally. This thesis shed light on the political constellations and dynamics behind this topic's emergence period from the earliest triggers of the developments in the 1960s (when both the Ramsar and IWC processes originated), over the most important milestone conferences (Mar del Plata, in 1977, as well as Dublin and Rio, both in 1992) until the late 1990s, with the end of the negotiations over the IWC and its formal adoption in the General Assembly.

The thesis has followed a three-step structure: (1) tracing the most important freshwaterrelated conferences and meetings with regard to international agenda setting and the portraying the dispersed emergence of freshwater issues during the above-mentioned period (chapter II); (2) analyzing global regulation efforts in the form of conventions (both Ramsar and IWC) for the same period; (3) establishing the relationship between these two conventions and developing the assessment of an emerging freshwater regime complex, particularly with regards to its origins and establishment (chapter III). This concluding chapter revisits the most important results of the chapter analyses, discusses the major contributions of the thesis and outlines further avenues of research with regard to freshwater, in particular the emerging freshwater regime complex.

The central argument of this thesis is that international cooperation on freshwater resources has resulted in the creation of a freshwater regime complex centered on the two main pillars of the Ramsar and IWC elemental regimes, which in fact overlap in their regulation of freshwater resources. Contrary to contemporary scholarship on the emergence of regime complexes, this study shows that the international institutional overlap and setup in this issue-area are not due to "strategic inconsistency" aimed at by specific powerful states, but rather owe their existence to functional and unintentional processes and dynamics. 


\section{Freshwater on the International Agenda}

A first important point to stress once more is that the freshwater problematique is in fact an umbrella topic with many subtopics, some of which have been dealt with in individual conferences and even conventions. It is important to highlight this aspect again before returning to the conclusions of the individual chapters and analyses because the nature of the topic and its root problem was, in the end, broken down into several sub-aspects with regard to norm development and regulation and has effects on the resulting global governance structures. The ultimate underlying problem with this resource is that it is finite while water consumption worldwide has been growing immensely over the last decades, thus leading to scenarios of global water scarcity. In addition, these resources are not evenly distributed over continents and countries, thus scarcity has a differential effect depending on physical location and temporal distribution. The limited availability of overall water resources then spills into more fragmented issues, such as use of shared rivers, lakes and aquifers as well as pollution and ecosystem functions at the local, national and regional level, amongst many others. While the overall freshwater problematique was treated as a whole in very few and mainly the first conferences and events of the emergence period, which generally resulted in normative declarations and vague recommendations (c.f. chapter II), some of the sub-issues have led to more concrete rules, treaties and conventions, most notables in the cases of wetlands protection and the use of international watercourses (c.f. chapter III).

The second important consideration to bear in mind is the lack of consensus in academic scholarship as to which are the key freshwater-related events that have shaped the topic globally. Even after inferring the overall importance of the conferences from the degree of overlap between the respective authors and thus reducing the number of events which deserve the milestone attribute, it is necessary to add the two conventions to this list in order to establish the complete picture. Most authors (and those from the IR community in particular) do not make any references to the Ramsar Convention and its role within the bigger debates on freshwater resources. This omission or lack of attention can be explained partially by the fact that this convention took shape outside of the main fora/forums on the international agenda (in contrast to the IWC and the center-stage UN negotiations) and deals with a sub-aspect of water that is not as clearly related to the most-pressing freshwater-related issues such as, for example, access to potable water and sanitation. In 
any case, this limited or outright lack of attention signals the marginal role that wetlands and their protection are attributed with within the overall freshwater emergence and evolution. This stands in stark contrast with the fact that wetlands protection in the form of the Ramsar Convention not just achieved important progress since their inception but also tangible norms and binding rules, which has not been the case in other sub-areas of the debate. At the same time, the more center-stage UN process of the IWC is only marginally more examined by authors and institutions. In spite of their low profile in many scholarly accounts, both conventions are central to the formation of global freshwater governance structures, which crystallize existing political consensus over these resources and have a longer lasting effect on the topics treatment at the international level, especially as regimes. One can therefore state that most overarching analyses and depictions of the freshwater umbrella topic's emergence and development on the international agenda have focused on the conferences and their outputs in the form of declarations, principles and statements rather than on the more formal, legally binding conventions and actual international agreements, which are dealt with more in scholarship situated within the narrower realm of International Law. This thesis has bridged these hitherto unconnected academic areas and brings them into dialogue with each other under the frameworks of international agenda setting and (complex) regime formation in the area of freshwater resources.

The joint analysis of the global emergence of the freshwater topic is a theory-guided examination of the key events in the area with a particular focus on hitherto mostly neglected political influence factors and constellations. The agenda-access-approach developed by Livingston proved crucial to identifying important dynamics and drivers of these large and complex developments and processes. By applying this approach, it was possible to make the conferences and conventions comparable with each other and to pinpoint the variations between them with regard to the international agenda.

It is noteworthy that the very first event that surfaced on the international agenda was directed at a side-issue of the overarching freshwater issue, namely wetlands under the Ramsar Convention of 1971. Furthermore, this regulation of freshwater resources in the form of wetlands, although broadly defined and widely applicable, was at first constructed in view of protecting migratory species that use wetlands as their habitat. Therefore, the emergence period first featured a more marginal sub-issue before the overall topic was considered in a more encompassing form in the first bigger UN water conferences of 1977 
and 1992. The Ramsar case is equally significant with regard to its process, insofar as it is different from most of the following UN related conferences and agreements due to its bottom-up approach and the important role of epistemic communities paired with NGO influence and individual policy entrepreneurs as main drivers. It not only preceded the two big water conferences of Mar del Plata and Rio de Janeiro but also the 1972 Stockholm UN Conference, which is widely labelled as the first conference to bring the environment to the forefront of the international agenda. Ramsar, however, though much less visible in the public eye, also deserves significant credit for its pioneering role with regard to conservation efforts and to including NGOs and epistemic communities in the process before the big wave of large UN conferences. Reasons for the success of the convention and its derivative regime include starting with a smaller group of countries and only expanding its membership and impact area gradually over time; a broader consensus on the topic level from the beginning on and thus possibilities of cooperation later on due to lack of great inherent conflict potential between the member states; relatively low costs of compliance and fulfillment of duties as well as little interference of the convention or states in each other's sovereignty because of self-control and self-reporting, while in return most of the benefits can be claimed internally by the respective countries.

For the largest part of the freshwater emergence period, UN conferences dominated the international agenda. After UNCHE in 1972, the further UN conferences on the sea in 1973, on population and on food in 1974, on habitat in 1976 and renewable energy sources in 1981 were also loosely connected to water issues; however, it was mainly the 1977 UN Conference on Water in Mar del Plata with the following International Drinking Water Supply and Sanitation Decade, that put these resources and related environmental and social problems firmly on the global agenda in the late 1970s. Yet, after these early advances, the freshwater topic did not receive sustained international attention for the next decades, apart from a follow-up on regional developments in New Delhi and featuring as a side-issue in the World Summit for Children as well as in the Natural Disaster Reduction Decade in the early 1990s. Global interest in freshwater was revived with the 1992 Dublin Conference and the subsequent Earth Summit in Rio de Janeiro, for which it functioned as a preparatory event confined to water issues. For internal issues of organization, format and timing, but mainly the strong competition of other issues perceived as more urgent, such as climate change, biodiversity and ozone depletion, freshwater resources did not feature prominently at the Earth Summit and interest declined once more in its aftermath. 
At the very end of the emergence period, international cooperation efforts peaked once more with the adoption of the Convention on International Watercourses in 1997 and brought along a change of arenas with the establishment of the First World Water Forum, which would draw considerable attention in the post-1997 evolution period. It needs to be underlined that the IWC process did not culminate in a final conference, like in the case of the Ramsar Convention or other UN processes. Rather, it was adopted as an international framework convention after decade long elaboration of draft articles and two years of negotiation in the UN General Assembly's $6^{\text {th }}$ Committee for legal issues. While successfully adopted in the end, the IWC consists of a compromise between opposing groups of downstream and upstream countries and does not feature as deep of a cooperation project as in the case of Ramsar. A great underlying challenge of the IWC came with one of its motivations, namely to positively influence existing conflictual situations on particular watercourses. It was established after many bi-, tri- and even plurilateral agreements at the regional level had been negotiated, thus engrafting a global framework convention on top of a fragmented array of sub-global regulations in place - in stark contrast to constructing a new institution and regime on a clean slate (even when disregarding the overlap with the Ramsar Convention), such as the case of other framework conventions, for example the case of ozone depletion.

All in all, the freshwater emergence on the international agenda features many different processes, dynamics, arenas, actors and sub-issues, which complicate broader global norm development and regulation attempts.

\section{Global Freshwater Governance and Regime Theory}

Concerning the creation of global agreements and treaties which regulate freshwater resources, the resulting picture is also not homogeneous. We can see that consensus in one aspect (wetlands) seems straightforward, widely applicable and with deep cooperation possible, while at the same time being less strict in terms of actual formal obligations and duties and keeping benefits mostly internal. In others (like transboundary water), there are more conflictual and strong resources aspects as well as greater international dimensions with negative externalities, which in the end presents more a case of coordination rather than deep cooperation. Yet again other topics seem even more complicated in terms of 
international regulation efforts as they include many additional levels and dimensions, and many uses of freshwater have a strongly national character, e.g. access to potable water and sanitation or internal pollution. When later considering their implementation, they also feature a bigger social component and include many more players - such as ministries of health, of the interior, of development or possibly even of the economy, as well as national NGOs and lobbying groups, which complicates achieving an agreement. In contrast with Ramsar or with the sub-issue of transboundary water (which was ultimately dealt with mostly at diplomatic level and which follows the logic of dividing the resources between two or at least only few countries), it appears that so far international compromises and consensus have not been reachable for many other sub-issues.

The application of regime theory to the case of freshwater regulation attempts has yielded important results. The lack of a global cohesive freshwater regime after a period of nearly 30 years of the broader issue's emergence and the high degree of fragmentation in the issue area made it impossible to validate the first hypothesis, which suggests that the problemstructural-approach is not applicable to the umbrella freshwater topic. This is due to an equally broad heterogeneity of actors, dynamics and process behind each of the sub-topics that make up the overarching freshwater issue. However, for the sub-issue of wetlands this approach seems to explain its success and rapid development fairly well as it follows the logic of consensual conflict over an absolutely assessed good. The applicability to the case of the IWC is more limited but when switching from consensual to dissensual conflict, it might also explain the resistance to regime formation, although ultimately it did occur. Considering the above, one can state while until now there is no existing overarching freshwater regime in the traditional sense, there are in fact two sub-regimes.

While these two conventions and their ensuing regimes had previously only been analyzed separately in various bodies of literature and scholarship with regard to their formation and effects, the analysis of their relationship in chapter III provided further significant insights. In-depth examination of their development and the characteristics of their processes, as well as the resulting regime principles and norms, has demonstrated a hitherto unnoticed functional overlap with regard to their regulation of freshwater resources. As a result, they are in fact not merely parallel sub-regimes of the broader freshwater issue that govern separate sub-issues, but due to their overlap they actually co-govern freshwater resources in the form a regime complex. Labelling this global governance structure as the freshwater 
regime complex is better than notions of a global rivers regime - as discussed for example by Conca et al (2006) - or a rivers regime complex, since the latter two are actually misnomers for the reason that their regulatory scope goes far beyond rivers and encompasses dimensions not just of supply but also usage and demand. While it would be possible to frame it as a transboundary freshwater regime complex, the above nomenclature explicitly featuring freshwater resources is similar to the one of the energy area, where both the notions of a global energy regime or an energy regime complex are used more broadly while the actual regulation overlap refers mainly to oil as the by far most trade resource in the energy sector (COLGAN et al, 2012).

In addition to identifying the freshwater regime complex as such, the thesis analysis of the formation of both sub-regimes and their overlap reveals further insights concerning the emergence of regime complexes. The consensus of contemporary regime complex literature, which argues that the origins of such global governance forms lie in strategic action of states dissatisfied with the status quo (i.e. the creation of so-called "strategic inconsistency" with existing institutions in order to subsequently apply strategies of forumshopping or regime shifting), forms the base for the central hypothesis. However, the case of freshwater resources shows that this does not always apply, since the emergence of its regime complex does not show traces of strategic institutional establishment in response to dissatisfaction with existing regulation efforts. Quite the contrary, there are no visible or measurable signs of dissatisfaction of member states with the Ramsar regime and its principles, norms and rules, which would trigger and justify actions to challenge the status quo. Instead, the wetlands regime is perceived as a regime in its own right, while the creation of the IWC and its related regime nearly 30 years later, features an entirely separate dynamic of different actors and taking place in a distinct arena. The newly created functional overlap as to the regulation of transboundary freshwater resources is, in this case, a non-intentional side-product of these two seemingly independent processes. This conclusion once again challenges the assumption of current scholarship and reveals a new path of emergence for regime complexes. 


\section{Contributions}

The principal contributions of this thesis to the discipline of International Relations are three-fold. In the first place, carrying out a systematic, theory-driven study focusing on the emergence of freshwater resources on the international agenda represents an additional effort to increasingly include this important issue area into contemporary IR scholarship and give it the place and attention it deserves. By joining the various literatures dealing with freshwater resources as well as combining the analysis of major conferences with that of the two key conventions of the emergence period, this thesis produces a distinct contribution to the contemporary scholarship in the field. Secondly, and in addition to merging these bodies of literature, the treatment of the freshwater topic has proven to be malleable to the application of IR theories and approaches, particularly regime theory. While this issue area has hitherto, for the most part, lacked such attempts, at least with regard to the global level, interesting new dynamics were revealed, mainly the identification of a new regime complex. Strengthening this connection enables the revelation of new insights with regard to the research object and the way it is being analyzed, but also to the discipline of IR as new testing ground for its theories and approaches. The third and final contribution is derived from the analysis of freshwater regime complex emergence, which sheds light on a new kind of path for the development of such global governance structures and directly advances this newest strand of regime theory.

\section{Implications and Future Avenues of Research}

Having identified a new regime complex in the issue area of freshwater resources opens the way to further analysis of this particular case. First insights have been won with regard to its origins and emergence but this assessment is still preliminary and subject to further comprehensive analysis of all relevant dimensions with regard to time and level as is illustrated in Table 8. 
Table 8

Analysis of the freshwater regime complex dimensions

Source

Elaborated by the author

\begin{tabular}{|l|c|c|}
\hline \multirow{2}{*}{ Level } & Emergence & Evolution \\
\cline { 2 - 3 } & $\begin{array}{r}\text { 1970s-late 1990s } \\
\text { Global }\end{array}$ & $\begin{array}{r}\text { 1: Ramsar (1971); } \\
\text { IWC (1997) }\end{array}$ \\
\hline Sub-global & 3 & 2 \\
\hline
\end{tabular}

In order to identify a new regime complex, it was necessary to prove a functional overlap of at least two regimes and/or institutions for a given area of regulation at any specific point in time. This follows the logic of Gehring and Faude (2014, p. 474), whose multicase study includes "[...] institutional complexes made up of only two elemental institutions, because there is no theoretically compelling reason to exclude these complexes from the universe of cases". However, the demonstration of such an overlap of the Ramsar and the IWC regimes does not exclude the existence of further possible elements of freshwater regime complex at a later stage or different dimension. The scope of this thesis was limited to the global level during the emergence period of the freshwater topic on the international agenda, i.e. from the early 1970s until the late 1990s, which is graphically represented as the top left green box labelled "1" in Table 8 .

A logical continuation for future research generally consists of extending the analyses of this thesis to the evolution period of post-1997, in which further global developments have taken place on the international agenda. One the one hand, an important shift in forums somewhat away from the UN and towards newer dynamics can be noted with regard to the creation and development of two new organizations, namely the World Water Council (WWC) and the Global Water Partnership (GWP). Together, these organizations established a sequence of triannual World Water Forums (WWFs), starting in 1997, which are drawing increasing public, academic and political attention to the freshwater topic in the weeks around the "World Water Day" of the $22^{\text {nd }}$ of March. The hallmark of these newer, cross-cutting forums consists of increasing and broadening participation from civil society, academic institutions, international organizations, and also the private sector; as of 
its 2000 event in The Hague, the WWFs also features Ministerial Declarations. At the same time, the UN has continued its efforts in the form of conferences - such as the Millennium Summit of 2000 and the resultant Millennium Development Goals (MDGs), which prominently feature freshwater issues and are now being followed up as Sustainable Development Goals (SDGs), as well as the Rio+10 and Rio+20 conferences in 2002 and 2012, respectively, regarding sustainable development -, of the International Decade for Action "Water for life" from 2005-2015 and of its post-2015 agenda. Moreover, outside of the format of conferences, one would need to consider the work of the World Commission on Dams (WCD) from 1997-2000, while the most important event on the international agenda certainly regards the formal recognition of the human right to water in 2002 and, ultimately, in 2010, which lies at the heart of many freshwater issues. Several of these, in particular the MDGs and the human right to water are expected to have influenced the freshwater regime complex, thus they should be considered for additional examination and analysis pertaining to the top right box of Table 8 , labelled " 2 ".

Furthermore, the regime complex concept does not exclude sub-global levels if these are important enough to influence the overall governance structure. An example of this is the inclusion of the domestic activities within the US and Europe as key drivers of the intellectual property field for the study of the plant genetic resources regime complex (RAUSTIALA; VICTOR, 2004). In the freshwater case, this would imply widening the scope of analysis to sub-global level, both for the emergence (bottom left box " 3 ") and evolution (bottom right box "4") periods. Likely candidates for inclusion include regional agreement, convention and regulations such as for example the 1992 Helsinki Convention of 1992 or the 2000 EU Water Framework Directive.

Finally, most of the contemporary scholarship on and approaches to other regime complexes could be applied to the new case of the freshwater one. Especially due to the entering into force of the IWC in 2014, the dynamics within the regime complex are expected to develop and change since at some point efforts aiming at legal consistency are likely to occur; this allows for application of several approaches with regard to internal bargaining dynamics and studies of the effects of regime complexes on the regulation. A particularly interesting possible avenue of future research would consider the interaction of regime complexes; with regard to freshwater, the interplay between its regime complex and the one of climate change appears to have interesting potential. 


\section{Final Remarks}

In the light of recent developments, the freshwater topic is certainly not moving away from the international agenda. The freshwater topic has become important within the context of the Millennium Development Goals (MDGs) and the newer Sustainable Development Goals (SDGs), it features in climate change negotiations with regard to changing precipitation levels and catastrophes and increasing occurrences of water scarcity at local, national and regional levels are noted. In particular, the current water crises in Brazil and the US have heightened the awareness for freshwater related issues even more. This thesis has demonstrated how over the first decades of the emergence period of the 1970s till 1990s global efforts at cooperating in this area have led to global governance structures that are still important to date. In particular, the dynamics of the emerging freshwater regime complex can provide valuable information regarding future efforts to negotiate and cooperate at the international level, while considering the fragmentation as well as the overlap in the freshwater area. 


\section{BIBLIOGRAPHY}

\section{PRIMARY SOURCES}

Brazil (1976), "Informação No. 034/1a.SC/76", 11th May 1976, Conselho de Segurança Nacional, Secretaria, Internal document. Available at: http://www.an.gov.br/sian/inicial.asp. Accessed on: $4^{\text {th }}$ August 2014.

ICWE - International Conference on Water and Environment (1992), The Dublin Statement on Water and Sustainable Development, adopted on $31^{\text {st }}$ January 1992. Available at: http://www.wmo.int/pages/prog/hwrp/documents/english/icwedece.html. Accessed on: $16^{\text {th }}$ November 2014.

ILC (1994a), "Draft Articles on the Law of the Non-Navigational Uses of International Watercourses", Yearbook of the International Law Commission (ILC) 1994, vol. II, Part II, pp. 89-135. Available at: http://legal.un.org/ilc/publications/yearbooks/Ybkvolumes\%28e\%29/ILC_1994_v2_p2_e.p df

ILC (1994b), "Resolution on Confined Transboundary Groundwater", Yearbook of the International Law Commission (ILC) 1994, vol. II, Part II, p. 135. Available at: http://legal.un.org/ilc/publications/yearbooks/Ybkvolumes\%28e\%29/ILC_1994_v2

MDPAP - Mar del Plata Action Plan (1977), adopted on the $25^{\text {th }}$ March 1977 in the $16^{\text {th }}$ plenary meeting. In: UN (1977), "Report of the United Nations Water Conference, Mar del Plata, 14-25 March 1977', E/Conf.70/29. Available at the Official Document System of the United Nations at: http://documents.un.org/

Ramsar (1971), "Convention on Wetlands of International Importance especially as Waterfowl Habitat", adopted on $2^{\text {nd }}$ February 1971. Available at: http://www.undocuments.net/ramsar.htm

Ramsar (1982a), "Final Act of the Conference to Conclude a Protocol to the Convention of Wetlands of International Importance especially as Waterfowl Habitat", adopted at the Extraordinary Conference of the Contracting Parties, $2^{\text {nd }}$ to $3^{\text {rd }}$ December 1982 at Paris, France. Available

at: http://www.ramsar.org/sites/default/files/documents/library/final_act_extraordinary_confer ence_paris_e.pdf

Ramsar (1982b), "Protocol to Amend the Convention on Wetlands of International Importance especially as Waterfowl Habitat", adopted at the Extraordinary Conference of the Contracting Parties, $2^{\text {nd }}$ to $3^{\text {rd }}$ December 1982 at Paris, France. Available at: http://www.ramsar.org/sites/default/files/documents/library/paris_protocol_e_0.pdf 
Ramsar (1987), "Amendments of the Convention adopted by the Extraordinary Conference", Extraordinary Conference of the Contracting Parties, $28^{\text {th }}$ May to $3^{\text {rd }}$ June 1987 at Regina, Saskatchewan, Canada. Available at: http://www.ramsar.org/sites/default/files/documents/library/regina_amendments_e.pdf

UN (1963), "Legislative texts and treaty provisions concerning the utilization of international rivers for other purposes than navigation", Report prepared by the UN Secretary General, A/5409. Reproduced in the Yearbook of the International Law Commission (ILC) 1974, vol. II, Part II, pp. 33-264. Available at: http://legal.un.org/ilc/publications/yearbooks/Ybkvolumes\%28e\%29/ILC_1974_v2_p2_e.p df

UN (1970) "Chapter XIII - The use and development of natural (non-agricultural) resources”, $U N Y B$, Vol. 24, pp. 459-460.

UN (1971) "Chapter X - The use and development of natural (non-agricultural) resources", $U N Y B$, Vol. 25, pp. 323-330.

UN (1974), "Legal problems related to the non-navigational use of international watercourses", Supplementary report prepared by the UN Secretary General, A/CN.4/274. Reproduced in the Yearbook of the International Law Commission (ILC) 1974, vol. II, Part II, pp. 265-366. Available at: http://legal.un.org/ilc/publications/yearbooks/Ybkvolumes\%28e\%29/ILC_1974_v2_p2_e.p df

UN (1976a), "Resources and Needs: Assessment of the World Water Situation", E/CONF. 70/CBP/1.

UN (1976b), "Present and Future Activities of the United Nations System in Water Resources Development", E/CONF. 70/CBP/4.

UN (1977), "Report of the United Nations Water Conference, Mar del Plata, 14-25 March 1977”, E/Conf.70/29.

UNCED (1992a), Agenda 21 - Environment and Development Agenda. Available at: http://habitat.igc.org/agenda21/

UNCED (1992b), Rio Declaration on Environment and Development, adopted on $14^{\text {th }}$ June 1992. Available at: http://habitat.igc.org/agenda21/rio-dec.htm.

UNECE (1992). Convention on the Protection and Use of Transboundary Watercourses and International Lakes, signed $17^{\text {th }}$ March 1992. Available at: http://www.unece.org/fileadmin/DAM/env/water/pdf/watercon.pdf

UNECE (1998). The Helsinki Declaration, adopted on $4^{\text {th }}$ July 1994. Available at: http://www.unece.org/fileadmin/DAM//env/water/cooperation/area414.htm

UNGA (1959), United Nations General Assembly Resolution 1401 (XIV), adopted on $21^{\text {st }}$ November 1959. Available at: http://www.worldlii.org/int/other/UNGARsn/1959/96.pdf 
UNGA (1970), United Nations General Assembly Resolution 2669 (XXV), adopted on $8^{\text {th }}$ December $1970 . \quad$ Available at: http://internationalwaterlaw.org/documents/intldocs/UNGA_1970_resolution_2669_\%28X XV\%29_on_progressive_development_and\%20codification.pdf

UNGA (1975), United Nations General Assembly Resolution 3513 (XXX), adopted on $15^{\text {th }} \quad$ December $1975 . \quad$ Available at: http://www.worldlii.org/int/other/UNGARsn/1975/161.pdf

UNGA (1979), United Nations General Assembly Resolution 34/191, adopted on $18^{\text {th }}$ December 1979, A/RES/34/191. Available at: http://www.worldlii.org/int/other/UNGARsn/1979/207.pdf

UNGA (1980), United Nations General Assembly Resolution 35/18, adopted on $10^{\text {th }}$ November 1980, A/RES/35/18. Available at: http://www.worldlii.org/int/other/UNGARsn/1980/25.pdf

UNGA (1988), United Nations General Assembly Resolution 43/196, adopted on $20^{\text {th }}$ December 1988, A/RES/43/196. Available at: http://www.worldlii.org/int/other/UNGARsn/1980/25.pdf

UNGA (1994), United Nations General Assembly Resolution 49/52, adopted on $9^{\text {th }}$ December 1994, A/RES/49/52. Available at the Official Document System of the United Nations: http://documents.un.org/

UNGA (1996a), United Nations General Assembly $6^{\text {th }}$ Committee WG report, $3^{\text {rd }}$ December 1996. A/51/869. Available at the Official Document System of the United Nations: http://documents.un.org/UNGA (1996b), United Nations General Assembly Resolution 51/206, adopted on $17^{\text {th }}$ December 1996, A/RES/51/206. Available at the Official Document System of the United Nations: http://documents.un.org/.

UNGA (1997a), United Nations General Assembly $6^{\text {th }}$ Committee WG report, $11^{\text {th }}$ April 1997. A/51/869. Available at the Official Document System of the United Nations: http://documents.un.org/.

UNGA (1997b), United Nations General Assembly Resolution 51/229, adopted on $21^{\text {st }}$ May 1997, A/RES/51/229. Available at the Official Document System of the United Nations: http://documents.un.org/. 


\section{SECONDARY SOURCES}

Atkinson-Willes, G.L. (1964). Liquid Assets. Wildfowl Trust, ICUN and IWRB, Slimbridge, UK.

Bachrach, P. and M.S. Baratz (1962). "The Two Faces of Power", American Political Science Review, 56.4, pp. 947-952.

Barandat, J. and Kaplan, A. (1998). "International Water Law: Regulations for Cooperation and the Discussion of the International Water Convention", in: Scheumann, W. and Schiffler, M. (Eds), Water in the Middle East: Potential for Conflicts and Prospects for Cooperation. Berlin, Heidelberg: Springer Science and Business Media, pp. 11-30.

Baumgartner, Frank and Bryan Jones (1992). Agendas and Instability in American Politics. Chicago: University of Chicago Press.

Benedick, R. E. (1991). Ozone Diplomacy: New Directions in Safeguarding the Planet. Cambridge, MA: Harvard University Press.

Bernauer, Thomas (1997). "Managing International Rivers", in: Young, Oran R. (Ed), Global Governance: Drawing Insights from the Environmental Experience, Cambridge, MA: MIT Press.

Bernauer, Thomas (1995). "The effect of International Environmental Institutions: how we might learn more”, International Organization, vol. 49, n 2, Spring 1995, pp. 351-377.

Biswas, A.K. (1981) "Water for the Third World”, Foreign Affairs, Vol. 60, pp. 148-166.

Biswas, A.K. (1988) "United Nations Water Conference Action Plan - Implementation over the past decade", Water Resources Development, Vol. 4, No. 3 (Sept. 1988), pp. 148159.

Biswas, A.K. (1996) "Water for Third World Development - A Perspective from the South", in: Young, O.R, Demko, G.J. and Ramakrishna, K. (Eds). Global Environmental Change and International Governance. The Nelson A. Rockefeller series in social science and public policy. Hanover: Dartmouth College, University Press of New England, pp. 95107.

Biswas, A.K. (1998) "Deafness to Global Water Crisis - Causes and Risks", Ambio, Vol. 27, No. 6 (Sept. 1998), pp. 492-493.

Biswas, A.K. (2004) "From Mar del Plata to Kyoto - an analysis of global water policy dialogue”, Global Environmental Change, Vol. 14, pp. 81-88.

Biswas, A.K. and Tortajeda, C. (2005) "Impacts of Global Mega-Conferences On the Water Sector", Asian Water, Special Feature. Magazine Article. 
Biswas, A.K. and Tortajeda, C. (2009). Impacts of Megaconferences on the Water Sector. Water Resources Development and Management. Berlin Heidelberg: Springer-Verlag.

Black, Maggie and King, Jannet (2009). The Atlas of Water-Mapping the World's most Critical Resource. London, UK: Earthscan. Second Edition.

Boere, G.C., Galbraith, C.A. and Strong, D.A. (Eds.) (2006). Waterbirds around the world. The Stationary Office, Edinburgh, UK.

Brady, David and McCubbins, Mathew D. (Eds.) (2002). Party, process, and political change in Congress new perspectives on the history of Congress. Stanford, California: Stanford University Press.

Breitmeier, H, Young, O.R. and Zürn, M. (2006). Analyzing International Environmental Regimes - From Case Study to Database. Cambridge, Massachusetts: MIT Press.

Busch, M.L. (2007). "Overlapping institutions, forum shopping, and dispute settlement in international trade”, International Organization, Vol. 61, No. 4, pp. 735-761.

Cano, Guillermo J. (1989). "The Development of the Law of International Water Resources and the Work of the International Law Commission", Water International, Vol. 14, No. 4, pp. 167-171.

Carp, E. (Ed.) (1972). Proceedings - International Conference on the Conservation of Wetlands and Waterfowl, Ramsar, Iran, 30 January - 3 February 1971. Slimbridge, UK: International Wildfowl Research Bureau (IWRB).

Cobb, R. W. and Elder, C.D. (1972). Participation in American Politics: The Dynamics of Agenda-Building. Boston: Allen and Unwin.

Cobb, R. W. and Elder, C.D. (1981). "Communications and Public Policy", in: Nimmo, D.D. and Sanders, K.R. (Eds.) Handbook of Political Communication. Beverly Hills: Sage.

Cobb, R.W., Ross, J.K. and Ross, M.H. (1976). "Agenda Building as a Comparative Political Process”, American Political Science Review, 71.1, pp. 126-138.

Cohen, M., March, J. and Olsen, J. (1972). “A Garbage Can Model of Organizational Choice", Administrative Science Quarterly, 17, pp.1-25.

Colgan, J.D., Keohane, R.O. and Van de Graaf, T. (2012). "Punctuated equilibrium in the energy regime complex", Review of International Organization, Vol. 7, Issue 2, pp. 117 143.

Conca, K., Wu Fengshi and Mei, Ciqi (2006). "Global Regime Building or Complex Institution Building? The Principled Content of International River Agreements", International Studies Quarterly, Vol. 50, pp. 263-285.

Constanza, R., d'Arge, R, de Groot, R.S. et al (1997). "The total value of the world's ecosystem services and natural capital, Nature, Vol. 387, pp. 253-260. 
Cox, Gary W. and Mathew D. McCubbins (2005). Setting the Agenda: Responsible Party Government in the U.S. House of Representatives. Cambridge: Cambridge University Press.

Dellapenna, G.W. and Gupta, J. (2013), "The Evolution of Water Law Through 4,000 Years". Forthcoming book Sovereignty and the Development on International Water Law, pp. 1-14; Villanova Law/Public Policy Research Paper No. 2013-2041.

Falkenmark, M. (1977). "UN Water Conference: Agreement on Goals and Action", Ambio, Vol. 6, No. 4, pp. 222-227.

Falkenmark, M. (1985) "Integration in the River-Basin Context", Ambio, Vol. 14, No. 2, pp. 118-120.

Falkenmark, M. (1990). “Global Water Issues Confronting Humanity”, Journal of Peace Research, Vol. 27, No. 2, Special Issue on the Challenge of Global Policy, pp. 177-190.

Gehring, T. (2011). "The Emerging Governance Structure on Trade and the Environment From Disruption to Division of Labor", in: Oberthür, S. and O. S. Stokke (Ed.), Managing Institutional Complexity, Cambridge MA: MIT Press, pp. 407-4.55.

Gehring, T. and Faude, B. (2014). "A theory of emerging order within institutional complexes - How competition among regulatory international institutions leads to institituional adaptation and division of labor", Review for International Organizations, Vol. 9, Issue 4, pp. 471-498.

Gleick, Peter and Lane, Jon (2005). "Large International Water Meetings: Time for a Reappraisal”, Water International, Vol. 30, No. 3 (September 2005), pp. 410-414.

Gleick, P. H., Allen, L., Christian-Smith, J., Cohen, M.J., Cooler, H., Heberger, M. Morrison, J., Palaniappan, M and Schulte, P. (2012). The World's Water Volume 7 - The Biennial Report on Freshwater Resources. Washington, Covelo, London: Islandpress.

Golubev, G.N. (1996), “Availability and Quality of Freshwater Resources - A Perspective from the North", in: Young, O.R, Demko, G.J. and Ramakrishna, K. (Eds). Global Environmental Change and International Governance. The Nelson A. Rockefeller series in social science and public policy. Hanover: Dartmouth College, University Press of New England, pp. 107-122.

Gupta, Joyeeta et al (2013). "Policymakers' Reflections on Water Governance Issues", Ecology and Society, 18 (1): 35.

Haas, E. (1980). "Why Collaborate? Issue-Linkage and International Regimes", World Politics, 32.3, pp. 357-405.

Haas, Peter M. (1990). "Obtaining Environmental Protection through Epistemic Consensus", Millennium, 19.3, pp. 347-363. 
Haas, Peter M. (1992). "Introduction: Epistemic Communities and International Policy Coordination", International Organization, 46.1, pp.1-35.

Hasenclever, Andreas et al. (1997). Theories of International Regimes. Cambridge: Cambridge University Press.

Helfer, L.R. (2004). "Regime Shifting - the TRIPs agreement and new dynamics of international intellectual property lawmaking", Yale Journal of International Law, vol. 29, pp. 1-58.

Helfer, L.R. (2009). "Regime Shifting in the International Intellectual Property System", Perspectives on Politics, Vol. 7, No. 1, pp. 39-44.

Hoekstra, A.Y. (2011) "The Global Dimension of Water Governance - Why the River Basin Approach Is No Longer Sufficient and Why Cooperative Action at Global Level Is Needed', Water, Vol. 3, pp. 21-46.

Hoffmann, Luc. (1993). "Foreword", in: Matthews, G.V.T., The Ramsar Convention on Wetlands: its History and Development. Ramsar Convention Bureau, Gland, Switzerland.

Hofmann, S. (2009). "Overlapping Institutions in the Realm of International Security - the case of NATO and ESDP, Perspectives on Politics, vol. 9, nr. 1, pp. 45-52.

Hofmann, S. (2011). "Why Institutional Overlap Matters - CSDP in the European Security Architecture, Journal of Common Market Studies, vol. 49, nr. 1, pp. 101-120.

International Water Law Project (2015a), Main webpage. Available at: http://www.internationalwaterlaw.org/. Accessed on: $7^{\text {th }}$ July 2013.

International Water Law Projects (2015b), Watercourse status. Available at: http://www.internationalwaterlaw.org/documents/intldocs/watercourse_status.html (first Accessed on: $7^{\text {th }}$ July 2013.

Jupille, J, Mattli, W. and Snidal, D. (2013). Institutional choice and global commerce. New York: Cambridge University Press.

Kearney, R. D. (1975), “The Twenty-sixth Session of the International Law Commission”, American Journal of International Law, Vol. 69, No. 3, pp. 591-611.

Keck, Margaret and Kathryn Sikkink (1998). Activists Beyond Borders: Advocacy Networks in International Politics. Ithaca: Cornell University Press.

Keohane, Robert O. (1984). After Hegemony: Cooperation and Discord in the World Political Economy. Princeton, NJ: Princeton University Press.

Keohane, Robert O., and Joseph S. Nye, Jr. (1977). Power and Interdependence: World Politics in Transition. Boston: Little, Brown. 
Keohane, Robert O., and Joseph S. Nye, Jr. (1989). Power and Interdependence, 2nd ed. Boston: Little, Brown.

Keohane, Robert O., and David G. Victor. 2010. "The Regime Complex for Climate Change." Discussion Paper 10-33, Harvard Project on International Climate Agreements, Belfer Center for Science and International Affairs, Harvard Kennedy School, January 2010.

Keohane, Robert O., and David G. Victor. 2011. "The Regime Complex for Climate Change", Perspectives on Politics, Vol. 9, No. 1, March 2011, pp. 7-23.

Keohane, Robert O., and David G. Victor. 2013. "The Transnational Politics of Energy", Dadalus, Vol. 142, No. 1, Winter 2013, pp. 97-109.

King, G., Keohane, O.R. and Verba, S. (1994). Designing Social Enquiry - Scientific Inference in Qualitative Research. Princeton, NJ: Princeton University Press.

Kingdon, John W. (1995). Agendas, Alternatives, and Public Policies. New York: Longman. $2^{\text {nd }}$ Edition of 1984 original.

Krasner, S. D. (Ed). (1983). International Regimes. Ithaca, NY: Cornell University Press.

Krasner, Stephen D. (1983). "Structural Causes and Regime Consequences: Regimes as Intervening Variables”. In: Krasner, S.D. (Ed). (2011). International Regimes. Ithaca, NY: Cornell University Press, pp. 1-21.

Kuijken, E. (2006). "A short history of waterbird conservation”. In: Boere, G.C., Galbraith, C.A. and Strong, D.A. (Eds.). Waterbirds around the world. The Stationary Office, Edinburgh, UK.

Light, P.C. (1982). The President's Agenda. Baltimore: Johns Hopkins University Press.

Little, R. (2011). "International Regimes", in: Baylis, John; Smith, Steve and Owens, Patricia. The Globalization of World Politics, $5^{\text {th }}$ edition.

Livingston, Steven G. (1992). "The Politics of International Agenda-Setting: Reagan and North-South Relations", International Studies Quarterly 36.3, pp. 313-329.

Lowi, M. (1993). Water and Power - The Politics of a Scarce Resource in the Jordan River Basin. Cambridge University Press, Cambridge, USA.

Mageed, Yehia Abdel (1977). Opening Statement to the United Nations Water Conference, reproduced in A. K. Biswas (1978), pp. 1-6.

Mansbach, R.W., and J.A. Vasquez (1981). In Search of Theory: A New Paradigm for Global Politics. New York: Columbia University Press.

Matthews, G.V.T. (1993), The Ramsar Convention on Wetlands: its History and Development. Ramsar Convention Bureau, Gland, Switzerland. 
McCaffrey, Stephen C. (1993a). "The Evolution of the Law of International Watercourses", Austrian Journal of Public and International Law, 5 (2), pp. 87-111.

McCaffrey, Stephen C. (1993b). "Water, politics, and international law". In: Gleick, Peter (Ed.) Water in Crisis. New York, Oxford: Oxford University Press, pp. 92-104.

McCaffrey, Stephen C. (1995). "The International Law Commission adopts Draft Articles on International Watercourses", The American Journal of International Law, 89, pp. 395404.

McCaffrey, Stephen C. and Sinjela, Mpazi (1998). "The 1997 United Nations Convention on International Watercourses", The American Journal of International Law, 92 (1), pp. 97-107.

McCaffrey, S.C. (2008a) "Convention on the Law of the Non-Navigational Uses of International Watercourses". Lecture for the UN Audiovisual Library of International Law Lecture Series. Available at: http://legal.un.org/avl/ls/McCaffrey_IW_video_1.html

McCaffrey, S.C. (2008b), "Convention on the Law of the Non-Navigational Uses of International Watercourses". Introductory Note for the UN Audiovisual Library of International Law Lecture Series. Available at: http://legal.un.org/avl/ha/clnuiw/clnuiw.html

Morse, Julia C. and Keohane, Robert O. (2014) "Contested Multilateralism", Review of International Organizations, Vol. 9, Issue 4, pp. 385-412.

Muzaka, V. (2011). "Linkages, contests and overlaps in the global intellectual property right regime", European Journal of International Relations, vol. 17, nr. 4, pp. 755-776.

Navid, Daniel (1989). "The International Law of Migratory Species: The Ramsar Convention”, Natural Resources Journal, Vol. 29, Fall 1989, pp. 1001-1016.

Navid, Daniel (1993). "Introduction", in: Matthews, G.V.T., The Ramsar Convention on Wetlands: its History and Development. Ramsar Convention Bureau, Gland, Switzerland.

Ohlsson, L. (Ed.) (1995) Hydropolitics - Conflicts over water as a development constraint. London: Zed Books.

O`Neill, K. (2009). The Environment and International Relations. Cambridge, UK: Cambridge University Press.

Peterson, M.J. (1988). Managing the Frozen South: The Creation and Evolution of the Antarctic Treaty System. Berkeley: University of California Press.

Queiroz, Fábio Albergaria de (2012). Hidropolítica e Segurança - as bacias Platina e Amazônica em perspectiva comparada. Brasília, Brasil: Fundação Alexandre de Gusmão (FUNAG). 
Ramsar (2015a), Ramsar Convention. Available at: http://www.ramsar.org. Accessed on: Accessed on: $3^{\text {rd }}$ January 2015.

Ramsar (2015b), Country profiles. Available at: http://www.ramsar.org/country-profiles. Accessed on: $3^{\text {rd }}$ January 2015.

Ramsar (2015c). Ramsar Mission. Available at: http://www.ramsar.org/about/the-ramsarconvention-and-its-mission. Accessed on: 3rd January 2015.

Raustiala, K. and David G. Victor. 2004. "The Regime Complex for Plant Genetic Resources", International Organization, 58, Spring 2004, pp. 277-309.

Ribeiro, W.C. (2001). A ordem ambiental internacional. São Paulo: Editora Contexto.

Ribeiro, W.C. (2008). A geografia política da agua. São Paulo: Editora Annablume.

Ruggie, John Gerard. (1975). "International responses to technology: concepts and trends", International Organization, vol. 29, $\mathrm{n}^{\circ} 3$ (Summer), pp. 557-84.

Salman, M.A. Salman (2003), "From Marrakech through The Hague to Kyoto - Has the Global Debate on Water Reached a Dead End? - Part One", Water International, 28: 4, pp. 491-500.

Salman, M.A. Salman (2004), "From Marrakech through The Hague to Kyoto - Has the Global Debate on Water Reached a Dead End? - Part Two", Water International, 29: 1, pp. 11-19.

Schattschneider, E.E. (1960). The Semi-Sovereign People. New York: Holt, Rinehart and Winston.

Schroeder-Wildberg, E. (2002). "The 1997 International Watercourses Convention Background and Negotiations". Working Paper on Management in Environmental Planning. Technical University of Berlin, Institute for Landscape and Environmental Planning.

Shiklomanov, I. (1993). "World Water Resources", in Gleick, Peter (Ed.). Water in Crisis. New York, Oxford: Oxford Univserity Press. Chapter 2.

Shiklomanov, I.A. and Rodda, J.C. (Eds.) (2003). World Water Resources at the Beginning of the $21^{\text {st }}$ Century. International Hydrology Series. Cambridge: Cambridge University Press.

Shrijver, N. (2008). Sovereignty over natural resources - Balancing rights and duties. Cambridge: Cambridge University Press.

Sinclair, B. (1982). Congressional Realignment 1925-1978. Austin: University of Texas Press. 
Souza, Matilde de (2005). "Os recursos hídricos e a agenda social das relações internacionais”, in: De Souza, Matilde (Ed.) A agenda social das relações internacionais. Belo Horizonte: Editora PUC Minas.

Stein, Arthur A. (1983). "Coordination and collaboration: regimes in an anarchic world". In: Krasner, S.D. (Ed). International Regimes. Ithaca, NY: Cornell University Press, pp. $115-40$.

Topaloglu, Ece (2008). Privatization of water utilities from an Integrated Water Resources Management Perspective. M.Sc. dissertation. Graduate School of Social Sciences, Middle East Technical University, Turkey.

Thomas, Caroline and Howlett, Darryl (1993). Resource politics - freshwater and regional relations. Milton Keynes: Open University Press.

UND - United Nations Documents (2015). Main webpage. Available at: http://www.undocuments.net/k-000287.htm. Accessed on 2nd February 2015.

UNESCO (2009). Atlas of Transboundary Aquifers - Global Maps, Regional Cooperation, and Local Inventories. Paris, France: International Hydrological Program.

UNESCO WWAP (2015), "Milestones 1972 - 2006: From Stockholm to Mexico". Available at: http://webworld.unesco.org/water/wwap/milestones/index.shtml\#1995b. Accessed on: $2^{\text {nd }}$ February 2015.

Urpelainen, J. and Van de Graaf, T. (2014). "Your Place or Mine? Institutional Capture and the Creation of Overlapping International Institutions", British Journal of Political Science.

Van Asselt, Harro (2011). "Legal and Political Approaches in Interplay Management: Dealing with Fragmentation of Global Climate Governance”, in: Oberthür, S. and O. S. Stokke (Ed.), Managing Institutional Complexity. Cambridge MA: MIT Press, pp.

Van de Graaf, T. (2013a). "Fragmentation in Global Energy Governance - Explaining the Creation of IRENA, Global Environmental Politics, Vol. 13, nnr. 3, pp. 14-33.

Van de Graaf, T. (2013b). The Politics and Institutions of Global Energy Governance. London: Palgrave.

Vasquez, J.A., and R.W. Mansbach (1983). "The Issue Cycle: Conceptualizing Long-Term Global Political Change”, International Organization 37.2, pp. 257-279.

Victor, David G., Joy, S. and Victor, N.M. (2006). The Global Energy Regime. Unpublished manuscript.

Warner, J. and M. Zeitoun (2008). "International relations theory and water do mix - A response to Furlong's troubled waters, hydrohegemony and international water relations", Political Geography, vol. 27, pp. 802-810. 
Wolf, A.T., Natharius, J., Danielson, J., Ward, B. and Pender, J. (1999). "International river basins of the world", International Journal of Water Resources Development, Vol. 15, No. 4, pp. 387-427.

WWC - World Water Council (2014), "Water on the International Agenda". Available at: http://www.worldwatercouncil.org/index.php?id=708. Accessed on: $6^{\text {th }}$ July 2014.

Zeitoun, M. and Warner, J. (2006). "Hyrdo-hegemony - a framework for analysis of transboundary water conflicts", Water Policy, vol. 8, pp. 435-460.

Zürn, Michael (1998). "The Rise of International Environmental Politics: A Review of Current Research", World Politics, 50, 4, 1998, pp. 617-649. 